Florida International University FIU Digital Commons

$6-5-2013$

\title{
An Examination of Psychological Meaningfulness, Safety, and Availability as the Underlying Mechanisms linking Job Features and Personal Characteristics to Work Engagement
}

Holly Jacobs

HollyJacobs7@gmail.com

DOI: $10.25148 /$ etd.FI13080518

Follow this and additional works at: https://digitalcommons.fiu.edu/etd

Part of the Industrial and Organizational Psychology Commons

\section{Recommended Citation}

Jacobs, Holly, "An Examination of Psychological Meaningfulness, Safety, and Availability as the Underlying Mechanisms linking Job Features and Personal Characteristics to Work Engagement" (2013). FIU Electronic Theses and Dissertations. 904.

https://digitalcommons.fiu.edu/etd/904 


\title{
FLORIDA INTERNATIONAL UNIVERSITY
}

Miami, Florida

\section{AN EXAMINATION OF PSYCHOLOGICAL MEANINGFULNESS, SAFETY, AND AVAILABILITY AS THE UNDERLYING MECHANISMS LINKING JOB FEATURES AND PERSONAL CHARACTERISTICS TO WORK ENGAGEMENT}

\author{
A dissertation submitted in partial fulfillment \\ of the requirements of the degree of \\ DOCTOR OF PHILOSOPHY \\ in \\ PSYCHOLOGY \\ by
}

Holly Jacobs 
To: Dean Kenneth G. Furton

College of Arts and Sciences

This dissertation, written by Holly Jacobs, and entitled An Examination of Psychological Meaningfulness, Safety, and Availability as the Underlying Mechanisms Linking Job Features and Personal Characteristics to Work Engagement, having been approved in respect to style and intellectual content, is referred to you for judgment.

We have read this dissertation and recommend that it be approved.

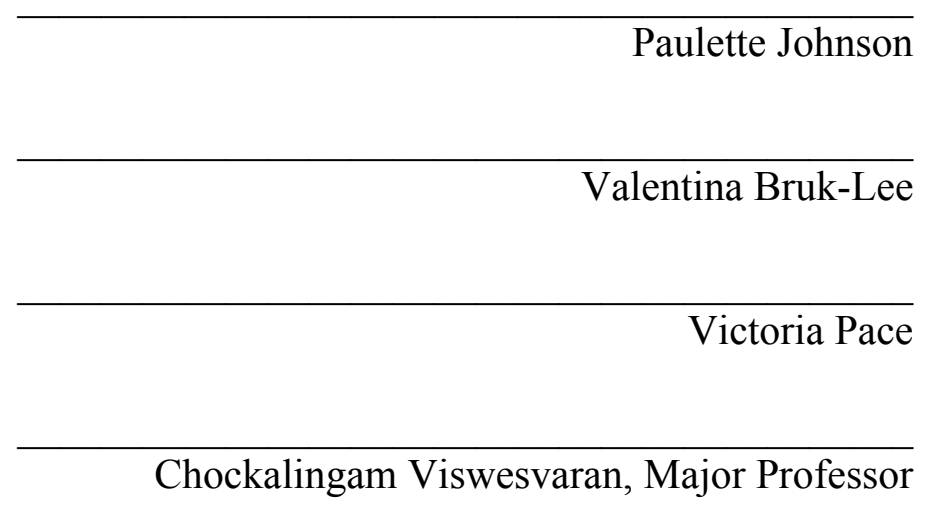

Date of Defense: June 5, 2013

The dissertation of Holly Jacobs is approved.

Dean Kenneth G. Furton

College of Arts and Sciences

Dean Lakshmi N. Reddi

University Graduate School

Florida International University, 2013 


\section{DEDICATION}

To Oscar, who has not only been the main source of love, support, and stability through one of my most difficult years, but also the biggest motivating force. Through your undying guidance and encouragement, you help me turn my dreams into a reality. With you by my side, I know that anything is possible. You truly are an angel sent from above and I thank the universe every day for steering you in my direction.

To Mary. More than a mentor and friend, you are without a doubt one of my soul mates. Not only have you been an invaluable resource, guide, and cheerleader for this dissertation, but every time that I speak to you I am reassured that I am not alone in my thoughts, perceptions, and hopes for this world. I look forward to carrying out my life work with you by my side, and spending more lives transforming from a dirty snowball into a gleaming sphere of lavender in your presence. 


\section{ACKNOWLEDGMENTS}

I would like to express the deepest appreciation to my major professor, Dr.

Chockalingam Viswesvaran, for his patience, support, and invaluable contributions to this dissertation. When you speak, genius flows out and I struggle to take it all down. I am thankful that I was able to record enough of it to do this dissertation justice. I would also like to thank my committee members, Dr. Victoria Pace, Dr. Valentina Bruk-Lee, and Dr. Paulette Johnson, for their encouragement, guidance, and insightful questions that always led to stimulating conversation and words of wisdom. You all inspire the researcher within me and keep my thirst for knowledge unquenched and avidly looking for statistical evidence to back up my real-life theories.

Last but certainly not least, I would like to thank my family: my mother, Charm, my father, Brian, and my two brothers Donny and Scotty. I know you all started to dread that this day would never come, but it has! I thank you for all of the effort that you made to get me from point $\mathrm{A}$ to point $\mathrm{B}$ of this dissertation including: turning your company upside down looking for data, holding rent over my head when I needed to hit a certain page count, having your $\mathrm{PhD}$ friends speak to me when you didn't know what to say, keeping my head above water when I just felt like drowning, and popping a bottle of champagne in my honor once I finished. Thank you all for your endless love and encouragement throughout my years in academia. I look forward to sharing my adventures in the real world with you and am forever in your debt for everything that you did to get me to where I am and where I'm going. 


\author{
ABSTRACT OF THE DISSERTATION \\ AN EXAMINATION OF PSYCHOLOGICAL MEANINGFULNESS, \\ SAFETY, AND AVAILABILITY AS THE UNDERLYING \\ MECHANISMS LINKING JOB FEATURES AND PERSONAL \\ CHARACTERISTICS TO WORK ENGAGEMENT \\ by
}

Holly Jacobs

Florida International University, 2013

Miami, Florida

Professor Chockalingam Viswesvaran, Major Professor

The present study tested a nomological net of work engagement that was derived from its extant research. Two of the main work engagement models that have been presented and empirically tested in the literature, the JD-R model and Kahn's model, were integrated to test the effects that job features and personal characteristics can have on work engagement through the psychological conditions of meaningfulness, safety, and availability. In this study, safety refers to psychological perceptions of safety and not workplace safety behaviors. The job features that were tested in this model included person-job fit, autonomy, co-worker relations, supervisor support, procedural justice, and interactional justice, while the personal characteristics consisted of selfconsciousness, self-efficacy, extraversion, and neuroticism. Thirty-four hypotheses and a conceptual model were tested in order to establish the viability of this nomological net of work engagement in which it was expected that meaningfulness would mediate the relationships between job features and work engagement, safety would mediate the 
relationships that job features and personal characteristics have with work engagement, and availability (physical, emotional, and cognitive resources) would mediate the relationships that personal characteristics have with work engagement. Furthermore, analyses were run in order to determine the factor structure of work engagement, assess whether or not it exhibits differential validity from organizational commitment and job satisfaction, and confirm that it is positively related to the outcome variable of organizational citizenship behavior (OCB). The final sample consisted of 500 workers from an online labor market who responded to a questionnaire composed of measures of all constructs included in this study. Findings show that work engagement is best represented as a three-factor construct, composed of vigor, dedication and absorption. Furthermore, support was found for the distinction of work engagement from the related constructs of organizational commitment and job satisfaction. With regard to the proposed model, meaningfulness proved to be the strongest predictor of work engagement. Results show that it partially mediates the relationships that all job features have with work engagement. Safety proved to be a partial mediator of the relationships that autonomy, co-worker relations, supervisor support, procedural justice, interactional justice, and self-efficacy have with work engagement, and fully mediate the relationship between neuroticism and work engagement. Findings also show that availability partially mediates the positive relationships that extraversion and self-efficacy have with work engagement, and fully mediates the negative relationship that neuroticism has with work engagement. Finally, a positive relationship was found between work engagement and OCB. Research and organizational implications are discussed. 


\section{TABLE OF CONTENTS}

\section{CHAPTER}

I. INTRODUCTION 1

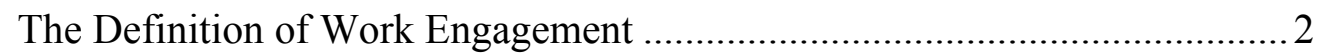

The Importance of Work Engagement........................................................

Two Models of Work Engagement.............................................................

Job Demands-Resources Model..........................................................

Personal Resources as Predictors of Engagement .................................. 10

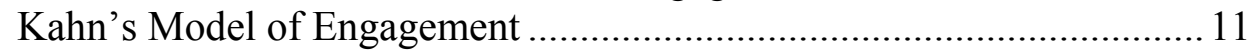

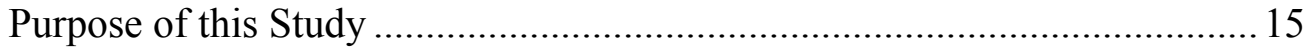

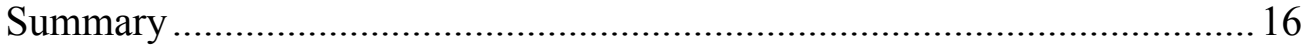

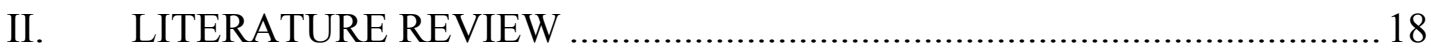

Work Engagement's Importance in the Workplace........................................ 18

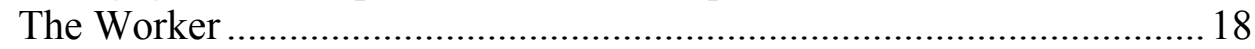

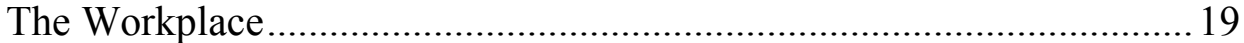

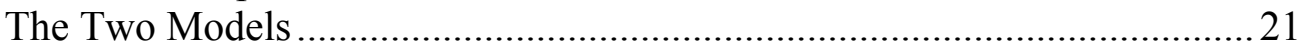

Job Demands-Resources Model.........................................................21

Kahn's Model of Engagement ..............................................................2

Integration of the Two Models …………………........................................29

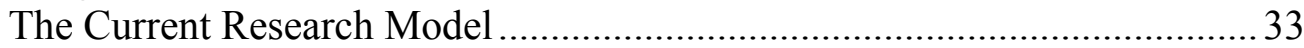

Job Features and Engagement................................................................. 38

Person-Job Fit and Engagement.........................................................39

Autonomy and Engagement..............................................................4

Co-Worker Relations and Engagement …………………...............4 42

Supervisor Support and Engagement................................................. 44

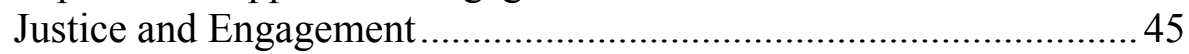

Personal Characteristics and Engagement ...............................................4 48

Self-Consciousness and Engagement ..............................................49

Self-Efficacy and Engagement ........................................................5

Personality and Engagement............................................................52

Psychological Meaningfulness, Safety, and Availability .........................56

Psychological Meaningfulness.................................................................5

Psychological Meaningfulness and Engagement......................59

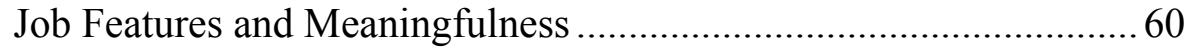

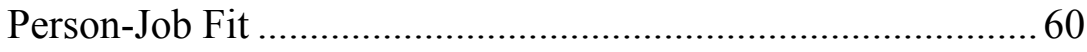

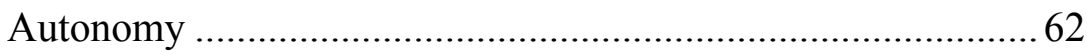

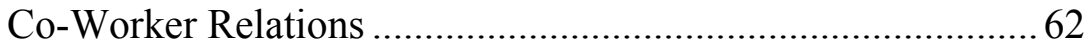

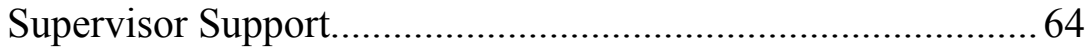

Procedural and Interactional Justice ...........................................64

Psychological Meaningfulness as a Mediator...............................65

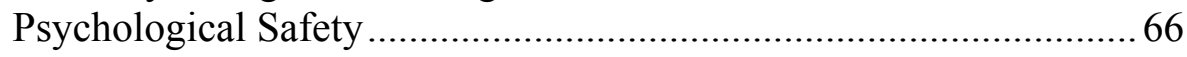

Psychological Safety and Engagement …………………….......66

Job Features and Psychological Safety ....................................................6 67 


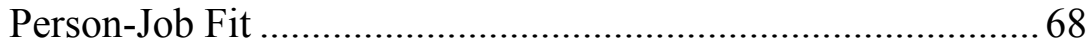

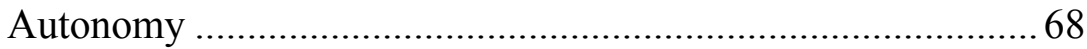

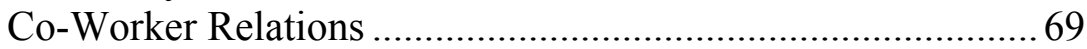

Supervisor Support................................................................ 70

Procedural and Interactional Justice ......................................... 71

Psychological Safety as a Mediator ............................................72

Personal Characteristics and Psychological Safety...................................72

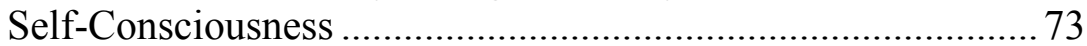

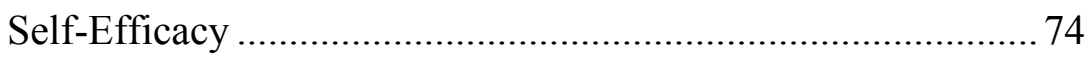

Personality ......................................................................

Psychological Safety as a Mediator ..........................................76

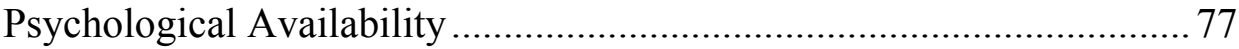

Psychological Availability and Work Engagement ....................77

Personal Characteristics and Availability ...............................................78

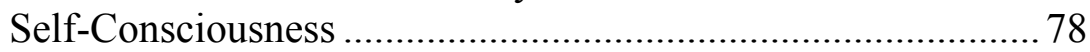

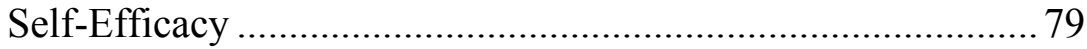

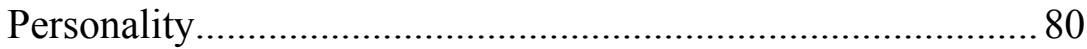

Psychological Availability as a Mediator .................................. 81

Work Engagement and Organizational Citizenship Behavior ...................82

Summarizing the Research Model ....................................................... 85

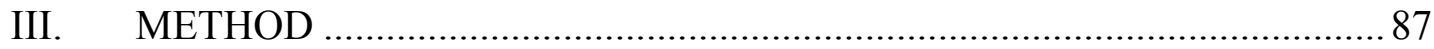

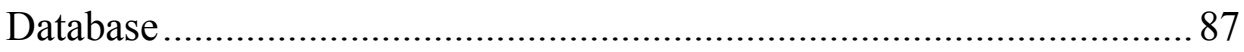

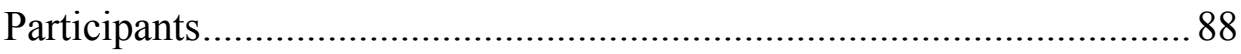

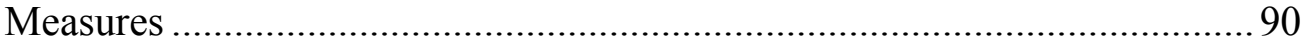

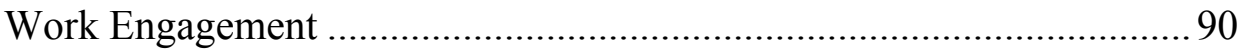

Organizational Commitment.............................................................93

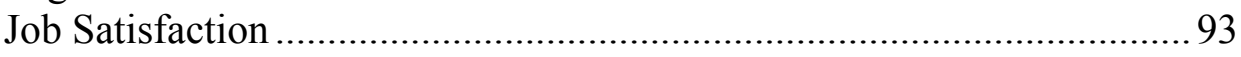

Organizational Citizenship Behavior ...................................................... 94

Psychological Meaningfulness..............................................................95

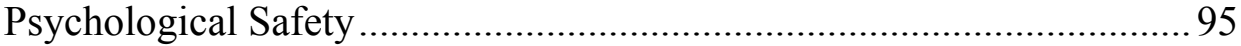

Psychological Availability ....................................................................96

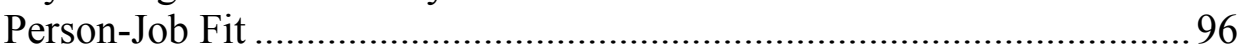

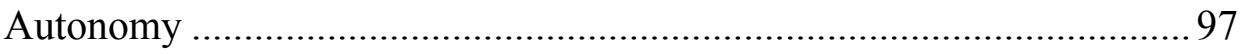

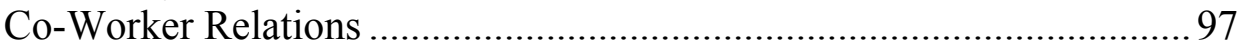

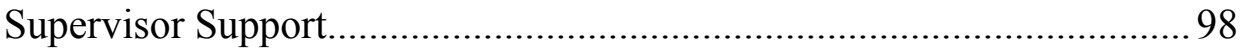

Procedural Justice ............................................................................. 98

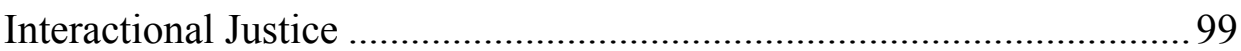

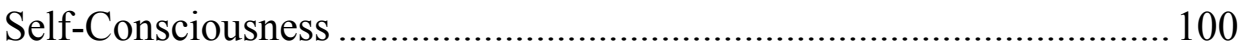

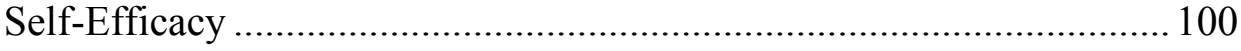

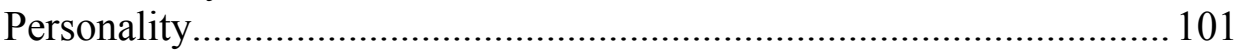

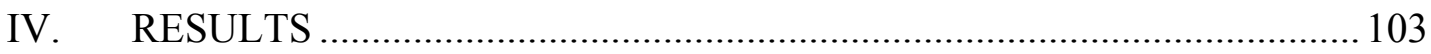

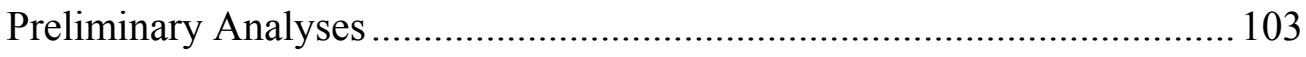

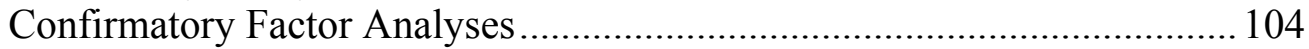




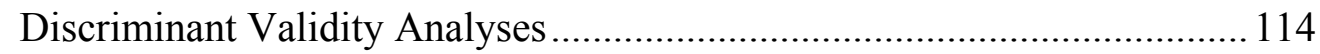

Partial Model Testing............................................................................ 124

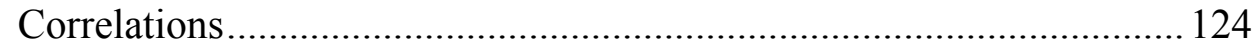

Correlations with Work Engagement....................................... 127

Correlations with Psychological Conditions............................ 129

Testing Blocks of Antecedents using Multiple Regression ...........................130

Meaningfulness as an Outcome of Job Features.................................... 131

Safety as an Outcome of Job Features ................................................. 132

Safety as an Outcome of Personal Characteristics................................132

Availability as an Outcome of Personal Characteristics.........................133

Work Engagement as an Outcome of the Psychological Conditions .... 134

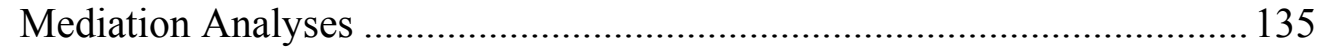

Psychological Meaningfulness as a Mediator........................................136

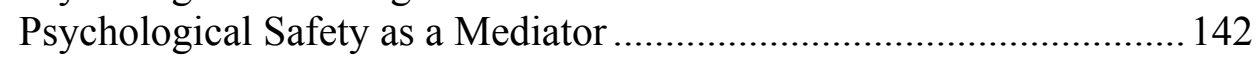

Psychological Availability as a Mediator ..............................................153

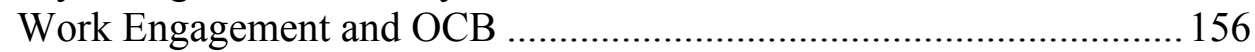

Structural Equation Modeling (SEM) .................................................. 157

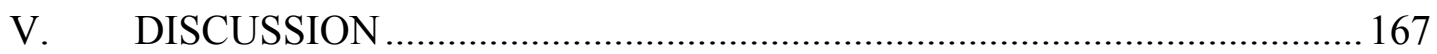

Factor Structure of Work Engagement ....................................................... 167

Engagement's Distinction from Satisfaction and Commitment ................... 169

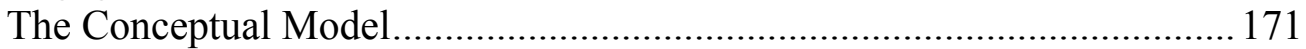

Meaningfulness as a Mediator ............................................................. 171

Safety as a Mediator for Job Features................................................... 173

Safety as a Mediator for Personal Characteristics ………..................... 175

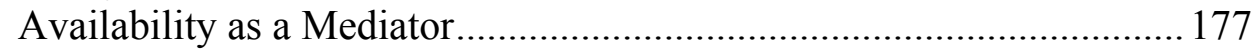

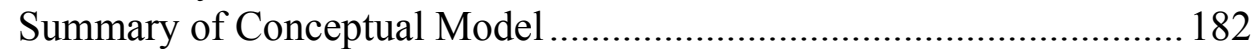

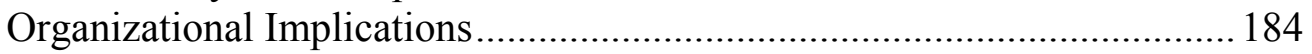

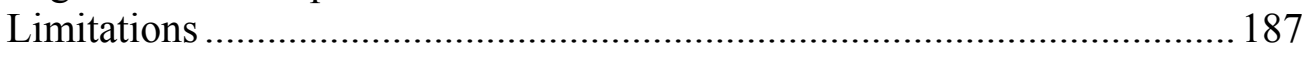

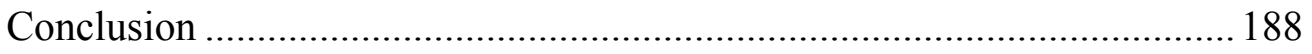

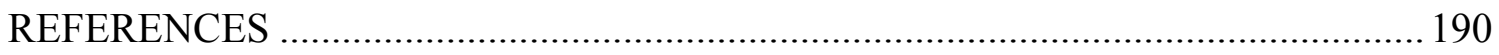

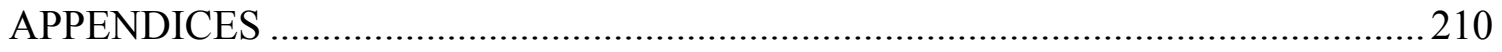

VITA … 


\section{LIST OF TABLES}

TABLE

PAGE

1. Fit Indices for CFA of Work Engagement

2. Correlations between Condensed and Full Versions of Engagement Scales

3. Reliability-Corrected Correlations between Vigor, Dedication, and

Absorption.

4. Reliability-Corrected Correlations between Work Engagement, Organizational Commitment, and Job Satisfaction

5A. Fit Indices for CFA of Engagement, Commitment, and Satisfaction

5B. Summary of Regression Analysis to see if Engagement explains Variance in OCB over Job Satisfaction.

5C. Summary of Regression Analysis to see if Engagement Explains Variance in OCB over Organizational Commitment

6A. Correlations between Job Features, Psychological Conditions, and Work

Engagement.

6B. Correlations between Personal Characteristics, Psychological Conditions, and Work Engagement

6C. Correlations between Job Features and Personal Characteristics

7A. Summary of Hierarchical Regression Analysis Testing Job Features as a Block Explaining Variance in Meaningfulness and Safety

7B. Summary of Hierarchical Regression Analysis Testing Personal Characteristics as a Block Explaining Variance in Safety and Availability

7C. Summary of Hierarchical Regression Analysis Testing the Psychological Conditions as a Block Explaining Variance in Work Engagement

8A. Summary of Hierarchical Regression Analysis Testing the Mediating Role of Meaningfulness between Person-Job Fit and Work Engagement

8B. Summary of Hierarchical Regression Analysis Testing the Mediating Role 
of Meaningfulness between Autonomy and Work Engagement

8C. Summary of Hierarchical Regression Analysis Testing the Mediating Role of Meaningfulness between Co-Worker Relations and Work

Engagement.

8D. Summary of Hierarchical Regression Analysis Testing the Mediating Role of Meaningfulness between Supervisor Support and Work Engagement.

8E. Summary of Hierarchical Regression Analysis Testing the Mediating Role of Meaningfulness between Procedural Justice and Work Engagement .. 141

8F. Summary of Hierarchical Regression Analysis Testing the Mediating Role of Meaningfulness between Interactional Justice and Work

Engagement.

9A. Summary of Hierarchical Regression Analysis Testing the Mediating Role of Safety between Person-Job Fit and Work Engagement

9B. Summary of Hierarchical Regression Analysis Testing the Mediating Role of Safety between Autonomy and Work Engagement 144

9C. Summary of Hierarchical Regression Analysis Testing the Mediating Role of Safety between Co-Worker Relations and Work Engagement 145

9D. Summary of Hierarchical Regression Analysis Testing the Mediating Role of Safety between Supervisor Support and Work Engagement

9E. Summary of Hierarchical Regression Analysis Testing the Mediating Role of Safety between Procedural Justice and Work Engagement.

9F. Summary of Hierarchical Regression Analysis Testing the Mediating Role of Safety between Interactional Justice and Work Engagement 148

10A. Summary of Hierarchical Regression Analysis Testing the Mediating Role of Safety between Self-Consciousness and Work Engagement 149

10B. Summary of Hierarchical Regression Analysis Testing the Mediating Role of Safety between Self-Efficacy and Work Engagement 150

10C. Summary of Hierarchical Regression Analysis Testing the Mediating Role of Safety between Extraversion and Work Engagement 151

10D. Summary of Hierarchical Regression Analysis Testing the Mediating Role 
of Safety between Neuroticism and Work Engagement.....

11A. Summary of Hierarchical Regression Analysis Testing the Mediating Role of Availability between Self-Consciousness and Work Engagement....... 153

11B. Summary of Hierarchical Regression Analysis Testing the Mediating Role of Availability between Self-Efficacy and Work Engagement. 154

11C. Summary of Hierarchical Regression Analysis Testing the Mediating Role of Availability between Extraversion and Work Engagement ................. 155

11D. Summary of Hierarchical Regression Analysis Testing the Mediating Role of Availability between Neuroticism and Work Engagement ................. 156

12. Summary of Hierarchical Regression Analysis Testing Work Engagement as a Predictor of OCB .......................................................................... 157

13. SEM Results for Full Model ........................................................... 160

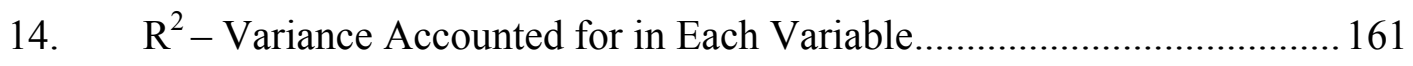

15A. Structural Equation Model Path Coefficients for Relationships Between Job Features, Personal Characteristics, and Psychological Conditions........... 162

15B. Structural Equation Model Path Coefficients for Relationships Between Psychological Conditions and Work Engagement................................. 163 


\section{LIST OF FIGURES}

FIGURE

PAGE

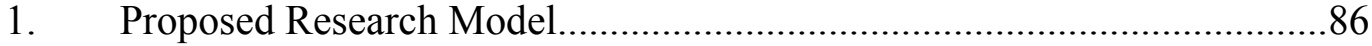

2A. Uni-Factor Model of Work Engagement (17-Indicators) .......................105

2B. Three-Factor Model of Work Engagement (17-Indicators) .....................106

2C. Uni-Factor Model of Work Engagement (9-Indicators) .........................111

2D. Three-Factor Model of Work Engagement (9-Indicators) ......................112

3A. Uni-Factor Model of General Work Attachment.................................117

3B. Three-Factor Model of Engagement, Commitment, and Satisfaction .....120

4. SEM Results for Conceptual Model of Job Features, Personality Characteristics, Psychological Conditions, and Work Engagement........159 


\section{Chapter I}

\section{Introduction}

Today's struggling economy has driven organizations to search for a quick fix to a problem that has been building for years: how to achieve the utmost level of efficiency so that their companies can be productive and profitable. While workers dread unemployment, companies fear bankruptcy. Companies seem to think that they may have found their solution in work engagement, a very hot topic in both the applied and academic world of Industrial-Organizational (I-O) psychology today. Reacting to this need, organizational consulting companies offer services regarding how to get employees more engaged in their work. As scientists, I-O psychologists question the offering of such services without a firm grounding in research. Since work engagement is a fairly new concept in literature, its nomological net is still in the process of being established and its predictors and their relationships with engagement are just beginning to be unveiled. This fact gives rise to the question "Exactly how sound is the advice that consulting companies are giving organizations today?" How is it that consulting companies are already advising organizations on how to foster work engagement when researchers are still trying to find the answer to this question themselves? Just as a patient would be hesitant to undergo a procedure that is not well grounded in research, so companies might want to think twice about receiving advice about work engagement until more of its research is done and published. There is a dire need for additional research regarding exactly what organizational and personal characteristics are associated with work engagement and how. Herein lies the purpose of this study— to look further into the 
mechanisms that underlie work engagement and get closer to achieving empirical evidence that will guide selecting for and promoting work engagement in the workplace.

\section{The Definition of Work Engagement}

Work engagement refers to the positive, fulfilling, motivational state of mind that people encounter when they are completely immersed in their work to the point that time seems like it is flying by. Most scholars agree that it includes both an energy dimension and an identification dimension (Bakker, Schaufeli, Leiter, \& Taris, 2008). Employees that are engaged in their work are enthusiastic about it and have an affective and energetic connection to it, rather than finding it disproportionately stressful and demanding (Bakker et al., 2008). Although researchers can generally conceive of what work engagement is, there is still some dispute over its specific definition and operationalization.

One of the first researchers to study engagement was Kahn (1990) who defined engagement as “...the harnessing of organization members' selves to their work roles, in engagement, people employ and express themselves physically, cognitively, and emotionally during role performances" (p.694). He described it as referring to how psychologically present individuals are during certain moments of their role performances. Furthermore, he asserted that the more individuals draw upon themselves to perform their roles within the boundaries between who they are and what roles they occupy, the more inspiring their performances are and the more content they are with playing those roles (Kahn, 1990). Kahn therefore described engagement almost as if it were synonymous with acting on a stage. Furthermore, he said that engagement is a product of two different forces: an individual's respective psychological experience of 
work that drives their attitudes and behavior and the individual, interpersonal, group, intergroup and organizational factors that influence this experience. Therefore, engagement is not only a product of one's individual drives, but it is also influenced by outside factors that may or may not motivate one to become engaged in a particular role (Kahn, 1990).

Rothbard (2001) defined engagement as having two critical components: attention and absorption. Attention refers to the allocation of mental energy to a role and the amount of time that one spends thinking about the role, whereas absorption refers to how engrossed or focused one is on their role. Much like the experience of flow, the absorption component of work engagement represents a feeling of intense concentration in which an individual may not experience themselves to be distinct from their activity (Csikszentmihalyi, 1990).

Schaufeli, Salanova, Gonzalez-Roma, and Bakker (2002) also studied engagement. They conceptualized it as being characterized by three distinct qualities. Specifically, they argued that engagement is “...a positive, fulfilling, work-related state of mind that is characterized by vigor, dedication, and absorption" (Schaufeli et al., 2002, p.74). Vigor refers to the level of energy and mental resilience that individuals have towards their work, how willing they are to invest effort in and persist in their work, even in the face of difficulties. Dedication is how involved one is in their work and to what extent they experience feelings of enthusiasm, pride, inspiration, significance, and challenge towards it. Absorption, similarly defined by Rothbard (2001), is characterized as how concentrated and happily engrossed one is in their work. It refers to a feeling akin to flow, where time passes by quickly and people find it difficult to detach themselves 
from their work (Bakker et al., 2008). For the purpose of my dissertation, the definition of engagement by Schaufeli et al. (2002) was used because it is the most recent and widely used definition of engagement in the literature today.

Scholars have argued over whether or not engagement is distinct from related constructs such as job satisfaction, job commitment, job involvement, workaholism, and/or flow. This is not surprising, considering that engagement has always been plagued by inconsistent construct definitions and operationalizations (Macey \& Schneider, 2008). The research concerning engagement's distinction from related variables is still in its infancy and although many researchers have been able to conceptually differentiate engagement from these variables, most have yet to empirically prove that engagement exhibits discriminant validity from, and criterion-related validity over, other job attitudes.

Researchers say that the difference between job satisfaction, organizational commitment, job involvement, and work engagement is that the first three refer only to the investment of one dimension (affective or cognitive) of the self into a job or organization, whereas work engagement represents the investment of several dimensions (physical, emotional, and cognitive) into the performance of work tasks (Rich, LePine, \& Crawford, 2010; Brooke, Russell, \& Price, 1988; Christian, Garza, \& Slaughter, 2011; Maslach, Schaufeli, \& Leiter, 2001). Hence, job satisfaction, commitment and involvement may be facets of engagement, but are certainly not conceptually synonymous with it. Researchers also argue that workaholism differs from engagement in that workaholics spend a great deal of time working and thinking about work not necessarily because they enjoy it as engaged workers do, but because they are obsessed with it (Schaufeli et al., 2001; Schaufeli, Taris, \& Bakker, 2006; Scott, Moore, \& Miceli, 
1997; Taris, Schaufeli, \& Shimazu, 2010). Finally, perhaps the most conceptually similar to work engagement, flow can be distinguished from engagement on the basis that it is a more acute state that lasts for a shorter period of time and is potentially of a more intense nature, whereas work engagement is a persistent positive affective-cognitive state of mind toward one's work (Wefald \& Downey, 2009).

Although scholars are able to conceptually differentiate engagement from related constructs, empirical evidence of its differential validity is still conflicting. In 2009, Wefald and Downey performed a study that aimed to differentiate engagement from job satisfaction using a sample of 453 students. They found that there was a great deal of overlap between engagement and job satisfaction and, furthermore, that engagement did not add incremental validity over job satisfaction towards the prediction of student performance. Conversely, Christian, Garza, and Slaughter (2011) later performed a meta-analytic study and found that engagement explained incremental variance in contextual performance over job satisfaction, job involvement, and organizational commitment. Therefore, more research is warranted in order to prove the validity of researchers' theoretical assertions and determine whether engagement adds incremental value over related constructs as a predictor of behavior.

\section{The Importance of Engagement}

The most direct implications of work engagement for the workplace are grounded in its very nature; it is inherently characterized by energy and focus. With this detail in mind, it is not surprising that research has found that engaged workers tend to perform better in terms of (in-role and extra-role) performance, and innovativeness (e.g., Bakker, Demerouti, \& Verbeke, 2004; Schaufeli, Taris, \& Bakker, 2006). In 2006, Schaufeli, 
Taris, and Bakker performed a cross-sectional study on a large heterogeneous dataset of Dutch employees to examine the relationship between trait work engagement and in-role performance, extra-role performance, and innovativeness. Results showed that engagement was positively related to all of these outcome variables, whereas workaholism was not. Furthermore, in an effort to examine more objective outcomes of engagement, Xanthopoulou, Bakker, Demerouti, and Schaufeli (2009) investigated work engagement as a mediator between job resources and financial returns in a fast-food company. They found that day-level resources were positively related to day-level work engagement, which in turn predicted daily financial returns. Research has also shown that engagement results in an upward spiral of personal and job resources, which then promotes performance levels. For example, Hakanen, Perhonieme, and Toppinen-Tanner (2008) performed a two-wave 3-year panel study using Finnish dentists to explore the gain spiral results of job resources. They found that there was a cross-lagged positive and reciprocal relationship between job resources and work engagement, as well as between work engagement and personal initiative (PI). Personal Initiative was also found to have a positive impact on work-unit innovativeness.

The transfer, or crossover, of engagement among members in the same organization has also been found to increase performance in teams and ultimately throughout the workplace. Bakker, Van Emmerik, and Euwema (2006), for example, found team-level work engagement to be related to individual team members' engagement, even after controlling for the job demands and resources of individual members. Some studies have even found positive associations between engagement and health (e.g., Hallberg \& Schaufeli, 2006; Schaufeli, Taris, \& Van Rhenen, 2008). For 
instance, Parzefall and Hakanen (2010) found support for both a motivational as well as a health-enhancing process in which engagement fully mediated the impact that psychological contract fulfillment had on mental health. Therefore, although engagement is still a fairly new construct in I/O psychology, empirical findings revealing its positive relationship with performance and other positive outcomes in the workplace are reason enough to see why researchers and practitioners have developed an interest in its nomological network in research and application to the workplace.

\section{Two Models of Work Engagement}

Since work engagement has been linked to so many beneficial health and performance outcomes, it seems only natural that researchers and practitioners would be interested in determining the causes, or antecedents, of work engagement. Research that has aspired to unveil work engagement's antecedents has utilized several different theoretical approaches to do so, such as job characteristics theory (Hackman \& Oldham, 1980), demand-control model (Karasek, 1979), social cognitive theory (Bandura, 1986), self-determination theory (Ryan \& Deci, 2000), job demands-resources (JD-R) theory (Bakker \& Demerouti, 2008; Demerouti, Bakker, Nachreiner, \& Schaufeli, 2001), broaden-and-build theory (Fredrickson, 2001), and conservation of resources (COR) theory (Hobfoll, 1989). Two models that have resulted from integrating these theories in order to explore the nomological net of work engagement are the job demands-resources (JD-R) model and Kahn's (1990) model.

Job demands-resources model. The origin of the JD-R model, and the perception of job demands as stressors, can be traced back to the demand-control model (DCM) first introduced by Karasek in 1979. His research found job strain to be a result 
of high job demands (i.e., work overload and time pressure) and low job control (i.e., skill discretion and decision latitude). Specifically, job strain was equal to how much workers' job demands exceeded the amount of control they had over those demands (Karasek, 1979). The appeal of the DCM (its simplicity) was also its most important weakness - its assumption that the complex reality of working organizations could be reduced to just a handful of variables.

Building upon the DCM, while also integrating the occupational stress literature regarding challenge and hindrance stress, Demerouti, Bakker, Nachreiner, and Schaufeli (2001) introduced the more complex job demands-resources (JD-R) model that replaced the outcome variable of job strain with exhaustion and disengagement (now identified as job burnout and work engagement) (LePine, LePine, \& Jackson, 2004; Karasek, 1979; Schaufeli \& Bakker, 2004). The JD-R model asserts that regardless of the type of job, work characteristics can be categorized into two groups: job resources and job demands. These two groups "evoke two psychologically different, although related processes: (1) an energy sapping, health impairment process in which high job demands exhaust employees' mental and physical resources leading to burnout, and eventually to ill-health; and (2) a positive motivational process in which job resources foster engagement and organizational commitment" (Bakker \& Leiter, 2010, p.87). Job demands refer to "those physical, social, or organizational aspects of the job that require sustained physical and/or psychological (i.e., cognitive and emotional) effort on the part of the employee and are therefore associated with certain physiological and/or psychological costs" (Demerouti, Bakker, Nachreiner, \& Schaufeli, 2001, p.501). Examples of job demands are role overload, role conflict, role ambiguity, work and time pressure, and adverse physical 
work environment characteristics. Conversely, job resources are "those physical, psychological, social, or organizational aspects of the job that may (a) reduce job demands and the associated physiological and psychological costs, (b) are functional in achieving work goals, and (c) stimulate personal growth, learning, and development" (Demerouti et al., 2001, p.501). Job resources can be found on four different levels: task, organization of work, interpersonal and social relations, and organizational factors. Because the focal topic of my dissertation is work engagement and not burnout, no further detail will be used to explore the 'energy sapping process' that makes up the 'burnout' portion of the JD-R model. Instead, the segment of the JD-R model that depicts job resources as antecedents of work engagement will now be discussed.

Some of the most commonly studied job resources that have been found to increase engagement levels are autonomy, feedback, social support, task variety/growth opportunities, supervisor support, and positive organizational climate (e.g., Hakanen, Bakker, \& Schaufeli, 2006; Schaufeli \& Bakker, 2004; Schaufeli, Bakker, \& Van Rhenen, 2009). Job resources' positive influence on work engagement is rooted in the fact that they are extrinsically and intrinsically motivating. They are extrinsic motivators because they are needed to deal with job demands and achieve professional goals. They are intrinsic motivators in that they satisfy the basic human needs of autonomy, belongingness, and competence (Van den Broeck, De Witte, Lens, \& Vansteenkiste, 2008; Bakker \& Leiter, 2010). In his meta-analysis of work engagement and its relationships with burnout, demands, resources, and consequences, Halbesleben (2010) found that social support, autonomy, feedback, and positive organizational climate were 
all positively related to engagement. Furthermore, out of these job resources, autonomy had the highest estimated population correlation with engagement.

The JD-R model asserts that job resources and demands interact in such a way that job resources become more salient when employees encounter high levels of job demands (the coping or motivational hypothesis) (Bakker \& Leiter, 2010). A study by Bakker, Hakanen, Demerouti, and Xanthopoulou (2007) provided support for the joint effect when they found interaction effects among six job resources (e.g., appreciation, supervisory support, and job control) and high job demands in teaching (i.e., pupil misconduct) on dimensions of engagement among Finnish teachers. Specifically, 14 out of the hypothesized 18 interaction effects were found. Supervisor support, appreciation, and organizational climate proved to be important job resources for teachers, helping them cope with demanding interactions with their students.

Personal resources as predictors of engagement. Before discussing Kahn's (1990) research model of work engagement, it is important to consider personal resources and their relationship with engagement. Although no particular model has been specified regarding their influence on work engagement, personal resources have also been noted as an important category of antecedents. Hobfoll, Johnson, Ennis, and Jackson (2003) define personal resources as positive self-evaluations that are generally linked to resiliency and refer to individuals' sense of ability to control and successfully impact their environment. Positive self-evaluations have been known to predict goal-setting, motivation, performance, job and life satisfaction, as well as other desirable outcomes (Judge, Van Vianen, \& De Peter, 2004). The reasoning behind this is that more positive self-regard and goal self-concordance are expected as an individual's personal resources 
increase (Judge, Bono, Erez, \& Locke, 2005). Individuals that have goal self-concordance are intrinsically motivated to pursue their goals, ultimately leading to higher performance and satisfaction levels (Luthans \& Youssef, 2007).

Some of the most notable personal resources that have been linked to engagement are self-efficacy, optimism, and self-esteem. For example, Xanthopoulou et al. (2007) found that self-efficacy, organizational-based self-esteem, and optimism explained variance in work engagement over time, above and beyond job resources and previous engagement levels. Also, in a study derived from questionnaire responses of and diary entries of flight attendants before and after consecutive flights to three destinations, Xanthopoulou, Bakker, Heuven, Demerouti, and Schfauli (2008) found that work engagement was a significant mediator of the relationship between work-related selfefficacy and (in-role and extra-role) performance. Finally, Rich, LePine, and Crawford (2010) found that work engagement mediated the relationships among value congruence, perceived organizational support, and core self-evaluations (i.e., locus of control, neuroticism, generalized self-efficacy, and self-esteem) and two job performance dimensions (task performance and organizational citizenship behavior). Other personal resources that have not been as salient in the work engagement literature, but whose positive relationships with this construct are still worth noting, are low neuroticism and high extraversion (Langelaan, Bakker, van Doornen, \& Schaufeli, 2006), resilience (Bakker, Gierveld, \& Van Rijswijk, 2006), achievement-striving (Hallberg, Johansson, \& Schaufeli, 2007), and adaptive perfectionism (Zhang, Gan, \& Cham, 2007).

Kahn's model of engagement. In addition to the JD-R model, the other popular model that has been used to explore the antecedents of work engagement is Kahn's 
model, which was introduced in 1990. Kahn's model specifically focuses on exploring the underlying psychological mechanisms through which resources affect work engagement. As previously mentioned, Kahn (1990) was one of the first researchers to study work engagement. In his ethnographic study, Kahn derived his definition and model for work engagement from previous theoretical frameworks as well as his own empirical fieldwork. He defined personal engagement as "the harnessing of organization members' selves to their work roles" and stated that "in engagement, people employ and express themselves physically, cognitively, and emotionally during role performances" (Kahn, 1990, p.694). He extracted his definition from the fundamental idea that people need both self-expression and self-employment in their professional lives (Kahn, 1990; Alderfer, 1972; Maslow, 1954). For his process model of engagement, he started with Hackman and Oldham's (1980) job characteristics model as a foundation, and then implemented perspectives focusing on interpersonal (Bennis, Schein, Berlew, \& Steele, 1964; Rogers, 1958), group (Bion, 1961; Smith \& Berg, 1987), intergroup (Alderfer, 1985), and organizational (Hochschild, 1983) contexts that affect individuals' motivation and sense of meaning at work. In essence, his model was a compilation of two different theories — the first being that individuals' psychological experience of work drives their behaviors and attitudes (Hackman \& Oldham, 1980), and the second that individual, interpersonal, group, intergroup, and organizational elements work together to affect these experiences (Alderfer, 1985).

Kahn's ethnographic study consisted of looking more closely at the determinants, or antecedents, of work engagement and the process by which it came to be. His study entailed first interviewing and observing camp counselors with regard to their own 
experiences with work engagement. He had them describe times that they could remember when they were very engrossed in and energetic about their work. From these descriptions, he derived three psychological conditions influencing engagement that were the result of one's own psychological experience of the work role. This premise is very similar to Hackman and Oldham's (1980) theory that there are three critical psychological states that influence individuals' internal work attitudes. The three psychological conditions are as follows: meaningfulness, psychological safety, and psychological availability. In order to ensure that he achieved generalizable understandings about work engagement, he tested the applicability of these concepts in an architecture firm as well.

Meaningfulness refers to the "feeling that one is receiving a return on investments of one's self in a currency of physical, cognitive, or emotional energy" (Kahn, 1990, p.704). People experience meaningfulness when they feel worthwhile, useful, and valuable, sensing that they are making a difference and not being taken for granted. Human beings have an inherent need to feel that the work they perform is meaningful (Alderfer, 1972; Herzberg, Mausner, \& Snyderman, 1959; Maslow, 1943, 1954, 1971; McClelland, 1965; McGregor, 1960; Rogers, 1959, 1961). Meaningfulness refers to the notion that individuals want to be able to take pride in what they do for a living. Kahn determined that a task or job needed to be meaningful in order for someone to become engaged in it. His data indicated that meaningfulness is influenced by task characteristics (e.g., autonomy and variety), role characteristics (e.g., role fit), and work interactions (e.g., supervisor support) (Kahn, 1990). 
The second psychological condition, psychological safety, refers to the feeling of being "able to show and employ one's self without fear of negative consequence to selfimage, status, or career" (Kahn, 1990, p.708). Individuals are more likely to become engaged in their work if they feel psychologically safe in their occupational surroundings or as though they can let their guard down and be themselves. Kahn (1990) concluded that psychological safety is influenced by characteristics that make one aware of the rules and regulations of the workplace: interpersonal relationships, group and intergroup dynamics, management style and process, and organizational norms. He found that employees' relationships with their supervisors played a part in determining their level of felt psychological safety. If supervisors are more supportive, employees are more likely to relax, be themselves, and say or do what is on their mind. Another factor that Kahn indicated would influence psychological safety was organizational norms. "Norms are shared expectations about the general behaviors of system members (Hackman, 1986). People that stayed within generally appropriate ways of working and behaving felt safer than those who strayed outside those protective boundaries." (Kahn, 1990, p.712). Situations that promote trust are those that are consistent, predictable, clear and nonthreatening. People are more likely to feel safe if they are able to understand the boundaries between what is allowed, what is disallowed, and the potential consequences of their behaviors (Kahn, 1990).

The last psychological condition that Kahn addressed with regard to a person becoming engaged is psychological availability. This condition refers to the notion that individuals must have the physical, emotional, and cognitive resources to devote towards becoming engaged in their work. How ready are people to engage, given the distractions 
that are encountered in life? Kahn found that the factors that influenced psychological availability were depletion of physical energy, depletion of emotional energy, individual insecurity, and outside lives. If workers are involved outside of work, then their personal resources are divided between work and those outside activities, leaving fewer resources to put towards their work. However, in some cases outside involvements may actually fuel one's personal resources towards work, by means of non-work to work enrichment (e.g., Rothbard, 2001). Research has found support for both of these theories. For example, Montgomery, Peeters, Schaufeli, and Den Ouden (2003) found that positive work-home interactions partially mediated the impact of social resources on engagement among Dutch newspaper managers. Additionally, in a study by Bakker, Demerouti, and Schaufeli (2005), they found that home resources were positively associated with engagement in both men and women, but interestingly enough, emotional home demands were negatively associated with engagement among women.

\section{Purpose of this Study}

Engagement's importance in the applied and academic world of I-O psychology is apparent from its significant positive relationship with outcome variables such as in-role and extra-role performance, innovativeness, financial returns, and mental health, just to name a few. This importance stirs up a need to determine how to get individuals engaged in their work, calling for more research to be done regarding the process that underlies engagement. Therefore, the present study integrated the two main work engagement models that have been presented and empirically tested in the literature (i.e., JD-R model and Kahn's model). Although some antecedents have been tested in Kahn's model, the two models have not been fully integrated. 
More specifically, the purpose of this dissertation was to take job resources that have been tested as antecedents in the JD-R model, along with job and personal characteristics that have been theorized and/or tested in Kahn's model, and incorporate them into one model that tested the effects that job and personal characteristics have on work engagement through the psychological conditions of meaningfulness, safety, and availability. My study looked more closely at the relationship between job features (i.e., PJ fit, autonomy, co-worker relations, supervisor support, procedural justice, and interactional justice), personal characteristics (i.e., self-consciousness, self-efficacy, extraversion, and neuroticism), and work engagement to determine whether or not the psychological conditions of meaningfulness, safety, and availability are the underlying mechanisms that link these to one another. A comprehensive model tested meaningfulness and safety as mediators between job features and engagement, and safety and availability as mediators between personal characteristics and engagement.

\section{Summary}

Work engagement is defined by Schaufeli et al. (2002) as “.... positive, fulfilling, work-related state of mind that is characterized by vigor, dedication, and absorption" (p.74). Considering the beneficial impact that it has on individual (e.g., mental and physical health) as well as organizational elements (e.g., job performance, commitment), it is no surprise that engagement has become a construct of interest in the academic and applied realm of I-O psychology. Furthermore, because it is linked to so many beneficial outcomes, one can understand why researchers and practitioners are eager to unveil the underlying personal and organizational factors that are associated with engagement. 
Two research models in the literature have served as frameworks to explore the nomological net of work engagement: the Job Demands-Resources (JD-R) model and Kahn's (1990) model. The first chapter of this dissertation has provided an overview of these models and an introductory discussion of how they have revealed job resources, personal resources, and psychological conditions as antecedents of engagement. The next chapter will discuss these models in more detail, and propose a new model that will integrate these two models into one in an effort to establish a more comprehensive nomological net of work engagement. 


\section{Chapter II}

\section{Literature Review}

The second chapter of this dissertation will provide a comprehensive review of the work engagement literature relevant to this dissertation's proposed model. First, the

importance of work engagement with regard to the worker and the workplace at large will be discussed in detail. Then, the literature regarding the two models most central to the engagement literature, the JD-R model and Kahn's (1990) model, will be reviewed. The examination of these models will be followed by a discussion of how the two can be integrated into one comprehensive model to explore the antecedents of work engagement from each model. The integrated model was the research model for this dissertation. As such, the extant literature regarding the variables that were included in this model and their associations with work engagement as well as other variables in the model will be discussed.

\section{Work Engagement's Importance in the Workplace}

Before discussing the nature and history of the relationships between the variables that were included in the aforementioned model, work engagement and its importance for the worker and the organization at large will be discussed.

The worker. Work engagement is beneficial to workers themselves. Schaufeli et al. (2002) noted that the experience of work engagement in and of itself is a positive experience. The linkage is likely the consequence of the fact that employees who are engaged in their work are bringing their full, authentic selves into the work, and experiencing an intrinsically motivating interest in it (Kahn, 1992). This motivated 
experience of the authentic self leads to the experience of positive emotions, which can ultimately have positive effects on people's performance as well as their physical wellbeing. For example, studies have found that those that exhibit high scores on work engagement measures tend to experience better physical and psychological health (e.g., Demerouti, Bakker, DeJonge, Janssen, \& Schaufeli, 2001; Rothbard, 2001). Additionally, work engagement has been proven to help individuals derive benefits from stressful work as those that are engaged tend to see their work as being meaningful, relevant, and personally important as opposed to taxing and debilitating (Britt, Adler, \& Bartone, 2001). Finally, work engagement is beneficial to the worker as it tends to be associated with such positive work attitudes as commitment, satisfaction, and involvement (Bakker, Demerouti, \& Schaufeli, 2003; Christian, Garza, \& Slaughter, 2011; Demerouti et al., 2001; Hakanen, Bakker, \& Schaufeli, 2006; Hakanen, Schaufeli, \& Ahola, 2008).

The workplace. The workplace is likely to benefit from having employees that are engaged as well. According to the broaden-and-build theory of positive emotions (Fredrickson, 2001), positive experiences and emotions such as joy, interest, and commitment can broaden individuals' thought-action repertoires and build their personal resources by expanding the array of thoughts and actions that come to mind, resulting in better performance (Fredrickson \& Losada, 2005). Because engagement is associated with such positive emotions, those that are engaged in their work tend to perform better than those that are not (Bakker \& Demerouti, 2008).

Additionally, workers that are fully present in their jobs are more likely to be engaged in relationships with coworkers and even help bridge gaps between workers of different gender, race, ethnic, and ethical standards and/or backgrounds (Alderfer, 1987; 
Toffler, 1986). Work engagement has also been shown to be somewhat contagious among workers. According to the concept of emotional contagion, or crossover, positive (or negative) experiences can be transferred from one person to another (Demerouti \& Cropanzano, 2010; Westman, 2001). Empirical studies have confirmed that engagement can be transferred between individuals and teams (e.g., Bakker, Van Emerik, \& Euwema, 2006; Salanova, Agut, \& Peiró, 2005). Accordingly, the presence of one engaged worker makes it probable that there will be several engaged workers in the corresponding workplace.

Other benefits of work engagement to the workplace are that it relates positively to organizational commitment (Demerouti et al., 2001) and has also been shown to have positive effects on one's job performance and extra-role behavior (Schaufeli \& Bakker, 2004). Along those same lines, engaged employees have a greater attachment to their organization and lower likelihood of leaving it (Schaufeli \& Bakker, 2004). Hence, the benefit of the impact that engagement has on workers' performance is augmented by the fact that these workers have also been shown to remain at the organization and continue to excel.

Engaged workers can also give an organization a competitive advantage in their field of work. In his discussion of psychological presence at work, Kahn (1992) discussed how empowering organizational members by asking them to involve more of themselves in their jobs initiates new ideas, self-expressions, questionings, and creativity in ways that help the organization reflect on itself and change accordingly (Weisbord, 1987; Kahn, 1992). Hence, having employees that are engaged can give organizations an advantage over the other organizations in their field, as engaged employees are likely to 
be more innovative and come up with new ways of doing things and/or new products that will fare better in the market. Organizational research concerning work engagement and how it ultimately impacts the bottom line is scarce. However, there is a general belief that a connection exists between employee engagement and business outcomes (Harter, Schmidt, \& Hayes, 2002; Saks, 2006).

\section{The two models}

With regard to work engagement, there are two main models that have been utilized in the research to explore and test its nomological net: the JD-R model and Kahn's model. Whereas the JD-R model is grounded in the burnout literature, Kahn's model arose from an interest in determining the origins of work engagement, specifically. Nevertheless, both models have made significant contributions towards unveiling antecedents, correlates, and consequences of work engagement. The purpose of the present section will be to address the research findings that have emerged from each model and the research gaps for one or both models.

Job demands-resources model. The JD-R model originated from a line of research designed to investigate the relationship between job characteristics and employee well-being. Before the JD-R model came the Demand-Control model (DCM; Karasek 1979), asserting that mental strain was a result of high job demands and low job decision latitude. The DCM was criticized for its failure to capture the complexity of work environments. Theorists and researchers argued that there are resources in the work environment besides job latitude that could ultimately affect workers' well-being. For example, Johnson and Hall (1988) argued that job control is not the only resource available for coping with job demands. They offered social support from colleagues and 
superiors as additional options of resources that could play an important role in the workplace. Studies also failed to find support for the interaction effects between job demands and job control that were proposed by the DCM (Bakker, Van Veldhoven, \& Xanthopoulou, 2010).

These shortcomings of the DCM left room for another model to emerge that could further investigate the underlying relationships between job characteristics and employee well-being: the Job Demands-Resources model (JD-R Model; Bakker \& Demerouti, 2007, Demerouti, Bakker, Nachreiner, \& Schaufeli, 2001). The JD-R model was initially proposed as a model to determine the features of the job that would lead to burnout, characterized as consisting of two dimensions, exhaustion and disengagement (Demerouti et al., 2001). Once researchers realized that these two dimensions were actually separate constructs that were consequences of related but different processes, they were renamed and reformatted as such (Schaufeli \& Bakker, 2004). The JD-R model is now characterized as one that tests the antecedents and consequences of burnout and work engagement. It demonstrates that job demands influence burnout, whereas job resources affect workers' engagement. Some studies have found job demands to be related to work engagement, though these relationships are much weaker than those that exist between job resources and work engagement (e.g., Mauno, Kinnunen, \& Ruokolainen, 2007; Halbesleben, 2010). Because the focus of this dissertation is on engagement, only the antecedents of engagement, as opposed to burnout, will be discussed.

Some of the most common antecedents of work engagement that have been tested and supported using the JD-R model are as follows: performance feedback/results (six studies), job control/autonomy (five studies), social support from colleagues (five 
studies), task variety/growth opportunities (four studies), and supervisory support/coaching (three studies) (Hakanen \& Roodt, 2010). Meta-analytic studies have been performed in order to acquire mean effect sizes between engagement and some of these antecedents. For example, in 2011 Halbesleben performed a meta-analysis of work engagement and found that job resources had the following corrected correlations with overall engagement and its dimensions: overall engagement with social support $\left(r_{c}=.37\right)$ and autonomy/control $\left(r_{c}=.27\right)$; vigor with feedback $\left(r_{c}=.41\right)$ and organizational climate $\left(r_{c}=.23\right)$; and dedication with feedback $\left(r_{c}=.46\right)$ and organizational climate $\left(r_{c}=\right.$ .30). Following that study, Nahrgang, Morgeson, and Hoffman performed a metaanalysis of the JD-R model and safety outcomes in the workplace in 2011 on 203 independent samples $(\mathrm{N}=186,440)$. They found support for the motivational process in the JD-R as job resources were significantly related to work engagement. Specifically, safety climate had the highest corrected correlation with engagement $\left(r_{\mathrm{c}}=.80\right)$, followed by social support $\left(r_{\mathrm{c}}=.69\right)$, leadership $\left(r_{\mathrm{c}}=.63\right)$, knowledge $\left(r_{\mathrm{c}}=.47\right)$, and autonomy $\left(r_{\mathrm{c}}\right.$ $=.30$ ). Overall, supportive environment (a latent variable composed of social support, leadership, and safety climate) was the most consistent job resource in terms of explaining variance in engagement across industries.

In the initial study to test the JD-R model, Demerouti et al. (2001) collected selfreport questionnaires and observers' job description data on a sample consisting of workers from three different occupational groups (human services, industry, and transport; $\mathrm{N}=374$ ). They found that the best fitting model was one in which job demands predicted exhaustion and job resources predicted disengagement. The path from job 
resources (i.e., feedback, rewards, job control, participation, job security, supervisor support) to disengagement was found to be highly negative and significant.

Engagement was not initially the focal endogenous variable in the motivationdriven process of the JD-R model. Instead, studies around the early period of the JD-R model focused on burnout and tested variables such as organizational commitment, dedication, disengagement and the like as endogenous variables associated with job resources. For example, a study by Bakker, Demerouti, and Schaufeli in 2003 found that job resources (social support, supervisory coaching, performance, feedback, and time control) predicted dedication and organizational commitment, which in turn affected turnover intentions. In 2004, Bakker, Demerouti, and Verbeke tested the JD-R model on employees in different sectors and job positions $(\mathrm{N}=146)$. They found that social support and autonomy were the most important job resource predictors of extra-role performance through their relationship with the disengagement component of burnout.

Around 2004 and thereafter, researchers testing the JD-R model primarily used engagement as the focal variable of the motivation process. In 2004, Schaufeli and Bakker used Structural Equation Modeling (SEM) to analyze data from four independent occupational samples $(\mathrm{N}=1698)$. They found that engagement was exclusively predicted by job resources (performance feedback, social support from colleagues, and supervisory coaching), and also that it mediated the relationship between job resources and turnover intention. Feedback exemplified the highest correlations with the individual components of work engagement (Vigor, $r=.30$; Dedication, $r=.30$; Absorption, $r=.21$ ), followed by supervisory coaching (Vigor, $r=.25$; Dedication, $r=.29$; Absorption, $r=.19$ ) and social support (Vigor, $r=.15$ Dedication, $r=.26$; Absorption, $r=.07$ ). 
In 2006, Hakanen, Bakker, and Schaufeli tested the model on Finnish teachers. Their findings were especially robust as they obtained them in one half of the sample and then cross-validated them in the other. Using SEM to test the model, these researchers again found support for work engagement as a mediator between job resources and a positive organizational outcome, organizational commitment. Among the job resources that were examined, they found job control, management's information sharing, and social climate to have the highest correlations with work engagement.

After confirming the basic structure of the JD-R model, researchers started to expand on their methods. Schaufeli, Bakker, and Van Rhenen (2009) tested its feasibility over time by running the model using a two-wave longitudinal study with a 1-year time interval on 201 Dutch telecom managers and executives. SEM analyses revealed that changes in job resources from Time 1 to Time 2 affected work engagement at Time 2 ( $r$ $=.45$ ). Engagement then negatively predicted registered sickness duration and frequency. Results demonstrated social support, learning opportunities, and performance feedback as the highest correlates of dedication ( $r=.34, .33, .31$, respectively), and autonomy as the highest correlate of vigor $(r=.23)$.

Hansez and Chmiel (2010) ran a study to see if the JD-R model could be extended to safety behavior. Results supported their hypotheses; engagement mediated the relationship between job resources and safety-related task performance variables. In this study, decision latitude (i.e., autonomy) exemplified the strongest correlation with engagement $(r=.42)$ followed by job quality $(r=.37)$ and work support $(r=.33)$. Studies have also confirmed that job resources have a stronger impact on work engagement when high job demands are present (e.g., Bakker, Van Veldhove, \& 
Xanthopoulou, 2010) and that when job demands are perceived as challenge rather than hindrance stressors, they are positively associated with work engagement (Crawford, LePine, \& Rich, 2010).

As one can see, the JD-R model has been one of the most prominent models in the work engagement literature. It has been used to confirm over and over again that job resources are an important category of antecedents that affect work engagement. However, by restricting the antecedents of work engagement to job resources, the JD-R model leaves out other important correlates of engagement that fall into such categories as personal characteristics and other characteristics of the job that might not necessarily be seen as 'resources'. Several studies have found that personal characteristics such as self-efficacy, optimism, organization-based self-esteem, extraversion, neuroticism, and self-consciousness also predict much of the variance in work engagement (e.g., Inceoglu \& Warr, 2011; Xanthopoulou, Bakker, Demerouti, \& Schaufeli, 2007; Xanthopoulou, Bakker, Demerouti, \& Schaufeli, 2009). Likewise, research has found that there are other job characteristics that might not necessarily fall under the classification of "job resources' but still manage to explain a significant amount of variance in work engagement (e.g., job clarity, value congruence, and fairness) (Cho, Laschinger, \& Wong, 2006; James, McKechnie, \& Swanberg, 2011; Rich, LePine, \& Crawford, 2010).

Kahn's Model of Engagement. This shortcoming of the JD-R model brings us to another model, Kahn's model (1990), which has been used to examine engagement and its antecedents from a slightly different vantage point. Kahn's (1990) model can be traced back to Goffman's (1961) work regarding the degree to which individuals embrace or distance their true selves from the roles they take on. From this theory, Kahn 
developed a definition of engagement that involved the extent to which "people employ and express themselves physically, cognitively, and emotionally during role performances" (Kahn, 1990, p.694). The antecedents in his model were derived from combining the theory of the job characteristics model with perspectives focusing on the interpersonal (Bennis, Schein, Berlew, \& Steele, 1964; Rogers, 1958), group (Bion, 1961; Smith \& Berg, 1987), intergroup (Alderfer, 1985), and organizational (Hoschild, 1983) contexts. From this compilation of theories, he was able to develop a framework that outlines the contextual and personal underpinnings of being personally engaged at work. One of the main differences between Kahn's model and the JD-R model is that Kahn's model focuses solely on work engagement and its antecedents, and does not include burnout in the model's structure. Another important difference between these two models is that Kahn's model incorporates three psychological states (i.e., psychological meaningfulness, safety, and availability) as antecedents to work engagement. These psychological states are similar to those that were in Hackman and Oldham's job characteristics model (1976) in that they indicate that the psychological experience of work drives people's attitudes and behavior. Finally, this model is different from the JD$\mathrm{R}$ model because it looks beyond job resources as antecedents to work engagement. Instead, it proposes that workers' job and personal characteristics influence their level of work engagement through the psychological states of meaningfulness, safety, and availability.

Although Kahn's theoretical model has been around for quite some time, it has not been tested to the extent that the JD-R model has. To date, two studies have tested Kahn's proposed model in its entirety. The first to do so was May, Gilson, and Harter in 
2004. They performed a field study on a U.S. Midwestern insurance company to explore the mediating effects that the three psychological conditions had between job/personal features and work engagement. Their findings provided empirical support for some of Kahn's original observations. Using path analysis, they found that all three psychological conditions were positively related to work engagement, with meaningfulness exhibiting the strongest relationship. Furthermore, the job/personal features were significantly related to the psychological conditions. Job enrichment and work-role fit exhibited positive relationships with psychological meaningfulness. Rewarding co-worker and supportive supervisor relations were positively associated while adherence to co-worker norms and self-consciousness were negatively associated with psychological safety. Finally, resources available (cognitive, emotional, and physical) were positively related and participation in outside activities was negatively related to psychological availability. Meaningfulness fully mediated the relationships of job enrichment and work-role fit with engagement, while psychological safety partially mediated the relationship between adherence to co-worker norms and engagement (May et al., 2004).

In 2007, Olivier and Rothmann performed another study to test Kahn's proposed model. They used stratified random sampling to test their model on employees in a South African-based multinational oil company. Similar to May et al. (2004), they found psychological meaningfulness to be the strongest predictor of engagement among the psychological conditions (predicting $37 \%$ of the variance in work engagement). Psychological meaningfulness fully mediated the relationships that co-worker relations and work-role fit had with work engagement. Furthermore, psychological availability mediated the relationships between cognitive, emotional and physical resources and work 
engagement. Psychological safety was significantly related to co-worker relations and norms, supervisor relations, and engagement. However, it did not mediate the relationships between these variables (Olivier \& Rothman, 2007).

\section{Integration of the two models}

One aim of my dissertation was to integrate these two models. The JD-R model essentially consists of job resources predicting work engagement, whereas Kahn's model is comprised of job features and personal characteristics affecting work engagement through the psychological states of meaningfulness, safety, and availability. Ultimately, then, integrating these two models required considering job resources that have proven to be significant in the JD-R model and incorporating them into the 'job features' portion of Kahn's model. Another goal of my dissertation was to expand on the engagement research and examine antecedents of engagement that have either never been assessed or have not been as prevalent in the literature as other variables. The following paragraphs will discuss the antecedents that were included in this study's model as well as how the two models were integrated.

Job resources that impact work engagement in the JD-R model can be broken down into four levels: task (e.g., autonomy, skill variety, feedback), organization of work (e.g., role clarity, participation in decision making), interpersonal and social relations (e.g., supervisor support, co-worker relations), and organizational factors (e.g., job security, salary, career opportunities) (Bakker, Demerouti, \& Verbeke, 2004). Kahn's model is a bit more extensive. In his discussion of constructs that have an effect on engagement through the three psychological states, he covered many different categories of antecedents. Psychological meaningfulness was influenced by task characteristics, 
role characteristics, and work interactions. Psychological safety was affected by interpersonal relationships, group and intergroup dynamics, management style and process, and organizational norms. Finally, psychological availability was impacted by physical energy, emotional energy, insecurity, and outside life (Kahn, 1990). At a very general level, the antecedents from both models could be organized into two overarching categories: job features and personal characteristics. Therefore, for my study's model, the antecedents were organized as such.

Two sets of antecedents were included in this study: those that have exemplified strong relationships with engagement in past research and those that have never, or have rarely, been tested. The job features chosen for this study, autonomy, co-worker relations, and supervisor support, have consistently shown strong significant relationships with work engagement (e.g., Hakanen, Bakker, \& Schaufeli, 2006; Shaufeli \& Bakker, 2004; Schaufeli, Bakker, \& Van Rhenen, 2009). For personal characteristics, selfefficacy, extraversion, and neuroticism were chosen based on empirical evidence of their consistently significant relationships with engagement (e.g., Inceoglu \& Warr, 2011; Langelaan, Bakker, Doornen, \& Schaufeli, 2006; Xanthopoulou, Bakker, Heuven, Demerouti, \& Schaufeli, 2008). In addition to these variables, PJ fit, procedural justice, interactional justice, and self-consciousness were included in the model in an attempt to expand upon the literature. These variables and the theoretical basis for their relationships with engagement as well as the psychological states will be discussed later in the literature review of this dissertation.

The step after the predictors in the hypothesized model consists of the three psychological states that were addressed by Kahn (1990). All three of these states were 
expected to significantly affect work engagement. However, it was not anticipated that job features and personal characteristics would all be significantly related to these three states. Instead, it was proposed that only job features would affect psychological meaningfulness, both job features and personal characteristics would affect safety, and only personal characteristics would affect availability. In line with this expectation, Rich, LePine, and Crawford (2010) argued that "perceptions of organizational and work factors related to tasks and roles are the primary influences on psychological meaningfulness; perceptions of social systems related to support and relationships are the primary influences on psychological safety; and self-perceptions of confidence and selfconsciousness are the primary influences on psychological availability" (p.620). Further arguments for these projected relationships will now be discussed.

Workers experience meaningfulness when they feel as though they have something to contribute. They must feel useful, worthwhile, and valuable — as if they can make a difference. To experience meaningfulness, they must also feel as though they are not taken for granted, as though they are recognized for their contribution and are gaining something in return. They must feel as though they are receiving a return on the investments that are made in terms of physical, cognitive, or emotional energy. Meaningfulness is experienced when workers receive feedback at the job that confirms these feelings. Such feedback can come from one's working relationships and/or from the work itself. With regard to relationships, this confirmation is manifested in high-quality co-worker relationships and supportive supervisors. High-quality relationships with others in the workplace promote self-appreciation, dignity, and a sense of worthwhileness. They are "an invaluable source of meaning in people's lives because 
they meet relatedness needs (Alderfer, 1972): they allow people to feel known and appreciated and that they are sharing their existential journeys with others (May et al., 1958)" (Kahn, 1990, p.707). In terms of the work itself, when individuals experience both a sense of competence (from the routine) and growth and learning (from the new) in their tasks, they receive confirmation that they have something to contribute as well as something to gain. The validation that this provides them with, in turn, makes the work meaningful to them. Theoretically then, meaningfulness was expected to only be affected by job features because it depends largely upon workers' assessment of the context in which they find themselves - characteristics of their relationships with others in the workplace (e.g., co-worker and supervisor relations) and characteristics of the job itself (e.g., level of autonomy, skill variety, PJ fit).

Psychological safety is experienced as feeling able to employ and show one's self without fear of negative consequences to status, career, or self-image. Kahn (1990) states that safety is determined by elements of the social system that create more or less nonthreatening, predictable, and consistent social situations in which workers can engage. A climate that promotes open communication, consists of interpersonal relationships that are supportive and trusting, and makes employees feel as though they belong and can be themselves will be more likely to foster feelings of psychological safety. Features of the job (e.g., supervisor support, justice perceptions) influence these factors in a workplace and were therefore expected to affect one's perceived level of psychological safety.

Individual characteristics were also projected to play a part in one's level of psychological safety. Individuals tend to be more or less likely to let their guard down on the basis of their level of such personality characteristics as extraversion, neuroticism, 
and self-consciousness. It was expected that those that are highly self-conscious would be less likely to let their guard down no matter what environment they are in simply because it is not in their nature to do so. On the contrary, those that are highly extraverted would be more likely to feel comfortable expressing themselves honestly in the workplace because of their outgoing nature. Therefore, this study anticipated that both job features and personal characteristics would affect safety since it depends on both the context within which workers find themselves as well as their own personal instincts.

The final psychological state, availability, refers to having the emotional, psychological, and physical resources to personally engage at a specific moment. It is a reflection of how ready individuals are to engage, given distractions that they experience in their social systems. According to Kahn (1990), workers' availability is associated with individual distractions that preoccupy people to various degrees and leave them more or fewer resources with which to engage in role performances. It has to do with the resources that they have and not the work context within which they find themselves.

Hence, this study anticipated to find that availability would be affected only by personal characteristics as this condition would ultimately depend on workers' personal resources and what they have to put towards their job. The next section will discuss this dissertation's proposed research model and the reasoning behind the relationships that the researcher expected to find.

\section{The Current Research Model}

My dissertation utilized the conceptualization of work engagement presented by Schaufeli, Salanova, Gonzalez-Roma, and Bakker (2002, p.74). Their definition characterizes work engagement as being composed of three dimensions: vigor, 
dedication, and absorption. Although it is important to recognize that these three individual dimensions make up work engagement, in an organizational context, work engagement as a whole is the construct of interest. An employee is not characterized as being highly engaged if they are highly vigorous about their job, but neither dedicated nor absorbed in it. Likewise, one is not described as being very engaged in their job if they are very dedicated to it, but neither absorbed in nor vigorous about it. One must rate highly on all three of these dimensions in order to exhibit high levels of work engagement. Therefore, for the purpose of finding which variables were antecedents and correlates of work engagement, it was necessary to confirm that one factor (i.e., work engagement) emerged from these three factors (vigor, dedication, and absorption) and, furthermore, that these three factors correlated positively with one another.

Hypothesis 1. One factor (i.e. work engagement) will emerge from vigor, dedication, and absorption and these three subdimensions will be positively correlated with one another.

In addition to ensuring that a single overall engagement factor emerged in my study's sample, this research also performed an analysis to address a popular debate in the work engagement literature. As discussed in Chapter I of the dissertation, researchers have argued over whether or not engagement is distinct from organizational commitment and/or job satisfaction (Christian, Garza, \& Slaughter, 2011; Wefald \& Downey, 2009). Job satisfaction represents an employee's overall assessment of his or her job as favorable or unfavorable. It refers to an employee's attitude towards his or her job. 
Researchers may argue over whether or not work engagement and job satisfaction are different from one another because, although they may seem to be conceptually different, their definitions and means of measurement overlap. According to Rich et al. (2010), job satisfaction is just one aspect of engagement. Specifically, they assert that employees can allocate themselves cognitively (i.e., degree to which individuals allow their jobs to take part in their lives in order to maintain a work-related identity), affectively (i.e., emotional reactions to the job associated with the human desire to maintain happiness), and physically (i.e., physically exerting oneself on the job in order to maintain autonomy and control) towards their job. Job satisfaction is a specific example of an affective attitude or exertion that one has towards their job, whereas engagement is more representative of the underlying mechanism that encompasses all three of these types of exertion. Accordingly, engagement is a measure of the degree to which one exerts him/herself cognitively, affectively, and physically towards their job (Rich et al., 2010).

Wefald and Downey (2009) made a similar argument regarding this issue and stated that as constructs, job satisfaction and engagement differ, but when measured, they are both measures of affect regarding one's job. The main difference between the two may be that engagement contains additional focus on the cognitive aspect of involvement in one's job whereas job satisfaction concentrates exclusively on the affective component. These researchers investigated the relation between engagement and satisfaction using a sample of 453 students. They found that there was a great deal of overlap between engagement and job satisfaction and, furthermore, that engagement did not add incremental validity towards the prediction of student performance. This finding 
suggests that engagement may not offer researchers and practitioners anything beyond job satisfaction.

Scholars argue that the difference between job satisfaction and work engagement lies in the fact that job satisfaction refers only to an affective (i.e., emotional) attitude that one has towards their job, as opposed to a physical, cognitive, and emotional investment in one's job (Rich et al., 2010). In addition, satisfaction refers to a state of satiation with one's job, whereas engagement speaks to one's level of activation towards their job: "engagement connotes activation, whereas satisfaction connotes satiation" (Macey \& Schneider, 2008, p.8). "In broad terms, engagement may be viewed as energized satisfaction; engaged workers are not necessarily satisfied in some respects, but satisfied workers may or may not be engaged" (Warr \& Inceoglu, 2012, p.2).

Organizational commitment refers to the extent to which employees are dedicated to, willing to work on the behalf of, and intend on retaining membership at the organizations that employ them. Therefore, while job satisfaction alludes to positive emotions that one may have towards their job, organizational commitment refers to the degree to which an employee feels loyalty towards their organization. Meyer and Allen (1991) proposed that there are three different types of commitment: affective, continuance, and normative. Affective commitment refers to the extent to which an employee is committed to their organization because they identify with and feel loyalty towards it. Continuance commitment refers to the idea that an individual may remain committed to an organization because they have made an investment in it and have determined that there would be costs if they chose to leave. Normative commitment refers to the notion that an employee may be committed to an organization because they 
feel a sense of obligation to the company and stay with them because morally, it is the right thing to do (Jex \& Britt, 2008).

In addition to different reasons as to why an employee may be committed to an organization, there are also different levels of the organization to which an employee could be committed. For example, an employee may be committed to the organization as a whole, a primary work group to which he or she belongs, the leader of a group, and/or the profession to which he or she belongs. In order to achieve a complete list of ways in which an employee could be committed to his or her organization, then, the three different types of commitment would have to be crossed with all of the possible foci within the organizational environment. That being said, organizational commitment is a very complex, multidimensional construct of interest within the field of I/O research (Jex $\&$ Britt, 2008).

Out of all of the different types of commitment, affective commitment has been shown to have the strongest positive relationship with desirable outcomes (Eisenberger, Huntington, Hutchison, \& Sowa, 1986). Previous research (e.g., Christian, Garza, \& Slaughter, 2011; Macey \& Schneider, 2008) suggests that affective commitment is the one most closely related to work engagement. Therefore, this is the dimension of commitment whose distinction from engagement was examined in this dissertation.

Scholars argue that commitment differs from work engagement on the grounds that it is an affective attachment to the values of an organization as a whole, as opposed to the work itself (Brooke, Russell, \& Price, 1988; Christian et al., 2011; Maslach, Schaufeli, \& Leiter, 2001). For example, Storm and Rothmann (2003) discussed how commitment refers to an employee's loyalty to their organization, whereas engagement 
addresses an individual's attitude towards the work itself. Also, commitment represents an emotional state of attachment, as opposed to an investment of all three dimensions of the self, into the organization at large.

Only one published study to date, performed by Hallberg and Schaufeli (2006), examined the distinction between commitment and work engagement. Their sample $(\mathrm{N}=186)$ consisted of employees from a Swedish management consulting company and they used the Utrecht Work Engagement Scale (UWES) to distinguish work engagement from job involvement and organizational commitment. Latent intercorrelations and a CFA showed that work engagement was distinct from these two constructs.

Research regarding the distinction of engagement from job satisfaction and organizational commitment is still in its infancy. At this point it is best to conclude that

although researchers may be able to conceptually distinguish engagement from these two variables, more research is warranted in order to prove the validity of their assertions. Therefore, this study tested whether or not there was differential validity between work engagement and the two constructs of job satisfaction and organizational commitment before moving forward to test the proposed research model.

Hypothesis 2. Work engagement is distinct from (a) organizational commitment and (b) job satisfaction.

\section{Job Features and Engagement}

My dissertation proposed that job features is one category of antecedents that affects work engagement. In particular, PJ fit, autonomy, co-worker relations, supervisor 
support, procedural justice, and interactional justice were expected to account for a significant amount of the variance in work engagement through the psychological conditions of meaningfulness and safety. The next section will discuss the reasoning as well as the literature behind these links.

Person-job fit and engagement. Person-environment (PE) fit can be broadly defined as the level of compatibility between an individual and their work environment, reflecting how well their characteristics are matched (French, Rogers, \& Cobb, 1974; Edwards \& Cooper, 1990). Because of its simple, and more importantly, broad definition and conceptualization, several distinct types of fit (i.e., person-vocation, person-job, person-organization, person-group, person-supervisor fit) emerged after PE fit's introduction into I-O psychology (Kristof-Brown, Zimmerman, \& Johnson, 2005). Of particular interest for the purpose of the dissertation was person-job (PJ) fit. This specific type of fit can be narrowly defined as the relationship between an individual's characteristics and those of the job or, more specifically, tasks that are performed at work (Edwards, 1991).

According to Edwards (1991), PJ fit can be dissected into two dimensions. The first dimension is the demands-abilities fit, which refers to how well employees' knowledge, skills, and abilities (KSAs) match those that are required of the job. The second dimension reflects the extent to which employees' needs, desires, and preferences are met by the job. The latter, often referred to as needs-supplies or supplies-values fit, has been the focus of various well-being, adjustment, and satisfaction research (Caplan, 1983; French, Caplan, \& Harrison, 1974; Harrison, 1978; Locke, 1969; Porter, 1961, 1962). This study investigated how overall PJ Fit (encompassing both dimensions) relates 
to work engagement. Harrison (1978) was one of the first researchers to focus on a lack of $\mathrm{PJ}$ fit and its association with lower well being with regard to dissatisfaction, anxiety, depression, irritation, boredom, and somatic complaints. Although the findings from this early study only provided moderate support for these links, later research confirmed that poorer PJ fit in terms of what is desired and what actually exists is associated with greater strain and lower job satisfaction (Kristof-Brown, Zimmerman, \& Johnson, 2005). In essence, then, research has found a positive relationship between PJ fit and job satisfaction. Much research has supported the close positive association between job satisfaction and work engagement, even to a point where scholars have questioned whether or not these constructs are distinct from one another (e.g., Demerouti, Bakker, DeJonge, Janssen, \& Schaufeli, 2001; Rich et al., 2010; Wefald \& Downey, 2009). Therefore, it was believed that PJ fit would exhibit a strong, positive association with work engagement.

PJ fit was expected to be positively related to work engagement as individuals whose desires and abilities are matched by the job would be intrinsically more motivated to perform that job, more interested in it, and therefore more likely to be engaged in it. In addition to related research and a theoretical argument, research supports a positive link between PJ fit and work engagement. For example, Cho, Laschinger, and Wong (2006) found a negative relationship $(r=-.51)$ between employees' fit in six areas of work life (workload, control, rewards, community, fairness, and values) and burnout (i.e., the opposite of engagement, Maslach \& Leiter, 1997) among nurses. Similarly, Greco, Laschinger, and Wong (2006) found that PJ fit mediated the relationship between 
structural empowerment and emotional exhaustion, ultimately exhibiting a negative relationship with emotional exhaustion (i.e., the opposite of engagement).

Hypothesis 3. Person-job fit will be positively related to work engagement.

Autonomy and engagement. The historical background of work engagement, specifically Karasek's Demand-Control Model (DCM, 1979) and Hackman and Oldham's Job Characteristics Model (JCM) (1980), indicates that autonomy (i.e., job control) was one of the first job characteristics revealed to have an impact on job attitudes. Autonomy refers to the freedom that individuals have with regard to carrying out their work as far as scheduling, decision-making, and determining work methods (Hackman \& Oldham, 1976; Morgeson \& Humphrey, 2006). According to selfdetermination theory (SDT, Deci \& Ryan, 1985), satisfaction of the basic psychological needs is essential for humans to actualize their potentials, flourish, and be protected from illness and maladaptive functioning. SDT postulates that there are three psychological needs: the needs for autonomy, belongingness/relatedness, and competence. If a job allows workers to achieve their basic need for autonomy, then they will be more likely to exhibit positive attitudes towards their job. Deci and Ryan (1985) claimed that events experienced as supporting autonomy tend to increase one's level of intrinsic motivation due the fact that it increases perceptions of their competence. Also, according to the JCM, autonomy is one of the five core job characteristics (in addition to skill variety, task identity, task significance, and job feedback) that positively affects one's experienced meaningfulness, experienced responsibility, and knowledge of results (i.e., the critical 
psychological states). These critical psychological states have then been proven to lead to more positive attitudinal (e.g., increased job satisfaction) and behavioral (e.g., higher performance) responses to work (Hackman \& Oldham, 1980).

Research confirms that there is a positive relationship between autonomy and work engagement. For example, Hakanen, Bakker, and Schaufeli (2006) found that job control ultimately had an impact on organizational commitment though its positive relationship with work engagement. Also, in their meta-analytic study examining the relevance of the JD-R model to safety outcomes in the workplace, Nahrgang, Morgeson, and Hofmann (2011) found that autonomy was one of the key job resources that had a positive effect on engagement, which in turn impacted one's likelihood of working safely. Finally, in his meta-analysis of work engagement and its relationships with burnout, demands, resources, and consequences, Halbesleben (2010) found that autonomy had a particularly high positive estimated population correlation with engagement. As a result, based on logical as well as empirical evidentiary backing, this study hypothesized that there would be a significant and positive relationship between autonomy and work engagement.

Hypothesis 4. Autonomy will exhibit a positive relationship with work engagement.

Co-worker relations and engagement. The nature of individuals' relationships with co-workers was expected to have a significant impact on work engagement. In accordance with Demerouti et al.'s (2001) definition, job resources may either play an 
intrinsic motivation role in terms of fostering employees' growth, learning, and/or development, or they may play an extrinsic motivation role by being instrumental in achieving work goals. With regard to co-worker relations and its effect on work engagement, this job resource can be both intrinsically and extrinsically motivating. With regard to being intrinsically motivating, relatedness is one of the basic human needs postulated by SDT. Humans are innately driven to relate to and be accepted by other human beings. Relations with co-workers is a specific example of an opportunity to fulfill this basic human need at work. In terms of being extrinsically motivating, supportive colleagues may help to increase one's likelihood of being successful in achieving work goals by lending a hand, offering advice, and/or being a sympathetic ear when needed (Bakker \& Demerouti, 2007). Therefore, the quality of a worker's relationship with coworkers was expected to have a positive impact on one's level of work engagement.

This association has been supported in the literature. In 2009, Rodríguez-Muñoz, Baillien, De Witte, Moreno-Jiménez, and Pastor performed two longitudinal studies to examine the relationships between workplace bullying, job satisfaction, and engagement. They found that Time 1 bullying had a negative impact on both Time 2 engagement and job satisfaction. Additionally, Xanthopoulou, Hueven, Demerouti, Bakker, and Schaufeli (2008) performed a study on flight attendants to gain insight into the motivational process of the JD-R model. They found that colleague support had an indirect effect on in-role performance through its positive association with work engagement. Therefore, it was hypothesized that there would be a positive relationship between co-worker relations and work engagement. 
Hypothesis 5. Co-worker relations will be positively related to work engagement.

Supervisor support and engagement. On a similar note, supervisor support is another job feature that was anticipated to exhibit a significant relationship with work engagement. Supervisors are an influential party when it comes to how individuals experience their work as well as how happy they are at work. Empirical evidence shows that managers can have a significant impact on employees' health and well-being in terms of causing such negative outcomes as psychological distress (e.g., Skogstad, Einarsen, Torsheim, Aasland, \& Hetland, 2007) and, alternatively, with regard to fostering a positive state of mind and enhancing general levels of psychological wellbeing (e.g., Arnold, Turner, Barling, Kelloway, \& McKee, 2007; Nielsen, Randal, Yarker, \& Brenner, 2008; Tuckey, Bakker, \& Dollard, 2012; Van Dierendonck, Haynes, Borrill, \& Stride, 2004). Like relations with co-workers, relationships with their supervisor can impact work engagement two-fold: through helping to fulfill basic relatedness needs, ultimately leading to intrinsic motivation, and through providing instrumental guidance and support towards achieving one's goals. For instance, proper feedback from a supervisor increases the likelihood that work goals will be achieved. Supervisors that foster a supportive work environment usually show concern for their workers' feelings and needs, encourage them to voice their concerns, provide positive and helpful feedback, and push them to develop new skills (Deci \& Ryan, 1987). Supervisor support helps promote employee interest and self-determination in their work. Self-determined employees experience "a sense of choice in initiating and regulating 
one's own actions," ultimately leading to higher levels of work engagement (Deci et al., 1989, p.580).

Empirical research provides support for a positive relationship between supervisor support and engagement. For example, Bakker and Bal (2010) performed a study on Dutch teachers, testing a model of weekly work engagement. They found that weeklevels of exchange with the supervisor was positively related to teachers' weekly level of engagement. In another study by Crawford, LePine, and Rich (2010), in which the researchers performed meta-analytic structural modeling on the data, they found that coworker, supervisor, and organizational support all had significant positive impacts on work engagement. Therefore, it was expected that there would be a positive relationship between supervisor support and work engagement.

Hypothesis 6. Supervisor support will be positively related to work engagement.

Justice and engagement. Not much literature has explored the relationship between justice and work engagement. However, it seems likely that one's level of engagement may be influenced by their justice, or fairness, perceptions in the workplace. According to Colquitt, Conlon, Wesson, Porter, and Ng (2001), justice connotes "oughtness" or "righteousness." In the context of the workplace, justice refers to whether or not individuals perceive fairness in the a) outcome distributions or allocations (distributive justice) (Adams, 1965; Deutsch, 1975; Homans, 1961; Leventhal, 1976), b) procedures used to determine outcome distributions or allocations (procedural justice) (Leventhal, 1980; Leventhal, Karuza, \& Fry, 1980; Thibault \& Walker, 1975), and c) 
quality of the interpersonal treatment people receive when procedures are implemented (interactional justice) (Bies \& Moag, 1986). My dissertation included only procedural and interactional justice in its model as they were deemed the most relevant types of justice that would impact work engagement through the psychological conditions of meaningfulness and safety.

The concept of procedural justice was introduced by Thibaut and Walker (1975) in their work concentrating on disputant reactions to legal procedures. However, Leventhal et al. (1980) were the ones that extended this concept into the organizational setting. According to them, there are six criteria that a procedure must meet in order to be deemed as fair. "Procedures should a) be applied consistently across people and across time, b) be free from bias (e.g., ensuring that a third party has no vested interest in a particular settlement), c) ensure that accurate information is collected and used in making decisions, d) have some mechanism to correct flawed or inaccurate decisions, e) conform to personal or prevailing standards of ethics or morality, and f) ensure that the opinions of various groups affected by the decision have been taken into account" (Colquitt, et al., 2001, p.426). Interactional justice was introduced by Bies and Moag (1986) after distributive and procedural justice.

As mentioned before, interactional justice refers to the quality of interpersonal treatment that individuals receive when procedures are carried out. Recently, interactional justice has been conceptualized as consisting of two particular types of interpersonal treatment (e.g., Greenberg, 1990, 1993). The first type, called interpersonal justice, refers to "the degree to which people are treated with politeness, dignity, and respect by authorities or third parties involved in executing procedures or determining outcomes" 
(Colquitt et al., 2001, p.427). The second type, informational justice, concerns the "explanations provided to people that convey information about why procedures were used in a certain way or why outcomes were distributed in a certain fashion" (Colquitt et al., 2001, p.427). Empirical studies have shown that justice perceptions are related to such organizational outcomes as organizational commitment, job satisfaction, organizational citizenship behavior, performance, and withdrawal (Colquitt et al., 2001). The relationship between justice perceptions and such outcomes may be partially due to employee engagement. In other words, if employees perceive high levels of justice in their organization, they may be more likely to return the favor by putting more of themselves into their work through means of engagement. Conversely, low perceptions of justice in their workplace may cause workers to withdraw and disengage themselves from their positions at work.

Justice and its relationship with work engagement is still a very new topic of discussion in the literature. However, research findings show that there is indeed a significant positive relationship between justice and work engagement. For example, justice (i.e., fairness) is one of the work conditions in the engagement model by Maslach et al. (2001). Specifically, low perceptions of fairness can increase levels of burnout whereas high perceptions of fairness can enhance engagement (Maslach et al., 2001). Saks (2006) also performed a study where he explored the relationships that procedural and distributive justice had with individual and organizational engagement. He found that both types of justice were positively related to the two engagement measures, but when included in a regression with job characteristics, resources, and rewards, the only significant relationship that remained was the positive one between procedural justice and 
organizational engagement. This could have been the result of the inclusion of perceived organizational support in the model, which could arguably account for similar variance in engagement as justice perceptions. Maslach and Leiter (2008) also performed a study in which they looked at perceptions of six areas of worklife (including perceived procedural fairness) over a year and how this affected one's level of burnout and/or engagement. They found that those whose engagement levels increased at Time 2 scored higher on procedural fairness perceptions at Time 1 than those whose burnout increased at Time 2 . Therefore, it was hypothesized that work engagement would exhibit positive relationships with both procedural and interactional justice perceptions.

Hypothesis 7. (a) Procedural justice and (b) interactional justice will both be positively related to work engagement.

\section{Personal Characteristics and Engagement}

Personal characteristics was the other category of antecedents proposed to affect work engagement through two psychological conditions, namely, safety and availability. Although much research focuses on job resources as the main variables to influence work engagement, personal resources have been shown to account for much of the variance in engagement as well (e.g., Llorens, Schaufeli, Bakker, \& Salanova, 2007; Xanthopoulou, Bakker, Demerouti, \& Schaufeli, 2009; Xanthopoulou, Heuven, Demerouti, Bakker, \& Schaufeli, 2008). My study investigated the relationship that self-consciousness, trait self-efficacy, extraversion, and neuroticism had with work engagement through the 
psychological conditions of safety and availability. These constructs and their relationships with engagement will now be discussed.

Self-consciousness and engagement. The roots of self-consciousness theory are grounded in the theory of self-awareness, which asserts that attention can be directed in two directions: outward towards the environment or inward towards the self (selfawareness) (Duval \& Wicklund, 1972). Self-aware people tend to conform more to salient standards of behavior than less self-aware individuals (e.g., Carver, 1974, 1975; Scheier, Fenigstein, \& Buss, 1974). Sometimes behavior standards are not salient. In such cases, self-aware persons will simply become more conscious of their own presence, feelings, and attributes. Factor analyses of the self-consciousness scale (SCS, Fenigstein, Scheier, \& Buss, 1975) have revealed that there are two separate aspects of selfconsciousness: private and public. The private subscale (PrSC) measures one's awareness of more personal and private aspects of the self. "A person high in private selfconsciousness is very cognizant of his or her own thoughts, feelings, and motives (e.g., "I'm generally attentive to my inner feelings")" (Carver \& Sheier, 1978, p.325). The public subscale $(\mathrm{PbSc})$ measures one's awareness of his or her self as a social object. "A person high in public self-consciousness is more cognizant of how he or she appears and is viewed by others (e.g., "I'm concerned about the way I present myself")" (Carver \& Sheier, 1978, p.326). People vary in their chronic predispositions to be self-conscious, and these individual differences have been shown to predict behavior. The more selfconscious workers are, the more likely their attention is to be on their inner thoughts, or how they appear to others, and the less likely it is to be on the performance of tasks. 
In his ethnographic study, Kahn (1990) noticed that when workers focused on how they were perceived and judged by others, whether or not such actions were actually occurring, they were too distracted to engage in their work. Their focus would turn to external rather than internal cues (Goffman, 1959). Kahn reasoned that this shift towards external cues was due to individuals perceiving themselves, consciously or not, as "actors on stages, surrounded by audiences and critics, rather than as people simply doing their jobs" (Kahn, 1990, p.716). These external orientations would preoccupy people and make them engage in managing their impressions as opposed to the work itself.

A couple studies besides Kahn's have confirmed the presence of a negative relationship between self-consciousness and engagement. May et al. (2004) found that self-consciousness' negative relationship with engagement was mediated by psychological safety. Furthermore, Olivier and Rothmann (2007) found that the negative relationship between self-consciousness and work engagement was mediated by psychological availability. Consequently, it was believed that there would be a negative relationship between self-consciousness and work engagement.

Hypothesis 8. Self-consciousness will be negatively related to work engagement.

Self-efficacy and engagement. Self-efficacy can be traced back to Bandura's (1977a, 1978) social learning theory. It refers to an individual's belief in his or her capability to perform specific tasks. Self-efficacy is a result of one's gradual acquisition of complex cognitive, linguistic, social, and/or physical skills through means of experience (Bandura, 1982). Individuals appear to regulate their choices and energies 
according to how they evaluate information concerning their capabilities. Employees that doubt their ability to respond to demands at work are likely to focus on their feelings of incompetence, which will then be accompanied by psychological distress and ultimately a failure to deal with those demands (Bandura, 1977b). Alternatively, individuals that have high levels of self-efficacy will not be likely to be distressed by feelings of inadequacy and, as a result, will be able to persist in their efforts to manage demands at work. For these reasons, it was believed that self-efficacy would be positively related to work engagement.

Research has shown that self-efficacy exhibits a positive relationship with work engagement. So much so, in fact, that some results from factor analyses have revealed that self-efficacy loads better onto the latent factor of work engagement than burnout (e.g., Schaufeli, Salanova, González-Romá, \& Bakker, 2002; Schaufeli \& Salanova, 2007). Though the researchers argue that this is due to the fact that the positive wording of the items on the self-efficacy scale contrasts with the negative wording of the items on the other burnout scales, it still provides evidence that self-efficacy is closely related to work engagement. Furthermore, several empirical studies have tested and found support for the positive relationship between self-efficacy and work engagement. These studies will now be discussed.

Most of the studies up to this point that have examined the relationship between efficacy and work engagement have investigated how specific work-related efficacy beliefs, rather than generalized efficacy beliefs, impact work engagement. For example, Xanthopoulou, Bakker, Demerouti, and Schaufeli (2009) examined the effect that daylevel job resources have on day-level personal resources, work engagement, and financial 
returns. Even after controlling for generalized personal resources and engagement levels, they found that day-level job resources had an effect on work engagement through day-level personal resources (which included day-level self-efficacy). More specifically, day-level self-efficacy fully mediated the relationship that day-level coaching had with day-level work engagement.

The relationship between efficacy and work engagement has been proven to be more than a relationship wherein efficacy influences work engagement. In a study performed by Llorens, Schaufeli, Bakker, and Salanova (2007) to look at the causal relationships between two job resources (i.e., time control and method control), efficacy beliefs, and engagement, they found that efficacy beliefs played a mediating role between the two job resources and work engagement. In addition, their findings suggested the presence of a positive gain spiral in which efficacy beliefs played a central role: engagement increased efficacy beliefs, which in turn increased task resources over time. Though most of the research up to this point has examined the relationship between specific work-related efficacy beliefs and engagement, this study aims to investigate the relationship between generalized efficacy beliefs and engagement. As a result of theoretical and empirical evidence of their association, it was hypothesized that generalized self-efficacy would be positively related to work engagement.

Hypothesis 9. Self-efficacy will be positively related to work engagement.

Personality and engagement. Personality is the last personal characteristic that was examined as an antecedent to work engagement. It refers to "relatively enduring 
personal characteristics in the sense of generalized and basic conduct tendencies that reflects long-term, pervasive individual differences in emotional style and has a general influence on emotional responses (Warr, 1999)" (Langelaan, Bakker, Doornen, \& Schaufeli, 2006, p.523). Personality consists of five traits, referred to in the literature as "the Big Five" (Norman, 1963), namely openness to experience, conscientiousness, extraversion, agreeableness, and neuroticism. The Big Five personality traits have received considerable attention in the burnout literature (e.g., Allen \& Mellor, 2002; Day \& Bedeian, 1995; De Vries \& Van Heck, 2002; Goddard et al., 2004; Mills and Huebner, 1998; Piedmont, 1993; Zellars et al., 2000). Kim, Shin, and Umbreit (2007) performed a study to examine the relationship between personality and burnout and found extraversion to be negatively related to exhaustion, agreeableness to be negatively related to cynicism, conscientiousness and agreeableness to be positively related to professional efficacy, and neuroticism to be positively related to exhaustion and cynicism. Furthermore, they reported that most of their results concur with previous findings with the exception of agreeableness, which usually exhibits a very weak relationship or no relationship at all with burnout.

Although the relationship between personality and burnout has received much attention in research, the same cannot be said for the relationship between personality and work engagement. Since engagement is essentially the opposite concept of burnout (Maslach \& Leiter, 1997), it is possible to speculate what the relationships are between personality traits and engagement. For example, Langelaan, Bakker, Doornen, and Schaufeli (2006) argued that it is reasonable to predict that engagement will be negatively related to neuroticism and positively related to extraversion since burnout displays the 
opposite relationships with these personality traits. It is also logical to presume that the personality traits that engagement would be related to are those that match its affective and motivational elements, namely neuroticism, extraversion, and conscientiousness. For the purpose of my dissertation, neuroticism and extraversion were the only personality correlates of engagement that were examined.

Extraversion embodies individual traits such as being gregarious, assertive, sociable, talkative, and active (Barrick, Mount, \& Judge, 2001). Research shows that extraversion is predictive of performance in sales positions, which require good social skills and high levels of energy (Barrick \& Mount, 1991). One of the dimensions of engagement is vigor (i.e., high energy). Therefore, for purposes of this study, it seemed reasonable to expect that there would be a positive relationship between extraversion and work engagement considering that both of these concepts share the attribute of high energy. Research has also shown that extraversion is a strong predictor of well-being (Diener \& Lucas, 1999).

Neuroticism refers to the extent to which an individual is anxious, hostile, depressed, and/or experiencing personal insecurity (Barrick et al., 2001). Considering that engagement is associated with the experience of such positive emotions as happiness, enthusiasm, and joy (Bakker \& Demerouti, 2008), it seemed logical to expect that neuroticism would be negatively related to engagement. Furthermore, research has shown that as neuroticism decreases, the probability of optimal well-being increases (Diener \& Luca, 1999).

The expectation that extraversion would display a positive relationship and neuroticism would exhibit a negative relationship with engagement is grounded in three 
research studies. The first, performed by Langelaan, Bakker, Van Doornen, and Schaufeli (2006) surveyed 572 Dutch employees using Eysenck's Two Factor Model of personality to investigate the impact that individual differences would have on work engagement. Their findings confirmed that work engagement is characterized by low scores on neuroticism and high scores on extraversion. The second study on engagement and its relationships with the Big Five was performed by Kim, Shin, and Swanger in 2009. They collected data from quick-service restaurant employees (in non-supervisory positions and managerial/supervisory positions) and found that the most eminent traits to predict engagement were neuroticism and conscientiousness. Conscientiousness was positively related to engagement whereas neuroticism was negatively related. An important difference to note in this study versus other studies is that work engagement was measured using an atypical scale consisting of the usual engagement sub-dimensions (vigor, dedication, and absorption) plus professional efficacy. The last study to look at personality and its relationship with engagement was performed by Inceoglu and Warr (2011). They found that engagement was positively related to emotional stability (negatively related to neuroticism) as well as extraversion. On the basis of these findings, as well as the intuitive links between these personality constructs and engagement, the researcher anticipated that extraversion would be positively related and neuroticism would be negatively related to work engagement.

Hypothesis 10. (a) Extraversion will exhibit a positive relationship and (b) neuroticism will display a negative relationship with work engagement. 


\section{Psychological Meaningfulness, Safety, and Availability}

Much of the research regarding work engagement has focused on discovering which workplace factors and individual characteristics affect workers' engagement levels. Seeing as research has confirmed which constructs those are, this study aimed to determine why that is the case. Why is it that these constructs impact workers' level of engagement? How do they affect the human psyche in such a way as to increase the likelihood that one will become more invigorated, absorbed, and dedicated to their job?

The purpose of my dissertation was to merge the two dominant models in the engagement research (JD-R model and Kahn's model) in an effort to answer such questions. This entailed exploring the possibility that the relationships that job and individual features have with work engagement are mediated by the psychological conditions that Kahn (1990) discussed in his ethnographic study. He believed that individuals' personal characteristics as well as their own perceptions of their work environments fostered psychological conditions that directly influenced their inclination to personally engage in their roles at work. This causal process resembles Hackman and Oldham's (1980) concept that job characteristics impact the critical psychological states that then influence individuals' internal work motivation.

Kahn (1990) observed that workers unconsciously asked themselves three questions in each work situation in order to determine whether to personally engage or disengage. These questions were "(1) How meaningful is it for me to bring myself into this performance? (2) How safe is it to do so? and (3) How available am I to do so?" (Kahn, 1990, p.703). Accordingly, in my study, the psychological conditions of meaningfulness, safety, and availability were proposed to be the means through which 
job features and individual characteristics impact work engagement. Specifically, my study proposed that job features were likely to affect work engagement by influencing how meaningful, or personally beneficial, workers perceive their job to be as well as how safe employees feel letting their guard down in the workplace. On the other hand, personal characteristics were expected to impact work engagement through their effects on workers' perceptions of workplace safety as well as how they influence levels of mental, emotional, and physical resources. The next section will discuss the research concerning the three psychological conditions and how job features and personal characteristics influence these states.

Psychological meaningfulness. Kahn (1990) defined meaningfulness as "a feeling that one is receiving a return on investments of one's self in a currency of physical, cognitive, or emotional energy. People [experience] meaningfulness when they [feel] worthwhile, useful, and valuable — as though they [make] a difference and [are] not taken for granted" (p.704). He argued that it tended to be associated with elements that created incentives or disincentives for workers to personally engage. Kahn is not alone in recognizing the importance of meaningfulness. Researchers both before and after him have discussed the experience of psychological meaningfulness within one's work as an important and influential condition that impacts worker behavior (e.g., Cartwright \& Holmes, 2006; Chalofsky \& Krishna, 2009; Hackman \& Oldham, 1980; Martela, 2010; May, 2003).

The idea that individuals have an inherent need to lead a work life that they consider meaningful was first introduced by classic humanistic psychologists and motivation theorists (Alderfer, 1972; Herzberg, Mausner, \& Snyderman, 1959; Maslow, 
1943, 1954, 1971; McClelland, 1965; McGregor, 1960; Rogers, 1959, 1961). Maslow

(1971), one of these classic motivation theorists, stated that individuals who do not believe their work to be full of meaning and purpose will not work up to their professional potential. His hierarchy of needs theory argued that individuals are initially motivated to take actions based upon fulfilling needs that are inherent to all human beings (e.g., breathing, eating, drinking, sleeping). As these basic survival needs are satisfied, individuals move on to higher order needs, which are more intrinsic and reflective in nature. These higher order needs are reflective of life values such as working toward a higher cause and leading a purposeful life. Specifically, he theorized that individuals have the potential to reach self-actualization or a level in which an individual focuses on the process of developing his or her potential to the fullest possible extent in a manner that is personally fulfilling.

Darling and Chalofsky (2004) discussed that in the late 1990s and early 2000s, meaning and spirituality at work emerged in reaction to the loss of job security. Perhaps the underlying reason why psychological meaningfulness is starting to appear in research and the workplace today is because the struggling economy, which has caused so many individuals to lose their sense of job security, has driven workers to realize just how much meaning their job carries in their life. In accordance with Maslow's hierarchy of needs, the meaningfulness of a job can extend anywhere from it being the medium through which individuals are able to put food on the table and shelter over their heads, to it being the channel through which they can carry out their life work and say to themselves "This is what I was meant to do in life." A job is meaningful to the extent that the needs that the individual expects to be fulfilled by the job are actually fulfilled. 
Chalofsky and Krishna (2009) argued that it is important to consider both individual and organizational elements when studying the development of motivational factors. Therefore, the next section will discuss how job features and personal characteristics influence psychological meaningfulness, which then impacts work engagement.

Psychological meaningfulness and engagement. Psychological meaningfulness is thought to have an impact on work engagement through the notion that individuals have an inherent drive to find meaning in their work (Frankl, 1992). If individuals perceive their work to be personally meaningful, they are likely to be motivated to invest more of themselves and, henceforth, become more engaged in it. Conversely, if one lacks meaning in their work, they are likely to alienate themselves or become 'disengaged' from it (Aktouf, 1992).

Previous research has demonstrated that meaningfulness is associated with internal work motivation (Fried \& Ferris, 1987; Renn \& Vandenberg, 1995). More recent research has investigated the relationship between meaningfulness and work engagement and found support for their positive relation with one another. For example, in their research that looked at the effect that task and relationship conflict had on knowledge sharing through the three psychological conditions (experienced meaningfulness, safety, and availability), Chen, Zhang, and Vogel (2011) found that experienced meaningfulness had the largest (positive) effect on work engagement $(r=.57)$ in comparison to safety $(r$ $=.18)$ and availability $(r=.27)$. Furthermore, May et al. (2004) performed a study to test the model proposed in Kahn's (1990) ethnographic work and found, once again, that meaningfulness displayed the strongest (positive) relationship with work engagement 
versus the other two psychological conditions of safety and availability. Finally, Olivier and Rothmann (2007) followed up on May et al.'s (2004) study to test further assumptions that were proposed in Kahn's (1990) model. Once again, they confirmed that meaningfulness displayed the strongest relationship with work engagement out of all psychological conditions. Therefore, my study proposed that psychological meaningfulness would be positively related to work engagement.

Hypothesis 11. Psychological meaningfulness will display a positive relationship with work engagement.

\section{Job Features and Meaningfulness}

Hackman and Oldham (1980) suggested that the antecedents likely to impact meaningfulness at work are those tasks which facilitate personal growth. Furthermore, Kahn (1990) identified interpersonal relationships as a predictor of experienced meaningfulness, asserting that good interpersonal interactions foster a strong sense of belonging, which then increase one's sense of meaningfulness (May et al., 2004). Finally, Rich et al. (2010) stated that "Perceptions of organizational and work factors related to tasks and roles are the primary influences on psychological meaningfulness" (p.620). In line with these assertions, it was expected that job features, specifically PJ fit, autonomy, co-worker relations, supervisor support, and procedural and interactional justice, would be significantly related to meaningfulness.

Person-job fit. If workers perceive a "fit" between their self-concept and a work role, they will feel more comfortable expressing their beliefs and values, which will then 
lead to experienced meaningfulness in their job (Brief \& Nord, 1990; Shamir, 1991). Shamir (1991) argued that rather than just being goal-oriented, human beings are creative and self-expressive. They seek out roles that allow them to express themselves authentically. Authentic expression of a person's self will be possible if their job is a good fit for them. Individuals will also be more likely to experience meaningfulness if the requirements of the job suit their abilities. A match between the requirements of the job and the abilities that one has will make that individual feel as though they can make a contribution to the job and the organization at large. This falls right in line with how Kahn (1990) described meaningfulness as being, in part, a result of feeling worthwhile and useful.

Research confirms the hypothesized link between PJ fit and psychological meaningfulness. May (2003) examined the relationship between work-role fit and experienced meaningfulness in a manufacturing company and found that they were significantly (and positively) related to one another. May et al. (2004) confirmed that psychological meaningfulness mediated the relationship between work-role fit and engagement. Finally, Olivier and Rothmann (2007) found that work-role fit and coworker relations were significantly related to engagement through their positive relationships with psychological meaningfulness. This reasoning and research supported the expectation that there would be a positive relationship between PJ fit and psychological meaningfulness.

\section{Hypothesis 12. Person-job fit will be positively related to psychological} meaningfulness. 
Autonomy. According to self-determination theory (SDT, Deci \& Ryan, 1985), autonomy is one of the basic psychological needs (i.e., autonomy, relatedness, and competence). Satisfaction of a psychological need is likely to make a job more meaningful to the individual. Also, with more autonomy, or control, comes more identification and ownership of the job, which therefore makes it more meaningful to the individual performing it. According to Hackman and Oldham's Job Characteristics Model (JCM, 1980), autonomy led to experienced responsibility for outcomes of the work. The more responsible workers feel for the outcomes of their work, the more likely they are to experience the work as meaningful.

Kahn (1990) found confirmation for a relationship between autonomy and meaningfulness in his study. He stated that "when organization members were doing work that was challenging, clearly delineated, varied, creative, and somewhat autonomous, they were more likely to experience psychological meaningfulness" (Kahn, 1990, p.704). Therefore, my study expected to find that the more autonomy workers are given in their job, the more likely that job is to be meaningful to them.

Hypothesis 13. Autonomy will be positively related to psychological meaningfulness.

Co-worker relations. Kahn (1990) found that people experienced meaningfulness when their jobs included rewarding interpersonal relations with clients and co-workers. These favorable interactions promoted self-appreciation, dignity, and a sense of worthwhileness. They created a condition in which people felt the desire to give 
to and receive from others. Relations with others are an invaluable source of meaning in individuals' lives as they meet the relatedness needs (Alderfer, 1972). They enable people to feel appreciated and known, as though they are sharing their life journey with others (May et al., 1958). Individuals are also likely to experience meaningfulness from the social identities that they receive from being members of a group. Interactions with co-workers that make individuals feel as though they belong are likely to foster experienced meaningfulness (May et al., 2004).

Qualitative (Kahn, 1990) and quantitative (May, 2003; May et al., 2004; Olivier \& Rothmann, 2007) research confirms the positive relationship between rewarding coworker relationships and psychological meaningfulness. Additionally, Vinarski-Peretz and Carmeli (2011) performed a study on employees from organizations in the service sector to examine the relationship between care felt, or the degree to which employees feel that their co-workers care about them, and the three psychological conditions of meaningfulness, safety, and availability. SEM results from their study indicated that care felt between employees was positively associated with the three psychological conditions, which in turn affected employees' motivation to become engaged in innovative behaviors. Therefore, this study expected to find that co-worker relations have a positive impact on employees' meaningfulness of the job.

Hypothesis 14. Co-worker relations will be positively related to psychological meaningfulness. 
Supervisor support. Similar to the argument for co-worker relations, it was believed that supervisor support would affect psychological meaningfulness through its gratification of individuals' innate need to connect with other human beings (Alderfer, 1972; Locke \& Taylor, 1990; SDT, Deci \& Ryan, 1985). In addition to that, supportive actions from a supervisor would be confirmation to workers that they are valuable assets to the organization and the role that they occupy. This feeling of being useful and worthwhile is the definition of meaningfulness according to Kahn (1990).

To the researcher's knowledge, only one quantitative study has provided empirical support for the positive relationship between supervisor support and perceived psychological meaningfulness of the job. In their test of Kahn's (1990) model, Oliver and Rothmann (2007) found a positive correlation between supervisor relations and meaningfulness. However, it was believed that Kahn's observation that “meaningful interactions [promote] dignity, self-appreciation, and a sense of worthwhileness" could be extended beyond just co-workers to supervisors' support of employees and, in turn, have a significant effect on workers' sense of meaningfulness of the job.

Hypothesis 15. Supervisor support will be positively related to psychological meaningfulness.

Procedural and interactional justice. The last job features that were expected to influence psychological meaningfulness are procedural and interactional justice perceptions. If employees perceive the procedures in the workplace and their interactions with management to be fair, they will see their workplace as an institution that will not 
take them for granted and one from which they will be likely to receive a fair return on the investments that they put into the job. Believing that an organization will not take advantage and will fairly compensate individuals for their work is the very definition of meaningfulness, according to Kahn (1990). Additionally, if one believes there to be interactional justice in the workplace, this leads to the perception that he or she is valued and not taken for granted, which falls in line with another aspect of Kahn's (1990) definition of meaningfulness. Finally, perceiving interactional justice fulfills relatedness needs because it reflects that the individual is being treated fairly and connecting with others around him or herself in a genuine manner. Fulfillment of relatedness needs makes the job more meaningful to the individual. Empirical research has yet to examine the relationship between justice perceptions and psychological meaningfulness. However, on the basis of the logic above, it was hypothesized that procedural and interactional justice perceptions would have a positive influence on psychological meaningfulness.

\section{Hypothesis 16. (a) Procedural and (b) interactional justice perceptions will be} positively related to psychological meaningfulness.

Meaningfulness as a mediator. The combination of hypotheses 3 through 7 and 11 through 16 made it possible to deduce that psychological meaningfulness would mediate the relationship between job features and work engagement. More specifically, this research expected to find that PJ fit, autonomy, co-worker relations, supervisor support, procedural justice, and interactional justice would be significantly related to engagement through their relationships with psychological meaningfulness. 
Hypothesis 17. Psychological meaningfulness will mediate the relationship between job features and work engagement.

\section{Psychological Safety}

Kahn (1990) defined psychological safety as the feeling of being able to employ one's self without fear of negative consequences to status, career, or self-image. Edmondson (2004) described it as an individual's perception of the consequences of interpersonal risks in the working environment. She further explained that it refers to the taken-for-granted beliefs of how others would respond if an individual puts him or herself on the line by asking a question, reporting a mistake, seeking feedback, or even proposing a new idea. Individuals ask themselves if they are likely to be embarrassed, criticized, or hurt by others if they do so. A safe environment is one in which individuals do not believe that they will receive negative reactions if they put themselves on the line, whereas an unsafe one is one in which they believe that they will. So, an action that may be welcomed in one work group might be unthinkable in another due to the differing beliefs of the interpersonal consequences.

Psychological safety and engagement. It was anticipated that psychological safety would have a positive influence on work engagement. If employees have high perceptions of psychological safety at work, they will be more likely to take risks and express their true selves. They will feel comfortable to actively engage their interests in work and try novel ways of doing it (Amabile, 1983; May et al., 2004). Conversely, those that perceive their workplace to be unpredictable and threatening will be more apt to disengage from their role and be hesitant to take risks and try new things (May et al., 
2004). In their longitudinal study of psychosocial safety climate (PSC) and its effect on psychological health and work engagement, Dollard and Bakker (2010) found that PSC positively predicted change in engagement through skill discretion. Other studies have also provided empirical support for the positive association between psychological safety and work engagement (e.g., May et al., 2004; Olivier \& Rothmann, 2007). Therefore, this study expected to find that psychological safety would be positively related to work engagement.

Hypothesis 18. Psychological safety will be positively related to work engagement.

\section{Job Features and Psychological Safety}

Kahn stated that one's assessment of psychological safety was associated "with elements of social systems that created more or less non-threatening, predictable, and consistent social situations in which to engage" (Kahn, 1990, p.703). He observed that two particular factors seemed to increase employees' levels of experienced safety: a climate that promoted open communication and interpersonal relationships that were supportive and non-threatening (Brown \& Leigh, 1996; Kahn, 1990). More specifically, an open climate would allow members to freely express themselves without fear of negative consequences, while supportive interpersonal relationships would enable employees to perform their jobs without fearing that if they try and fail, other organizational members would criticize them for it (Kahn, 1990). Further confirming this logic, Rich et al. (2010) stated that “...perceptions of social systems related to support 
and relationships are the primary influences on psychological safety" (p.620). Therefore, the first set of factors that were believed to have a significant influence on psychological safety were features of the job that help to promote an open, non-threatening environment.

Person-job fit. If a worker feels that they are a good fit (in terms of their skill-set and values) for the job that they perform, then they will be more likely to feel that they are competent and belong in that job and at that workplace. This sense of belonging will give them the confidence to believe that acting themselves and letting their guard down is possible and, more importantly, appropriate. Research carried out by May et al. (2004) confirmed this perspective. Though it was not a hypothesis of theirs, a positive correlation was found between work-role fit and psychological safety. The same result occurred in the study that Olivier and Rothmann (2007) carried out. These researchers also found a positive correlation between work-role fit and safety. Therefore, PJ fit was expected to be positively related to perceptions of psychological safety.

Hypothesis 19. Person-job fit will be positively related to psychological safety.

Autonomy. If workers are given a high level of autonomy in their job, they will believe that management approves of how they perform that role. This approval lets them know that who they are and how they carry out their duties is acceptable and desirable. In support of this perspective, Brown and Leigh (1996) argued that when employees have control over their work and the methods that they use to accomplish it, it signals to them that management trusts and has confidence in their ability to carry out job 
duties without close supervision. In a way, autonomy implies supervisor support, which has also been shown to be a strong predictor of psychological safety (e.g., Kahn, 1990; May et al., 2004; Nembhard \& Edmondson, 2006). Higher levels of autonomy, therefore, ultimately help employees perceive their work environment as a safe one in which they can be themselves without fear of negative repercussions. Hence, a positive relationship was anticipated to exist between autonomy and psychological safety.

Hypothesis 20. Autonomy will be positively related to psychological safety.

Co-worker relations. Good relations with co-workers give individuals the sense that they fit into the work environment and that being themselves is appropriate. Supportive co-worker relations enable people to believe that if they try and fail, their coworkers will be constructive rather than destructive in any criticism that they may give (Kahn, 1990). Furthermore, Edmondson (2003) argued that positive co-worker relations' impact on psychological safety is a result of the fact that it insinuates that others see one as competent, making them less likely to feel they will be judged or monitored if they open up and share their opinions. Alternatively, if workers do not have good relations with their co-workers, then they will feel the need to bottle themselves up, hide their true selves from those around them, not feel like they fit in, and not take risks in what they do. Qualitative and quantitative studies have found support for the positive relationship between co-worker relations and psychological safety (e.g., Kahn, 1990; May et al., 2004; Olivier \& Rothmann, 2007). It was believed that my study would find support for this relationship as well. 
Hypothesis 21. Co-worker relations will be positively related to psychological safety.

Supervisor support. Supervisors play a significant role in the level of psychological safety that is felt in the workplace. They set the tone in the workplace for what is acceptable and not acceptable behavior (i.e., norms) (Kahn, 1990). The more supportive a supervisor is, the more workers will feel able to take risks and be creative in the execution of tasks. In fact, managerial support has been shown to positively affect creativity, a form of free self-expression that likely involves a high level of psychological safety (e.g., Amabile, Conti, Coon, Lazenby, \& Herron, 1996; Deci, Connell, \& Ryan, 1989). Ultimately, supportive actions from supervisors help to enhance employee selfdetermination and interest in their work. Employees that are self-determined feel that they have a choice in initiating and regulating their own actions. Such support makes employees more "likely to feel safer to engage themselves more fully, try out novel ways of doing things, discuss mistakes and learn from these behaviors" (May et al., 2004, p.16).

Kahn (1990) argued that one of psychological safety's most influential factors is management's level of support. May et al. (2004) confirmed Kahn's proposition with their SEM pathway model in which they found that supervisor relations was the strongest predictor of psychological safety $(r=.55)$. Therefore, it was believed that my study would provide further support for the positive impact that supervisors can have on employees' levels of psychological safety. 
Hypothesis 22. Supervisor support will be positively related to psychological safety.

Procedural and interactional justice. Kahn (1990) described psychological safety as being associated with environments that are consistent, clear, predictable, and non-threatening. Higher perceptions of procedural and interactional justice are achieved when the procedures and interpersonal treatment in the workplace are viewed in this same way. Therefore, it was believed that both types of justice would be positively affiliated with psychological safety.

If employees perceive the processes in the workplace to be carried out in a fair manner, they will be more likely to feel safe being themselves and being creative with the way in which they perform their tasks. They will believe that as long as they follow the rules, any actions taken against them will be fair. On the contrary, if employees believe that procedures are carried out in a preferential manner, not derived from any concrete terms or logical processes, they will be more fearful of letting their guard down, taking risks, and expressing themselves out of concern they may do something that will get them in trouble without even realizing it.

On a related note, if employees perceive fairness in the way that management treats them (interactional justice), they will feel more comfortable letting their guard down and being themselves. Not only would the consistent and non-threatening manner of the relationship be likely to make employees feel psychologically safe in the workplace, but interactional justice has much to do with how they perceive their relations with their supervisors and management. The strong positive relationship between 
supervisor relations and psychological safety has already been discussed. Therefore, it seemed reasonable to expect that interactional justice would correspondingly make a significant impact on psychological safety.

Hypothesis 23. (a) Procedural and (b) interactional justice perceptions will be positively related to psychological safety.

Psychological safety as a mediator. The combination of hypotheses 3 through 7 and 18 through 23 made it possible to deduce that psychological safety would partially mediate the relationship between job features and work engagement. More specifically, this research expected to find that PJ fit, autonomy, co-worker relations, supervisor support, procedural justice, and interactional justice would partially affect work engagement through their relationships with psychological safety.

Hypothesis 24. Psychological safety will partially mediate the relationship between job features and work engagement.

\section{Personal Characteristics and Psychological Safety}

The other category of variables that was believed to have a significant impact on one's level of felt psychological safety is personal characteristics. Specifically, those personal characteristics that would naturally make individuals hesitant to open up and be themselves at the workplace would affect how likely they are to let their guard down, take risks, and be completely open with their thoughts and ideas. Though Kahn did not 
originally propose that personal characteristics would significantly affect psychological safety, Zhang, Fei, Wang, and Chen (2010) discussed how workers' perception of how psychologically safe a work environment results from two factors: social factors (e.g., social relationships) that cue them into the reality of their surroundings and personal-trait factors (e.g., self-consciousness) that make them more or less likely to feel threatened in their surroundings. May et al. (2004) confirmed one such trait's effect on safety when they had to revise their model in order to account for the negative impact that selfconsciousness had on work engagement through safety. Therefore, my study aimed to take this finding and Zhang et al.'s (2010) argument a bit further and examine other personal characteristic correlates of engagement that may affect engagement through psychological safety.

Self-consciousness. Level of self-consciousness was expected to have a negative influence on workers' psychological safety. Specifically, individuals that have a high level of public self-consciousness are naturally preoccupied with and concerned about what others think of them (Carver \& Sheier, 1978; Fenigstein, Scheier, \& Buss, 1975). They are likely to engage in impression management tactics in order to ensure that how they appear to others is acceptable (Schlenker, 1980). This behavior means that when they perform tasks, they are very sensitive to how others perceive their actions and fearful of being rejected or intimidated (Zhang, Fei, Wang, \& Chen, 2010). If workers are worried about how others see them, they will be less likely to feel safe letting their guard down in the workplace and trying out new ways of accomplishing their tasks. Therefore, it was reasoned that individuals that are self-conscious would be less likely to perceive psychological safety in their work environment. 
May et al. (2004) were the first researchers to discover the negative association between self-consciousness and psychological safety. Their research model testing the viability of Kahn's (1990) theoretical framework had to be revised to include a negative pathway between self-consciousness and psychological safety in order to achieve a good model fit. Results of their study proved that self-consciousness had a small negative influence on safety $(r=-.19)$. Six years later, Zhang et al. (2010) investigated trust and self-consciousness as antecedents to psychological safety in a virtual community. They found self-consciousness to be a strong, negative predictor of psychological safety $(r=-$ .61). Therefore, my study proposed to also find that self-consciousness would be negatively related to psychological safety.

Hypothesis 25. Self-consciousness will be negatively related to psychological safety.

Self-efficacy. Individuals with high generalized self-efficacy were expected to perceive higher levels of psychological safety than their counterparts. Self-efficacy is defined as a personal belief in "how well one can execute courses of action required to deal with prospective situations" (Bandura, 1982, p.122). Individuals with high selfefficacy have high levels of confidence in their abilities, which ultimately make them believe that how they respond to work demands is acceptable. Workers with high trait self-efficacy will therefore feel very comfortable being themselves and taking risks in their roles as they believe that they are capable of carrying out their work in a way that is desirable and warranted. 
To the researcher's knowledge, no published studies examined the relationship between trait self-efficacy and psychological safety. However, Zhang et al. (2010) argued that psychological safety is a result of one's perception of how threatening the work environment is. By nature, those that have high levels of self-efficacy are less likely to see their environment as threatening because they believe that they have the skills to execute whatever work demands come their way. Since a high level of generalized self-efficacy makes individuals feel more secure in themselves and their abilities, they will be more likely to feel more psychological safety in their surroundings. Hence, it was believed that trait self-efficacy would be positively related to psychological safety.

Hypothesis 26. Generalized self-efficacy will be positively related to psychological safety.

Personality. Two personality traits, namely neuroticism and extraversion, were expected to exhibit significant relationships with psychological safety. It was expected that extraversion would display a positive relationship and neuroticism would exhibit a negative relationship with psychological safety. Individuals that are extraverted are naturally characterized as being more likely to open up and be themselves considering that they are described as being outgoing, gregarious, assertive, active, sociable, and seeking excitement (Barrick, Mount, \& Judge, 2001). Their natural inclination to feel comfortable opening up and being themselves in their surroundings would likely lead 
them to innately perceive their surroundings as more psychologically safe than those that are low on extraversion.

Neuroticism, on the other hand, is the extent to which an individual is anxious, hostile, depressed, and/or experiencing personal insecurity (Barrick et al., 2001). By nature, these individuals are less likely to open up and perceive their surroundings to be safe enough to let their guard down. They are naturally wired to perceive their environment as less safe as a consequence of their naturally high level of anxiety and insecurity. Therefore, their natural inclination to be nervous, anxious, and less likely to open up would make them more apt to perceive their surroundings as unsafe to unwind in and be their true selves. No empirical research to date has examined the relationships between these personality traits and psychological safety. However, on the basis of these theoretical arguments, it was believed that both extraversion (positively so) and neuroticism (negatively so) would be significantly related to psychological safety.

\section{Hypothesis 27. (a) Extraversion will be positively related and (b) neuroticism} will be negatively related to psychological safety.

Psychological safety as a mediator. The combination of hypotheses 8 through 10 and 25 through 27 made it possible to deduce that psychological safety would partially mediate the relationship between personal characteristics and work engagement. More specifically, my study expected to find that self-consciousness, trait self-efficacy, extraversion, and neuroticism would partially affect work engagement through their relationships with psychological safety. 
Hypothesis 28. Psychological safety will be a partial mediator between personal characteristics and work engagement.

\section{Psychological Availability}

Psychological availability refers to how many physical, emotional, and/or psychological resources one has to put towards their role at work (Kahn, 1990). It is a reflection of one's readiness to engage in a work role given the other work and non-work activities that he or she may be involved in and/or distracted by. Although psychological availability (as a specific term) has the least amount of empirical backing, there is much research regarding individuals' availability of resources and how it may affect job performance and/or engagement. Research regarding psychological availability is closely related to, if not the same as, research concerning the importance of recovery from work, achieving a balance between work and family demands, and having the ability to engage in stress coping strategies (Eden, 2001; Frone, 2003; Pearlin, 1983). The following sections will discuss the impact that psychological availability was expected to have upon work engagement, as well as individual factors that were likely to affect how available one is to become engaged at work.

Psychological availability and work engagement. Psychological availability was expected to be significantly related to engagement such that the more psychologically available one is, or the more personal (emotional, cognitive, physical) resources they have to put towards work, the more engaged he or she will be. This proposition has to do with the notion that individuals cannot engage themselves in their work role if they do not have the personal capacity to become engaged. Stress literature 
confirms this fact as it suggests that when workers experience overload, they withdraw or disengage from work, perhaps in an effort to replenish their resources (Ganster \& Schaubroeck, 1991; May et al., 2004). Further, research supports a positive relationship between psychological availability and work engagement (e.g., Kahn, 1990; May et al., 2004). Hence, this research proposed that psychological availability would exemplify a positive relationship with work engagement.

Hypothesis 29. Psychological availability will be positively related to work engagement.

\section{Personal Characteristics and Availability}

In his ethnographic study, Kahn (1990) said that "psychological availability was associated with individual distractions that preoccupied people to various degrees and left them more or fewer resources with which to engage in role performances" (p.703). Rich et al. (2010) further argued that “ “...self-perceptions of confidence and self-consciousness are the primary influences on psychological availability" (Rich et al., 2010, p.620). On the basis of these assertions, it was believed that personal traits that may lead one to be distracted from the job, as well as those that might provide one with more innate resources than their fellow employees to deal with the job, were expected to be significantly related to psychological availability.

Self-Consciousness. Self-consciousness was expected to exhibit a negative relationship with psychological availability. Individuals that are highly self-conscious are likely to put a lot of energy into focusing on what others think of them and how they 
are being perceived (Carver \& Scheier, 1978). The energy that they put towards this reflects a loss in personal resources that they could be putting towards, or is psychologically available to apply to, the job at hand. Olivier and Rothmann (2007) found support for this relationship in their empirical test of Kahn's theoretical model. Specifically, they found that self-consciousness was a statistically significant predictor of psychological availability $(r=-.40)$. Therefore, my research expected to find the same result.

Hypothesis 30. Self-consciousness will be negatively related to psychological availability.

Self-efficacy. Generalized self-efficacy would be positively related to psychological availability such that individuals with higher efficacy beliefs will be more aware of the resources that they have to apply towards their work role. When individuals have high self-efficacy, they are confident in their abilities to perform work demands. Another way of looking at this is that they are aware of the personal resources (cognitive, emotional, physical) that they have to put towards completing a task. Conversely, when individuals are low on self-efficacy, they doubt their abilities and focus more of their attention on their inadequacies than their capabilities (Bandura, 1977b). These workers are not as aware of the resources that are available to them as those that rate high on selfefficacy. So, individuals' level of self-efficacy ultimately affects how salient, or available, their personal resources are to them. 
Kahn (1990) discussed how psychological availability corresponded to how secure individuals felt in their work. Insecure workers were distracted by their anxieties. Energies that could have been put towards being engaged in work were instead applied towards focusing on their inadequacies. Furthermore, he said that "being available was partly a matter of security in abilities and status and maintaining a focus on tasks rather than anxieties" (Kahn, 1990, p.716). By definition, self-efficacy is a measurement of one's belief, or level of felt security, in his or her ability to perform a task (Bandura, 1982). Therefore, it was believed that self-efficacy would be positively related to psychological availability.

Hypothesis 31. Generalized self-efficacy will be positively related to psychological availability.

Personality. Personality was expected to make a significant impact on psychological availability as well. Extraversion and neuroticism in particular are believed to have a positive and negative effect, respectively, on how available one is to be engaged in his/her job. Kahn (1990) stated that physical and emotional energy were two elements that directly affected one's level of psychological availability. Highly extraverted individuals are characterized as having high levels of energy, in addition to being sociable, assertive, and gregarious among other attributes (Barrick et al., 2001). Due to this inherent high level of energy, they will have more physical resources to put towards the job at hand. In turn, they will be more physically available than their counterparts to become engaged in their work role. Individuals that score high on 
neuroticism, on the other hand, are characterized as being anxious, depressed, hostile, and insecure (Barrick et al., 2001). They are likely to be distracted and put more energy into worrying about personal issues that are irrelevant to the task at hand. This naturally makes them less emotionally and/or cognitively available to perform the job. Therefore, it was believed that this study would find a positive relationship between extraversion and psychological availability and a negative relationship between neuroticism and availability.

Hypothesis 32. (a) Extraversion will be positively and (b) neuroticism will be negatively related to psychological availability.

Psychological availability as a mediator. The combination of hypotheses 8 through 10 and 29 through 32 made it possible to deduce that psychological availability would mediate the relationship between personal characteristics and work engagement. More specifically, this research expected to find that self-consciousness, trait selfefficacy, extraversion, and neuroticism would all be significantly related to engagement through their relationships with psychological availability.

Hypothesis 33. Psychological availability will mediate the relationship between personal characteristics and work engagement. 


\section{Work Engagement and Organizational Citizenship Behavior}

Finally, research has shown that work engagement is positively related to desirable outcomes in the workplace. My research aimed to confirm engagement's positive impact in the workplace by testing for a positive relationship between it and organizational citizenship behavior (OCB). The two most popular conceptualizations of OCB are those proposed by Organ $(1988,1990)$ and Williams and Anderson (1991).

Organ (1988) originally defined OCB as "individual behavior that is discretionary, not directly or explicitly recognized by the formal reward system, and that in the aggregate promotes the effective functioning of the organization" (p. 4). In 1997, he modified his definition of OCB and instead described it as "performance that supports the social and psychological environment in which task performance takes place" (Organ, 1997, p.95). Organ first proposed that it was composed of five factors - altruism, courtesy, civic virtue, conscientiousness, and sportsmanship. Later, he expanded this five-factor model to a seven-factor model by adding two more dimensions, peacekeeping and cheerleading (Organ, 1990). Sportsmanship refers to an employee's willingness to tolerate less than ideal conditions and not complaining or making problems out to be worse than they are; conscientiousness (i.e., compliance) is defined as behavior reflecting employees' adherence to and acceptance of the procedures, rules, and regulations of the organization; and civic virtue refers to behavior indicating that employees are actively interested in the life of their workplace (Organ, 1988). As for the other dimensions, empirical research (Bachrach, Bendoly, \& Podsakoff, 2001; MacKenzie, Podsakoff, \& Fetter, 1991) has shown that managers often experience difficulty distinguishing the other dimensions from one another. Therefore, most researchers categorize the remaining 
factors of altruism, courtesy, peacekeeping, and cheerleading under a second-order latent construct of helping behavior.

The other major conceptualization of OCB was provided by Williams and Anderson (1991). They organized OCB into dimensions according to the direction or target of the behavior. In particular, those behaviors that were directed towards other individuals were labeled OCBIs and those that were aimed at the organization were called OCBOs. All of Organ's $(1988,1990)$ OCB dimensions can be categorized under the two dimensions provided by Williams and Anderson (1991). For example, Organ's dimensions of altruism, courtesy, peacekeeping, and cheerleading are aimed at benefitting other individuals and could therefore fall under the category of OCBI; whereas the remaining dimensions of conscientiousness (i.e., compliance), civic virtue, and sportsmanship are clearly geared towards benefitting the organization and would therefore fall into the OCBO category.

Williams and Anderson's (1991) conceptualization can also be used to accurately capture most other OCB-related constructs. For example, OCBI captures such constructs as Graham's (1989) interpersonal helping, Van Scotter and Motowidlo's (1996) interpersonal facilitation, and Farh, Earley, and Lin's (1997) interpersonal harmony and helping co-workers constructs. Furthermore, OCB-related constructs such as Graham's (1991) organizational loyalty; Borman and Motowidlo’s $(1993,1997)$ endorsing, supporting, and defending organizational objectives; Van Scotter and Motowidlo's (1996) job dedication; LePine and Van Dyne's (1998) voice behavior; Morrison and Phelps's (1999) taking charge (or individual initiative); and Farh, Zhong, and Organ's (2004) promoting the company's image constructs fall under the conceptual umbrella of 
OCBO. Hence, as a result of its all-encompassing nature, William and Anderson's (1991) conceptualization of OCB will be used for this study.

OCB's importance in the workplace is evident from its association with individual consequences such as performance evaluations, managers' reward allocation decisions, and employee withdrawal; and organizational level outcomes such as efficiency, productivity, profitability, and costs (Allen \& Rush, 1998; Chen, 2005; Dunlop \& Lee, 2004; Ehrhart \& Naumann, 2004; Koys, 2001; MacKenzie et al., 1991; Podsakoff \& MacKenzie, 1997; Walz \& Niehoff, 2000). Researchers in the field of I-O psychology have only recently started to examine its association with work engagement. The connection between these two variables was first suggested by Kahn (1990) who claimed that employees who are personally engaged in their work role are likely to possess a broader conception of the role and, therefore, likely to expend effort beyond the formal boundaries of their job in order to benefit the organization as well as the workers within it. My study aimed to empirically test Kahn's proposition that those who are more engaged in their work will be more likely to exhibit OCB.

Researchers that have ventured to explore the association between work engagement and OCB have found empirical support for a positive relationship between the two constructs. For example, in 2010, Babcock-Roberson and Strickland examined the impact that leader charisma could have on OCB and found that the relationship was fully mediated by work engagement (with work engagement positively affecting OCB). Furthermore, in their meta-analytic study of work engagement and its association with antecedents, outcomes, and constructs closely related to it (i.e., job satisfaction, organizational commitment, job involvement), Christian, Garza, and Slaughter (2011) 
found that work engagement was positively related to contextual performance $\left(r_{c}=.43\right)$, which is a construct that is virtually synonymous with OCB (Borman \& Motowidlo, 1993). Therefore, in line with Kahn's (1990) qualitative observation as well as other researchers' quantitative empirical findings, this study expected to find that work engagement exhibits a positive relationship with OCB.

Hypothesis 34. Work engagement will be positively related to OCB.

\section{Summarizing the Research Model}

In summary, my study aimed to test a nomological net of work engagement that was derived from its extant research. Thirty-four hypotheses were tested in order to establish the viability of this nomological net. First of all, my study expected to find that a single engagement factor would emerge from the engagement measure created by Schaufeli et al. (2003) consisting of vigor, dedication, and absorption dimensions. Next, this study anticipated that work engagement would exhibit differential validity from the related constructs of organizational commitment and job satisfaction. After testing these two preliminary hypotheses, my study ventured to test that psychological meaningfulness, safety, and availability mediate the relationships that job features and personal characteristics have with work engagement. Finally, my study expected to find that work engagement has a positive impact on OCB. An illustrated depiction of the full model that was tested in this research study is presented on the next page (Figure 1).

The next chapter of this dissertation will describe the methods that were used to test the hypotheses that were presented in this chapter. Specifically, the measures that 
were used in this dissertation will be described in detail, as will the means of collecting data, the population from which data were collected, and the analyses that were used to determine whether or not the hypotheses were supported.

Figure 1.

Research Model

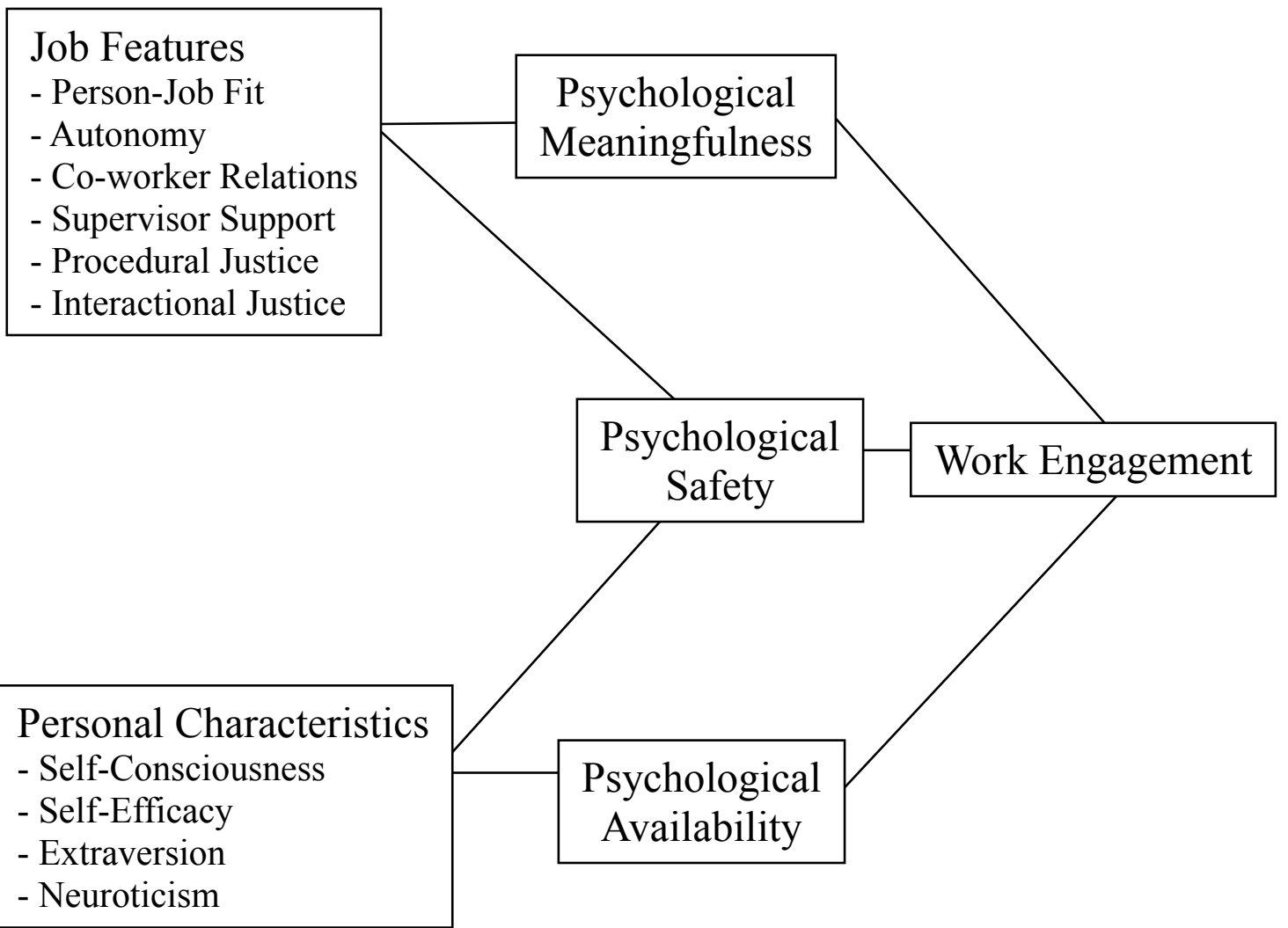




\section{Chapter III}

\section{Method}

The third chapter of the dissertation will describe the sample that was collected and the methodology that was used to test the hypotheses presented in the second chapter. First, a description of the database, sample, and means of collecting the data for this study will be provided. This will be followed by a review of the measures that were used.

\section{Database}

In order to test the hypotheses presented in Chapter II, an online labor market was used to access and survey a diverse population of workers. The online service serves as a platform where employees (i.e., workers) can be recruited by employers (i.e., requesters) in order to complete tasks (called HITs or Human Intelligence Tasks) in exchange for a wage, or reward. Use of this online service for research has been validated in recent studies and was therefore an appropriate avenue through which to collect data for the dissertation (e.g., Buhrmester, Kwang, \& Gosling, 2011; Paolacci, Chandler, \& Ipeirotis, 2010).

When workers accessed the website, this task appeared alongside other tasks posted by 'requesters' on the site. Tasks can be sorted according to various criteria including the size of the reward and the date posted. Workers can click on the link of tasks in order to read brief descriptions and/or preview tasks before accepting to work on them. If they accepted to work on this task, the participant was provided with a link that took them to the online questionnaire for the study. The study's questionnaire took approximately one hour to complete and was composed of measures of all the constructs described in the previous chapter including work engagement, organizational 
commitment, job satisfaction, organizational citizenship behavior, psychological meaningfulness, psychological safety, psychological availability, PJ fit, autonomy, coworker relations, supervisor support, procedural justice, interactional justice, extraversion, neuroticism, self-consciousness, and self-efficacy. The questionnaire also included demographic items such as gender, age, and industry, as well as test items (e.g., "Please select the response Strongly Agree for this question") in order to ensure that individuals were paying attention while filling out the survey.

All participants had the option to exit the survey at any time. Participation in the study was completely voluntary and anonymous, and those participants that completed the survey and did not miss any of the test items received \$1 United States dollar in exchange for their participation. All of the data that was obtained for this study remains confidential and all Institutional Review Board (IRB) standards are maintained.

\section{Participants}

The sample for the present study was screened for random responses using the previously mentioned test items that were included in the survey. Five test items were randomly dispersed throughout the survey. These items helped the researcher determine if participants were paying attention while filling out the survey and, ultimately, whether or not lines of data would have to be removed from the set prior to analysis. An example of a test item that was included in the survey is "For this question, please select the response Strongly Disagree." Any participant that did not answer all five of the test questions correctly was not included in this study's final sample. Responses were collected through the online service until a sample size of 520 participants that answered 
all of the test questions correctly was achieved. A total of 20 lines of data were removed due to missing demographics, leaving a final sample size of 500 for this study.

In the final dataset $(\mathrm{N}=500), 53.6 \%$ of the participants were female. The majority of the sample was 18 to 40 years old. Specifically, $29.8 \%$ were 18 to 25 years old, $28.6 \%$ were 26 to 30 years old, and $27 \%$ were 31 to 40 years old. Other participants were 41 to 50 years old (9.4\%), 51 to 60 years old (3.6\%), and 61 years or older (1.6\%). Caucasians made up a large portion of the sample (54\%), while $36.4 \%$ were Asian/Pacific Islander, and the other $9.6 \%$ of the sample consisted of a mix of ethnicities (Blacks-3.8\%, Hispanics-3.2\%, Native American/Alaskan Native-1.2\%, Indian-1\%, Middle Eastern$.2 \%$, and Biracial- $.2 \%$ ) that were lumped into an 'Other' category to provide more evenly distributed categories for analytical purposes. In order to qualify for this study, participants had to work at least 30 hours per week. In the final sample, $53 \%$ of participants worked between 30 and 40 hours and $47 \%$ worked 40 hours or more.

It was anticipated that the sample for this study would be very diverse in terms of industry, occupational level, and geographic location, since the data was collected online and nationwide. The frequencies of the demographic variables reflect this. Many participants worked in the Southern United States (32.2\%), 25.5\% worked in the Northeast, $24.7 \%$ worked in the West, and $17.6 \%$ worked in the Midwest. Most of the participants worked in the services industry (28.5\%), others worked in retail/sales (16.8\%), health care (12.4\%), education (12.4\%), finance/real estate $(10.2 \%)$, manufacturing (7.8\%), other (7\%), or public administration/government (4.8\%). The majority of participants had been employed at their current job for 5 to 10 years (26.2\%), 
while others had been at their job for 2 to 3 years (23.6\%), 1 to 2 years (22.2\%), 3 to 4 years $(11 \%), 4$ to 5 years $(8.6 \%)$, more than 10 years $(7 \%)$, or less than a year $(1.4 \%)$.

Finally, participants were asked to report certain specifics about their job such as their income, whether or not they supervised any employees, and whether they would consider their current position to be 'just a job' or 'a part of their career'. With regard to these items, the $20.2 \%$ of participants earned an income between $\$ 35,000$ and $\$ 49,999$, other participants earned $\$ 25,000$ to $\$ 34,999$ (19.8\%), $\$ 15,000$ to $\$ 24,999$ (18.6\%), $\$ 50,000$ to $\$ 74,999(17.6 \%), \$ 10,000$ to $\$ 14,999(15.2 \%), \$ 75,000$ to $\$ 99,999(4.2 \%)$, $\$ 100,000$ to $\$ 149,000(3.2 \%), \$ 150,000$ to $\$ 199,999$ (1.0\%), and $\$ 200,000$ or more (.2\%). The majority of participants (57.4\%) were not supervisors to other employees, and most considered the current job that they were in to be a part of their career (60.4\%) rather than 'just a job'. The next section will describe the measures that were included in this study's questionnaire and their respective alpha coefficients.

\section{Measures}

Work engagement. Work engagement was the dependent variable of interest in the SEM model. It was also the dependent variable of interest in several hierarchical regression analyses. It was measured using the Utrecht Work Engagement Scale (UWES), a 17-item scale developed by Schaufeli, Salanova, Gonzalez-Roma, and Bakker (2002). Items are designed to measure the three dimensions of work engagement, which include vigor (VI), dedication (DE), and absorption (AB). Items were scored on a 7-point frequency-rating scale ranging from 0 ('Never') to 6 ('Always'). Higher scores indicated higher levels of work engagement. 
After performing confirmatory factor analyses (CFA) to test the factor structure of work engagement, it was determined that the original 17 -item scale would need to be condensed to achieve good model fit. In order to decide which items would be used to represent work engagement in a condensed form, a study in which Schaufeli et al. (2006) validated a 9-item version of the original engagement scale using data collected from 10 different countries $(\mathrm{N}=14,521)$ was consulted.

Schaufeli et al. (2006) used an iterative process to select three items to represent each dimension of engagement (vigor, dedication, and absorption). The researchers first used face validity to choose the most characteristic item of each scale. The chosen item was then regressed onto the remaining items in its respective scale, and the item with the highest $\beta$ value was added to the initial item. Finally, the third item for each scale was chosen by regressing the sum of the two chosen items onto the remaining items and then choosing the item with the highest $\beta$ value to add to the other two items. The iterative process was aborted when either no similar additional item emerged across the 10 countries or no substantial variance was added by a subsequent item. For all three subscales, this resulted in each of the scales being best represented by three items, meaning that a total of nine items represented the construct of work engagement. The final nine items are as follows: "At my work, I feel bursting with energy" (VI), "At my job, I feel strong and vigorous" (VI), "When I get up in the morning, I feel like going to work" (VI), "I am enthusiastic about my job” (DE), "My job inspires me” (DE), "I am proud of the work that I do" (DE), "I am immersed in my work" (AB), "I get carried away when I'm working" (AB), and "I feel happy when I am working intensely" (AB). 
After confirming through the CFA that Schaufeli et al.'s (2006) condensed engagement scale fit the data better than the full scale, the nine items were used to represent engagement in all analyses that were run from that point on. The correlations between the condensed and full versions of the engagement scales are as follows: 3-item with 6-item vigor $(r=.89, \mathrm{p}<.001), 3$-item with 5 -item dedication $(r=.97, \mathrm{p}<.001), 3$ item with 6-item absorption $(r=.95, \mathrm{p}<.001)$, and 9-item with 17 -item engagement $(r=$ $.98, \mathrm{p}<.001)$. Schaufeli and Bakker $(2003)$ have argued that the total score for work engagement is more useful in empirical research due to the moderate to high correlations between the dimensions. Therefore, to achieve an overall work engagement score, the scores of all scale items were averaged as other researchers have done in the past (e.g., Sonnentag, 2003; Roberson \& Strickland, 2010). A total score for work engagement was used in the regression analyses, whereas a latent factor of engagement with the three dimensions as its indicators was used to test the conceptual model in AMOS using SEM with a path analysis technique.

During development and validation, internal consistency coefficients of Schaufeli et al.'s (2006) 9-item scale at the factor-level ranged from .78 to .79 for VI, .84 to .89 for $\mathrm{DE}$, and .72 to .73 for $\mathrm{AB}$. Other researchers have achieved high internal reliability for the overall scale of work engagement as well. Babcock-Roberson and Strickland (2010) achieved an alpha coefficient of .90 when an overall score was computed to measure work engagement. Similarly, Sonnentag (2003) achieved a coefficient of .91 when measuring work engagement as one overall construct. In my study, internal consistency coefficients for the condensed (3-item) scales of work engagement at the factor-level 
were .84 for VI, .89 for DE, and .81 for AB. An alpha coefficient of .93 was achieved for the 9-item overall construct of work engagement.

Organizational commitment. Organizational commitment was measured using the 8-item affective commitment scale from Allen and Meyer (1990). Allen and Meyer's (1990) commitment scale is composed of three separate scales: affective, normative, and continuance commitment. However, previous research (e.g., Christian, Garza, \& Slaughter, 2011; Macey \& Schneider, 2008) suggests that the affective commitment dimension is the one most closely related to work engagement, and therefore the one worth distinguishing from it. This scale measures the degree to which one is emotionally attached to the organization. More specifically, it measures the extent to which a worker identifies with, is involved in, and enjoys membership in the organization. Items were scored on a 7-point Likert scale ranging from 1 ('Strongly Disagree') to 7 ('Strongly Agree'), and four items in the scale were reverse-coded. The higher one rated on this scale, the higher their affective commitment was determined to be. Sample items include "I really feel as if this organization's problems are my own" and "This organization has a great deal of personal meaning for me." Allen and Meyer (1990) achieved an alpha coefficient of .87 while validating it, and other researchers have found similar alpha coefficients for it ranging from .82 to .87 (Meyer, Allen, \& Smith, 1993; Meyer, Irving, \& Allen, 1998). In this study, an alpha coefficient of .88 was achieved.

Job satisfaction. Job satisfaction was assessed using the abridged version of the Job in General scale (aJIG; Russell, Spitzmuller, Lin, Stanton, Smith, \& Ironson, 2004). This scale contains eight adjectives or short phrases that can be used to describe one's overall perception of their job (e.g., "Makes me content" and "Enjoyable"). Similar to 
what Madlock (2008) did in his study, a 7-point Likert scale (1 'Strongly Disagree' to 7 'Strongly Agree') was used in the current study instead of the original scale formatting (e.g., 0 'No', 1 '?/Can't Decide', 3 'Yes') in order to be more consistent with other scales in the questionnaire. A higher score on this scale reflected higher satisfaction with one's job. Three items in this scale were negatively worded and were therefore reverse-coded before analyses were run. The aJIG scale has been found to have acceptable alpha coefficients of .87 and .92 (Madlock, 2008; Russell et al., 2004). My study attained an alpha coefficient of .94 for job satisfaction.

Organizational citizenship behavior. Organizational citizenship behavior (OCB) was the other dependent variable of interest, besides work engagement, in the hierarchical regression analyses. The 20-item Organizational Citizenship Behavior Checklist (OCB-C; Fox \& Spector, 2011) was used to assess OCB. This scale contains items that measure the frequency with which an individual carries out altruistic acts directed towards the organization as well as towards the people in the organization. Separate subscale scores can be computed that reflect acts that benefit the organization $(\mathrm{OCBO})$ and acts that benefit coworkers (OCBP). Participants responded to the items on a 5-point Likert scale ranging from 1 ('Never') to 5 ('Every Day'). A higher score on this scale reflected more frequent performance of OCB. Sample items include: "Took time to advise, coach, or mentor a co-worker" and "Said good things about your employer in front of others." The alpha coefficient of this scale is sufficient as Fox et al. (in press) reported values of .89 and .94 for two self-report samples and .94 for a coworker sample (co-workers reporting on a target employee). In my study, an alpha coefficient of .92 was achieved for OCB. 
Psychological meaningfulness. Psychological meaningfulness was measured using a scale that was compiled by May et al. (2004). It consists of six items that were drawn from Spreitzer (1995) and May (2003) and assesses the degree of meaning that individuals perceive in their work-related activities. The items were scored on a 7-point Likert scale ranging from 1 ('Strongly Disagree') to 7 ('Strongly Agree'). All items are positively worded and examples of some of them are as follows: "My job activities are personally meaningful to me" and "I feel that the work I do on my job is valuable." A higher score on this scale reflected a higher degree of meaning in one's job. When May et al. (2004) first used this scale, they reported an alpha coefficient of .90. Olivier and Rothmann (2007) used this scale in their study three years later and reported an even higher coefficient of .92. In my study, an alpha coefficient of .97 was achieved.

Psychological safety. A 3-item scale created by May et al. (2004) was used to measure psychological safety. This scale measured psychological perceptions of safety, not workplace safety behaviors. The measure was created based on Kahn's (1990) work and assesses whether individuals feel comfortable being themselves and expressing their opinions at work, as well as whether they perceive a threatening environment at work. Two out of the three items were negatively worded and needed to be reverse-coded before a mean score was calculated for this construct. Examples of items found on this scale are "I'm not afraid to be myself at work" and "There is a threatening environment at work”. Items were scored on a 7-point Likert scale ranging from 1 ('Strongly Disagree') to 7 ('Strongly Agree'). After the items were appropriately coded, higher scores reflected a higher level of perceived psychological safety. When the scale was first used, May et al. (2004) achieved an alpha coefficient of .71. Recently, Chen, Zhang, and Vogel (2011) 
reported an alpha coefficient of .70 for this scale. This study achieved an alpha coefficient of .67 .

Psychological availability. Psychological availability was also measured using a scale created by May et al. (2004). This scale contains five items that measure the confidence that individuals have regarding their ability to be physically, cognitively, and emotionally available for work. This scale was created based on Kahn's (1990) work. Similar to the other scales for psychological conditions, items on this scale were scored on a 7-point Likert scale ranging from 1 ('Strongly Disagree') to 7 ('Strongly Agree'). All scale items were positively worded and did not need to be recoded prior to calculating a mean availability score. A higher score on this scale reflected that an individual was more psychologically available to perform his/her job. Example items include "I am confident in my ability to handle competing demands at work" and "I am confident in my ability to display the appropriate emotions at work." The authors of this scale reported an alpha coefficient of .85 (May et al., 2004), as did Olivier and Rothmann when they used the scale a few years later in their study (2007). This study attained an alpha coefficient of .91 .

Person-job fit. PJ fit (PJ Fit) was measured using a 9-item scale from Brkich, Jeffs, and Carless (2002). This scale measures the extent to which a fit exists between an individual's KSAs and the requirements of the job as well as the degree to which an employee's needs, desires, and preferences are met by the job. The items in this scale were scored on a 7-point Likert scale ranging from 1 ('Strongly Disagree') to 7 ('Strongly Agree'). Four of the items in this scale were negatively worded and needed be reverse-coded. Sample items include "My current job is not really me" and "My abilities, 
skills, and talents are the right type for this job". The higher one scored on this scale, the better the fit between their characteristics and needs, and the job itself. Acceptable alpha coefficients ranging between .89 and .92 have been found for this scale (Kilic, Keles, \& Gelibolu, 2010). This study achieved an alpha coefficient of .93.

Autonomy. A scale from the Questionnaire on the Experience and Assessment of Work (QEEW; Van Veldhoven \& Meijman, 1994) was used to measure respondents' level of autonomy at their job. The autonomy scale from this questionnaire consists of five items that ask participants how much freedom and influence they have over their work. Examples of some of the items are as follows: "Do you have freedom in carrying out your work activities?" and "Can you participate in the decision about when something must be completed?". Items were scored on a 4-point scale ranging from 0 ('Never') to 4 ('Always'). A higher score on this scale reflected that one has a higher level of autonomy at his or her job. Several studies have reported acceptable alpha coefficients for this scale including Schaufeli, Bakker, and Rhenen (2009), who achieved coefficients ranging from .79 to .9. This study attained an alpha coefficient of .84 .

Co-worker relations. Co-worker relations was also measured using a scale from the QEEW (Van Veldhoven \& Meijman, 1994). This 9-item scale contains questions whose content ranges from social support to outright aggressive tendencies experienced among colleagues. Items were scored on a 4-point Likert scale ranging from 0 'Never' to 4 'Always'. Example items include "Can you count on your colleagues when you encounter difficulties in your work" and "Do you experience any aggressiveness from colleagues?". Three of the items in this scale were negatively worded and needed to be reverse-coded. A higher score on this scale, after recodes were completed, was indicative 
of better relations with one's co-workers. Bakker, Van Veldhoven, and Xanthopoulou (2010) found this scale to have an alpha coefficient of .82 in their study. In this study, an alpha coefficient of .84 was achieved.

Supervisor support. A scale from the QEEW (Van Veldhoven \& Meijman, 1994) was used to assess participants' levels of supervisor support at work. The 9-item scale measures the nature of an individual's relationship with their supervisor including the extent to which he or she feels supported by and able to go to their supervisor when in need of help. All items in this scale are questions that are answered by the respondent on a 4-point scale ranging from 0 ('Never') to 4 ('Always'). Sample items from this scale are as follows: "Do you get along well with your superior?" and "If necessary, can you ask your superior for help?" Three items on this scale were reverse-coded before a mean score was calculated. A higher mean score on this scale was reflective of a better relationship with one's supervisor. Bakker, Van Veldhoven, and Xanthopoulou (2010) used this measure in their study and found its alpha coefficient to be adequate at .88 . This study found the alpha coefficient to be .91 .

Procedural justice. Procedural justice was measured using a scale created by Colquitt in 2001. This scale measures the extent to which an individual perceives the procedures used to arrive at a certain outcome in their workplace to be fair, free of bias, and open to employee input. In this particular study, perceptions of the procedures used for annual performance evaluations within an organization were assessed. There were six items (questions) in this scale to which a participant was supposed to respond regarding the procedures that are carried out regarding annual performance evaluations in their workplace. Sample items include "Have you been able to express your views and 
feelings during those procedures?" and "Have those procedures been based on accurate information?" Items were scored on a 5-point scale ranging from 1 ('To a small extent') to 5 ('To a large extent'). A high score on this scale reflected a high perception of procedural justice regarding annual performance evaluations in the workplace. Alpha coefficients of .95 (Ehrhart, 2004) and .97 (Colquitt, Noe, \& Jackson, 2002) have been achieved for this measure. In this study, an alpha coefficient of .89 was achieved.

Interactional justice. A scale created by Colquitt (2001) was also used to measure interactional justice. The scale consists of two subscales: an interpersonal justice scale to assess how the respondent is treated by an authority figure and an informational justice scale to assess the degree of explanation and communication that an individual receives from an authority figure. These questions were asked in reference to the participant's direct supervisor. The interpersonal justice scale consisted of four items including "Has he/she treated you in a polite manner?" and "Has he/she refrained from improper remarks or comments?" The informational justice scale consisted of five items including "Has he/she been candid in his/her communications with you?" and "Were his/her explanations regarding the procedures reasonable?". Both of these scales were rated on a 5-point scale ranging from 1 ('To a small extent') to 5 ('To a large extent'). The scores on each of these subscales were averaged to arrive at a final interactional justice score. A higher averaged score reflected a higher perception of interactional justice regarding the respondent's direct supervisor. Alphas reported for each of these scales have been acceptable. For the interpersonal justice subscale, Roch and Shanock (2006) achieved alpha coefficients ranging between .85 and .93 , while Judge and Colquitt (2004) obtained a coefficient of .96. With regard to the informational justice subscale, 
Roch and Shanock (2006) achieved alpha coefficients ranging between .77 and .89, whereas Judge and Colquitt (2004) achieved a coefficient of .90. Ambrose and Schminke (2003) obtained an alpha coefficient of .86 when they combined the scales to measure interactional justice. This study achieved an alpha coefficient of .93 for interactional justice.

Self-consciousness. Self-consciousness was measured using the 7-item public self-consciousness scale from the Self-Consciousness Scale (SCS; Fenigstein, Scheier, \& Buss, 1975). Public self-consciousness measures one's level of awareness of his or her self as a social object. A person that scores high on public self-consciousness is more cognizant of how he or she appears and is viewed by others. The items for this scale were rated on a 5-point scale ranging from 0 ('extremely uncharacteristic') to 4 ('extremely characteristic'). Sample items include "I'm concerned about the way I present myself" and "One of the last things I do before I leave my house is look in the mirror". Fenigstein et al. (1975) reported an alpha coefficient of .84 for this scale. Other researchers that have used this scale in studies have reported coefficients of .73 (Bogels, Alberts, \& Jong, 1996) and .74 (Ryan \& Kuczkowski, 1994). In this particular study, an alpha coefficient of .80 was achieved.

Self-efficacy. The 10-item General Self-Efficacy Scale (GSE; Schwarzer \& Jerusalem, 1995) was used to measure self-efficacy. The scale is unidimensional and assesses a general sense of perceived self-efficacy, or an optimistic self-belief that one can perform novel or difficult tasks and cope with adversity in various domains of human functioning. Items refer to successful coping and imply an internal-stable attribution of success. Participants responded to items on a 4-point scale ranging from 1 ('Not at all 
true') to 4 ('Exactly true'). Examples of some of the items contained in this scale are "I can always manage to solve difficult problems if I try hard enough" and "I can usually handle whatever comes my way". A high score on this scale is reflective of a high level of self-efficacy. In samples from 23 nations, Schwarzer and Jerusalem (1994) achieved alpha coefficients ranging from .76 to .90 , with the majority of those coefficients in the high .80 s. This study achieved an alpha coefficient of .90 .

Personality. Items from the International Personality Item Pool (IPIP; Goldberg, 1999) were used to measure the personality traits of extraversion and neuroticism. Each scale consisted of ten items that were scored on a 5-point scale ranging from 1 ('Very Inaccurate') to 5 ('Very Accurate'). The instructions for each of the scales asked respondents to describe themselves as they generally were in relation to other people of the same sex and roughly the same age. Sample items for the extraversion scale are "Am the life of the party" and "Talk to a lot of different people at parties." The scale measured the extent to which one was outgoing, talkative, and liked attention from others. Five of the items for this scale were negatively worded and needed to be reverse-coded.

The neuroticism scale is phrased as a measure of emotional stability, and therefore had to be reverse-coded. Sample items for this scale included "Am relaxed most of the time" and "Seldom feel blue". Eight items in this scale were negatively worded, meaning that a higher score reflected higher levels of neuroticism. These items could be left coded as they were since this study is interested in measuring neuroticism, not emotional stability. The two positively worded items listed above were reverse-coded so that a higher rating on these items reflected higher levels of neuroticism. A higher score on the neuroticism scale was reflective of the extent to which one is anxious, irritable, 
and depressed. Reported alpha coefficients for each of the personality scales have been adequate, at .87 for the extraversion scale and .86 for the emotional stability (neuroticism) scale (Goldberg et al., 2006). My study achieved acceptable alpha coefficients as well, at .92 for the extraversion scale and .91for the neuroticism scale. 


\section{Chapter IV}

\section{Results}

Several analyses were run in order to determine whether or not the data support the hypotheses that were proposed in the dissertation. These included the following: preliminary analyses to clean up the data and report descriptive statistics on the variables measured; a confirmatory factor analysis to determine the factor structure of work engagement; correlations and discriminant validity tests between work engagement and related constructs; structural equation modeling (SEM) to test the conceptual model; and partial model testing including individual correlations, multiple regression, and mediation analyses to test each of the individual hypotheses presented in Chapter II. The next sections will describe in detail how these analyses were carried out and what results were achieved.

\section{Preliminary analyses}

Before any of the formal hypotheses were tested, some time was spent cleaning up the dataset. This included removing lines of data that reflected insufficient responses to the test items, reverse-coding the appropriate items in the dataset, mean-scoring the scales of each of the variables included in the hypotheses, and finally, running descriptive statistics and frequencies on the data to describe the sample. With regard to removing lines of data in accordance with test item responses, any data line for those participants that did not answer all five test items correctly was removed. This ensured that the only data that were used in the formal hypotheses tests was data for those participants that were paying close attention while filling in their survey responses. Finally, there was a very little missing data in the dataset. In order to address this, regression imputation was 
used in SPSS to fill in missing data as this is the process that is recommended when less than $10 \%$ of the data is missing (Kline, 1998). With regard to data that had missing values on demographic items, these lines of data were removed from the dataset before regression imputation as it would not make sense to replace them with scores calculated from running regressions composed of other variables' scores.

\section{Confirmatory Factor Analysis}

Hypothesis 1 proposed that one factor (i.e., work engagement) would emerge from vigor, dedication, and absorption and these three subdimensions would be positively correlated with one another. In order to test the factor structure of work engagement, a Confirmatory Factor Analysis (CFA) was run using AMOS. Two models were run and compared to one another to determine which had the better model fit. The first model was a uni-factor model ("work engagement") that consisted of all 17 items of the engagement scale as indicators of one latent factor of engagement. This model is illustrated in Figure 2A. The second model, pictured in Figure 2B, was a three-factor model in which the latent variables of vigor (VI), dedication (DE), and absorption (AB) were correlated with one another. 
Figure 2A.

Uni-Factor Model of Work Engagement (17-indicators)

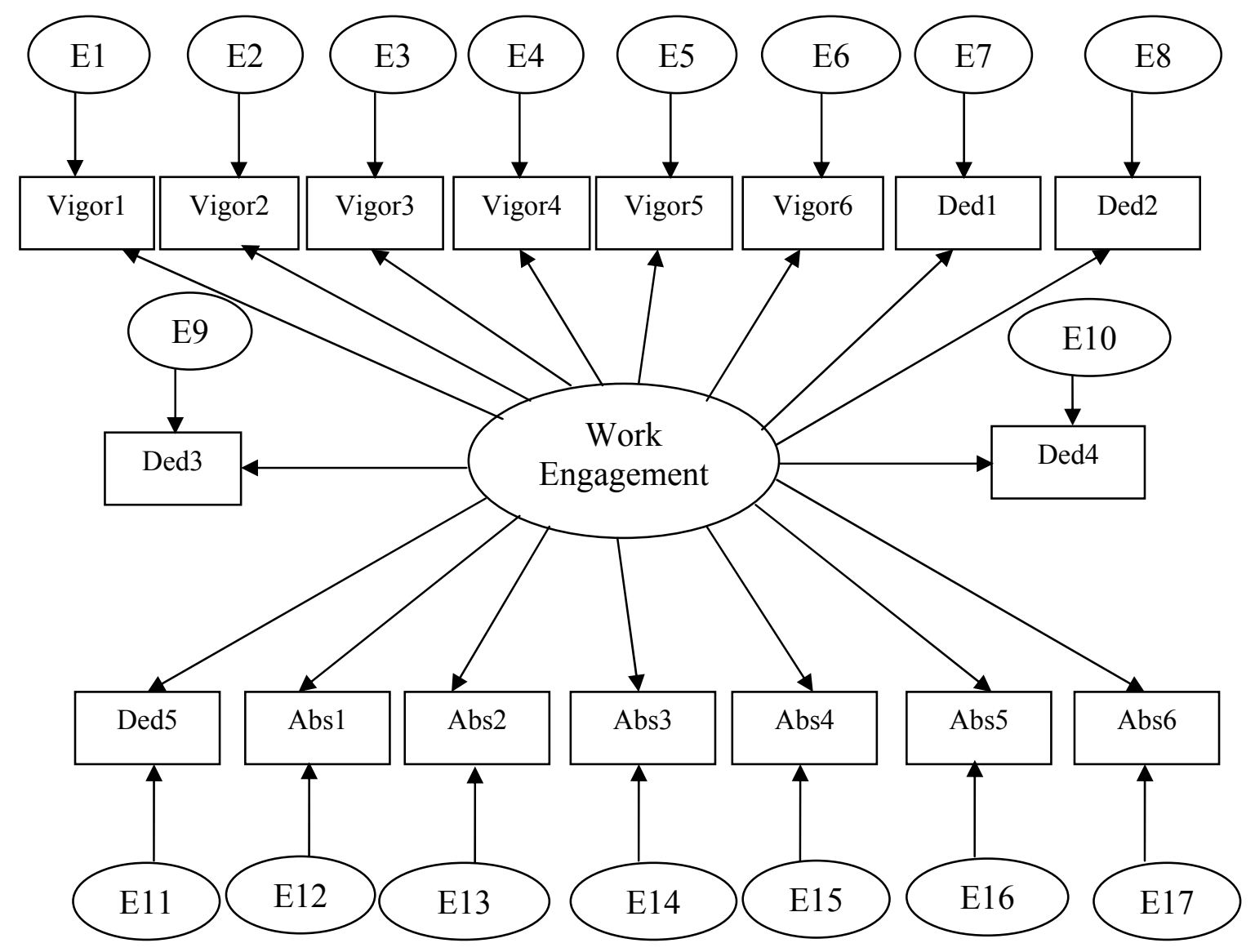


Figure 2B.

Three-Factor Model of Work Engagement (17-indicators)

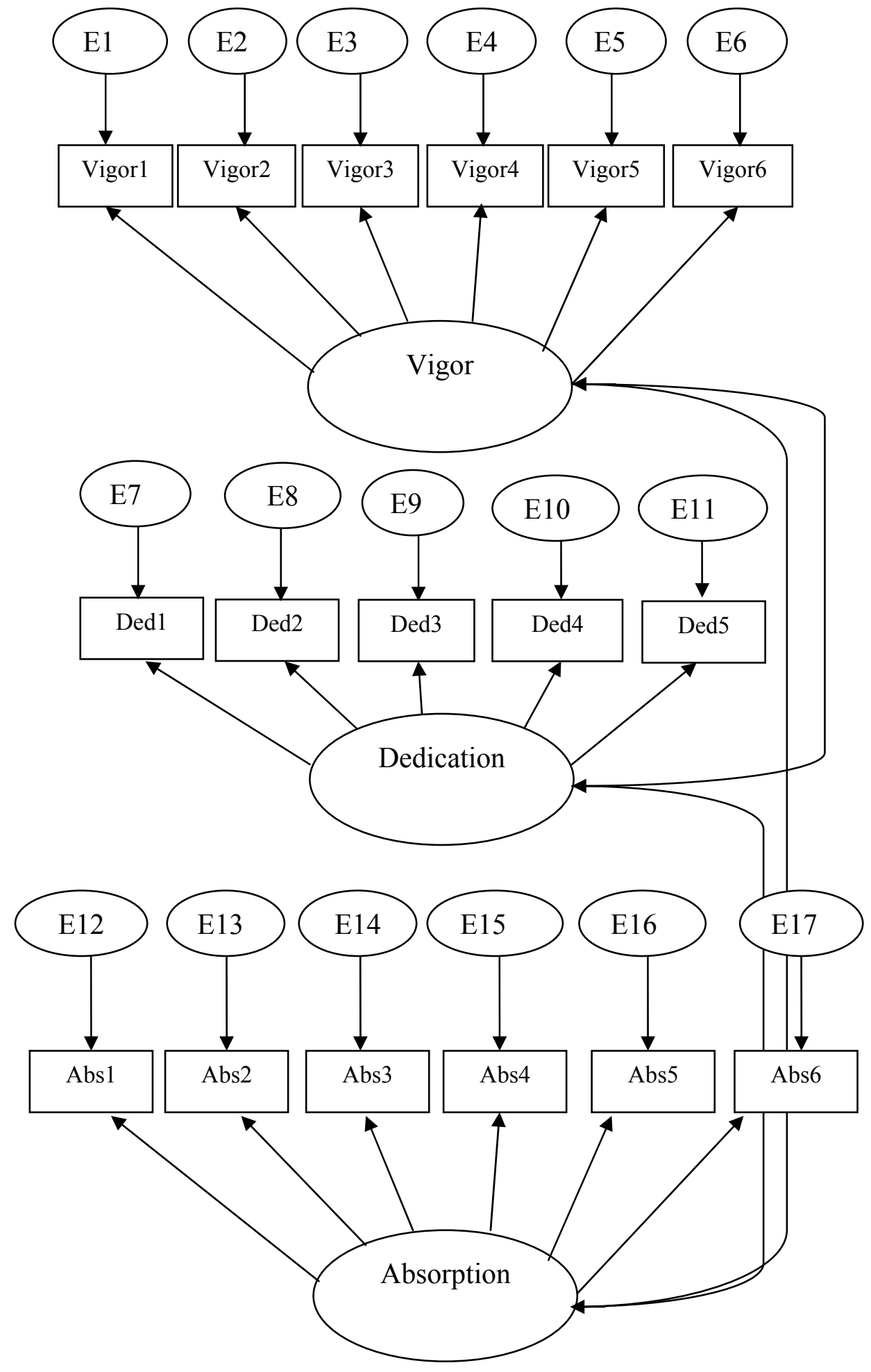


The indicators for each latent variable were the corresponding items that made up that subscale. The global fit indices that were used to determined which model achieved a better fit are as follows: the Tucker-Lewis index (TLI), comparative fit index (CFI), root-mean-square error of approximation (RMSEA), p-value for the test of close fit, standardized root mean square residual (Standardized RMR), and Akaike's information criterion (AIC). The chi-square test of model fit was not used because of the fact that for models with sample sizes larger than 400 , such as this one, the chi-square is almost always found to be statistically significant (denoting a bad model fit). In addition, chisquare is also known to be affected by the size of the correlations in the model as welllarger correlations lead to poorer model fits (Kenny, 2012). For these reasons, the AIC was used instead. AIC does not carry a penalty for sample size the way that the chisquare does. It is used when comparing two or more models estimated with the same data. Unlike performing a chi-square test to determine which model is a better fit, when using the AIC the model with the smallest AIC value is chosen as the one exemplifying a better fit of the hypothesized model and the one most likely to replicate in future samples (Byrne, 2001; Hu \& Bentler, 1995; Kline, 2011).

The TLI and CFI was indicative of a better fit as their value approached 1 , and a score of .9 or better was indicative of a good model fit. The RMSEA measures the average fitted residual. A score of less than .1 (preferably less than .08) on this measure was indicative of a good model fit (Jaccard \& Wan, 1996). A standardized root mean square residual value less than .05 was consistent with a good model fit. As previously discussed, the smaller AIC value among competing models was the one with a better model fit (Byrne, 2001; Hu \& Bentler, 1995; Kline, 2011). Modification indices greater 
than 4.0 were taken into consideration as they indicate that there are important associations in the data for which the estimated model neglected to account. Of these, however, only those pathways that made conceptual sense were incorporated into the models.

When these two models were first run, good fits were not achieved for either model, even after incorporating all modification indices greater than 4.0 that conceptually made sense. The global fit indices' results for these models are listed in Table 1. SEM is known to follow the parsimony principle, which states that "given two models with similar fit to the same data, the simpler model is preferred, assuming that the model is theoretically plausible" (Kline, 2011, p.102). Therefore, it was decided that a better fitting model would probably be one that had fewer indicators representing the latent variables. 
Table 1.

Fit Indices for CFA of Work Engagement

\begin{tabular}{|c|c|c|c|c|c|c|}
\hline Model & $\mathrm{AIC}$ & TLI & CFI & RMSEA & p-close & St. RMR \\
\hline \multicolumn{7}{|c|}{ 17-item scale } \\
\hline Uni-Factor & 813.72 & .87 & .89 & .10 & .00 & .07 \\
\hline 3-Factor & 570.90 & .92 & .93 & .08 & .00 & .05 \\
\hline \multicolumn{7}{|c|}{ 9-item scale } \\
\hline Uni-Factor & 175.10 & .95 & .96 & .09 & .00 & .03 \\
\hline 3-Factor & 102.59 & .98 & .99 & .06 & .28 & .02 \\
\hline
\end{tabular}

Note. 17 -item scale $=$ Full UWES Work Engagement Scale with 6 VI items, 5 DE items, and 6 AB items; 9-item scale $=$ Condensed Work Engagement Scale with 3 VI items, 3 DE items, and 6 AB items; AIC = Akaike's information criterion; TLI = Tucker-Lewis index; CFI = comparative fit index; RMSEA = root-mean-square error of approximation; $\mathrm{p}$-close $=\mathrm{p}$-value for test of close fit; $\mathrm{St}$. $\mathrm{RMR}=$ standardized root mean square residual. Note. Good fit is indicated by a small AIC value (relative to other models); TLI closer to 1 and $\geq .9$, CFI closer to 1 and $\geq .9$, RMSEA $<.1$ (preferably $<.08$ ), p-close $>.05$, and St. RMR $<.05$.

Note. . Uni-Factor Model $=$ Work Engagement is one latent factor with all subscale items as its indicators. 3-Factor Model $=$ Work engagement is three separate latent factors (VI, DE, and AB), with all corresponding subscale items serving as their indicators.

Note. ${ }^{*} p<.05 .{ }^{* *} p<.01$.

At this point, a study by Schaufeli et al. (2006) was consulted in which the researchers validated a shorter version of work engagement. In accordance with this article, each one of the subscales of work engagement was reduced down to 3 items. For a list of which three items were chosen for each dimension and why these items were chosen, please consult the description of the engagement measure that is provided in Chapter III of this dissertation. Also, see Table 2 for correlations between the condensed and full versions of the engagement scales, as well as their reliabilities. 
Table 2 .

Correlations between Condensed and Full Versions of Engagement Scales

\begin{tabular}{|c|c|c|c|c|c|c|c|c|}
\hline & 3-item Vigor & $\begin{array}{c}\text { 3-item } \\
\text { Dedication }\end{array}$ & $\begin{array}{c}\text { 3-item } \\
\text { Absorption }\end{array}$ & $\begin{array}{c}\text { 9-item } \\
\text { Engagement }\end{array}$ & 6-item Vigor & $\begin{array}{c}5 \text {-item } \\
\text { Dedication }\end{array}$ & $\begin{array}{c}\text { 6-item } \\
\text { Absorption }\end{array}$ & $\begin{array}{c}17 \text {-item } \\
\text { Engagemen }\end{array}$ \\
\hline 3-item Vigor & .84 & & - & - & & - & - & - \\
\hline $\begin{array}{c}\text { 3-item } \\
\text { Dedication }\end{array}$ & $.80^{* * *}$ & .89 & - & & - & - & - & - \\
\hline $\begin{array}{c}\text { 3-item } \\
\text { Absorption }\end{array}$ & $.70 * *$ & $.72 * *$ & .81 & - & - & - & - & - \\
\hline $\begin{array}{c}\text { 9-item } \\
\text { Engagement }\end{array}$ & $.91^{* *}$ & $.93^{* * *}$ & $.88^{* * *}$ & .93 & - & - & - & - \\
\hline 6-item Vigor & $.89 * *$ & $.74 * *$ & $.67 * *$ & $.84 * *$ & .81 & - & - & - \\
\hline $\begin{array}{c}5 \text {-item } \\
\text { Dedication }\end{array}$ & $.80^{* *}$ & $.97 * *$ & $.74 * *$ & $.93^{* *}$ & $.74^{* *}$ & .91 & - & - \\
\hline $\begin{array}{c}\text { 6-item } \\
\text { Absorption }\end{array}$ & $.69 * *$ & $.69 * *$ & $.95 * *$ & $.85 * *$ & $.64 * *$ & $.72 * *$ & .89 & - \\
\hline $\begin{array}{c}17 \text {-item } \\
\text { Engagement }\end{array}$ & $.88^{* * *}$ & $.90^{* *}$ & $.89^{* *}$ & $.98^{* *}$ & $.87 * *$ & $.92 * *$ & $.90^{* *}$ & .94 \\
\hline
\end{tabular}

Note. ${ }^{*} p<.05,{ }^{* *} p<.01$.

Note. Numbers on the diagonal are Cronbach's alpha (reliability) coefficients of the corresponding scale.

After reducing the one-factor model down from having 17 to 9 indicators (See Figure 2C), reducing the three-factor model from 6, 5, and 6 indicators, respectively, to 3 each on the VI, DE, and AB latent variables, (See Figure 2D), the competing models were run again in AMOS. This time, after correlating the errors on the third and fifth items in the AB scale, both models achieved an acceptable fit. However, the model that portrayed work engagement as three separate, yet correlated, factors achieved a much better fit (Table 1). 
Figure 2C.

Uni-Factor Model of Work Engagement (9-indicators)

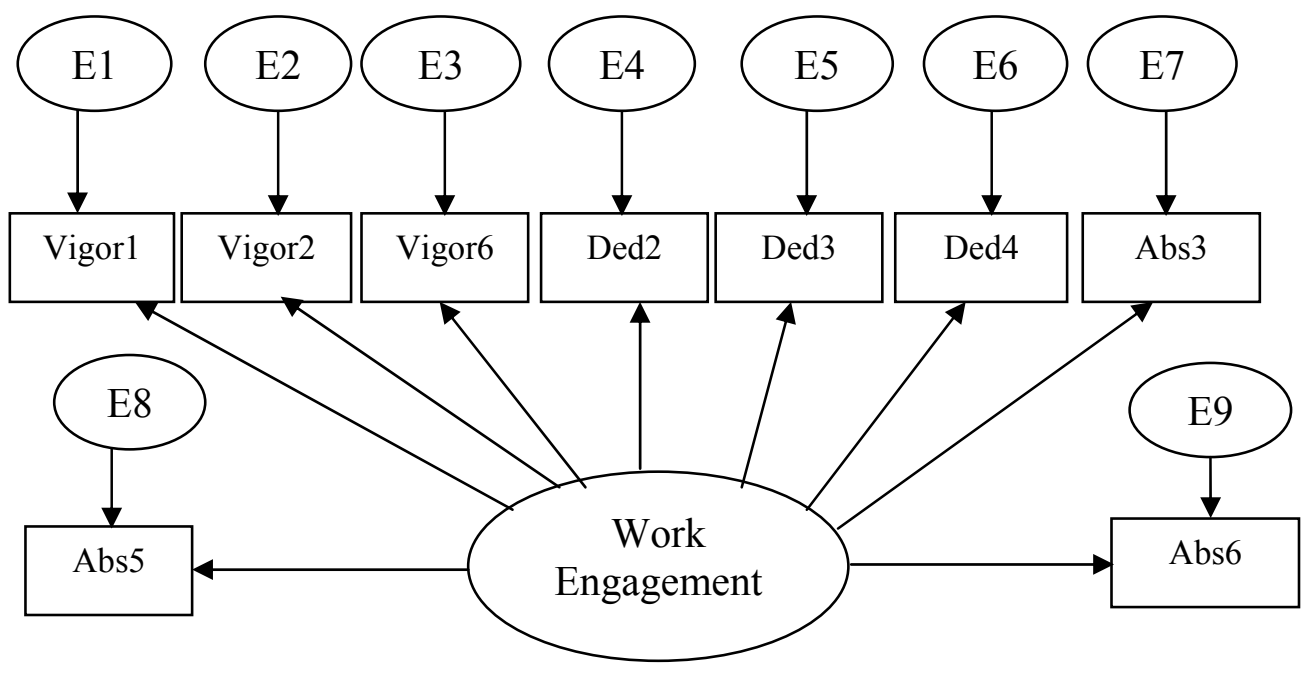


Figure 2D.

Three-Factor Model of Work Engagement (9-indicators)

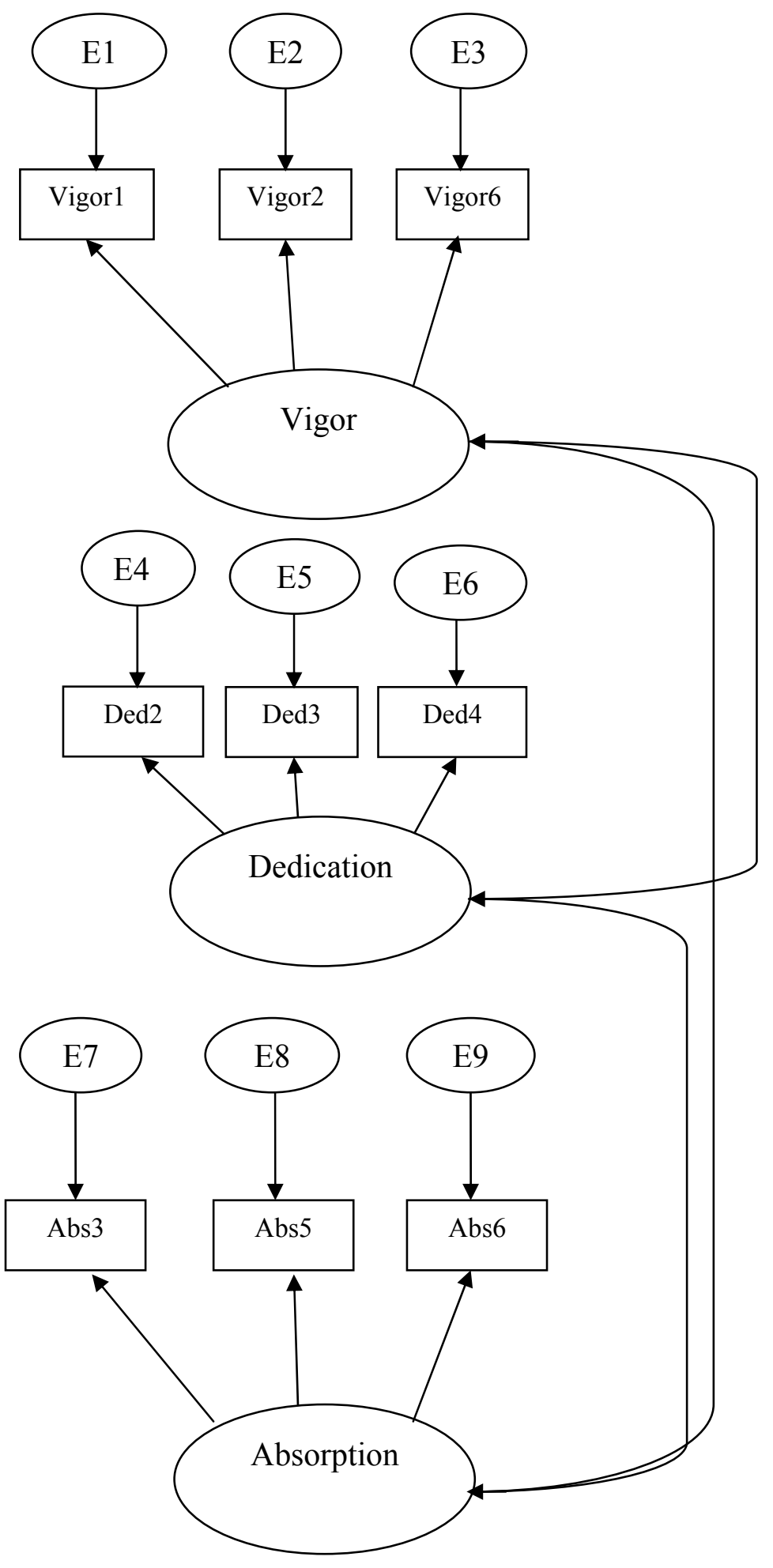


In order to test the second part of Hypothesis 1, correlations were calculated between the individual dimensions of work engagement (i.e., vigor, dedication, and absorption) to ensure that they were positively related to one another. The 9-item scale of work engagement was used for this analysis as well as all other analyses in this study from this point forward. Preliminary analyses were performed to ensure that no violation of the assumptions of normality, linearity, and homoscedasticity were present. The correlations (see Table 2) confirmed that all of the individual dimensions of work engagement had strong and positive relationships with one another. In order to determine that these correlations were not so strong as to warrant concern that these constructs are identical, reliability corrections were performed on all latent intercorrelations and these corrected correlations were compared to 1.0. The results of these calculations are presented in Table 3. One can see that all corrected correlations are less than 1.0, even after examining the $95 \%$ confidence interval of the corrected value. These findings confirm that though the correlations between the subdimensions of engagement are strong and positive, they are not indicative of these constructs being identical to one another. 
Table 3.

Reliability-Corrected Correlations between Vigor, Dedication, and Absorption

\begin{tabular}{cccc}
\hline Correlated Constructs & $r$ & $r_{c}$ & $\begin{array}{c}\text { Upper Bound } \\
95 \% \text { Confidence } \\
\text { Interval }\end{array}$ \\
\hline Vigor and Dedication & $.80^{* *}$ & .93 & .96 \\
Vigor and Absorption & $.70^{* *}$ & .85 & .89 \\
Dedication and Absorption & $.72 * *$ & & .85 \\
\hline
\end{tabular}

Note. ${ }^{*} p<.05 .{ }^{* *} p<.01$.

Hypothesis 1 stated that one factor (i.e., work engagement) would emerge from the three subdimensions of work engagement (VI, DE, and AB) and that they would all be positively correlated with one another. Only partial support was found for this hypothesis in that the three subscales of work engagement were positively correlated with one another but the three-factor model was found to be a better fit for work engagement rather than the one-factor model. These results will affect the way in which work engagement is depicted in the final path model that is to be tested.

\section{Discriminant Validity Analysis}

The next analysis that was run tested Hypotheses $2 \mathrm{a}$ and $2 \mathrm{~b}$ which addressed whether or not work engagement is distinct from two similar constructs: organizational commitment and job satisfaction. This analysis was accomplished by following a threestep process similar to the one outlined by Hallberg and Schaufeli (2006): intercorrelations between the three constructs were examined, a CFA was run to determine whether or not a three-factor model (work engagement, organizational commitment, and job satisfaction) was a better fit to the data than a uni-factor model 
(“general work attachment"), and finally, a usefulness analysis was performed to examine the unique contribution that each of the three constructs made towards OCB.

In the first step of the process, latent intercorrelations were inspected between work engagement, organizational commitment, and job satisfaction in order determine whether or not there might be conceptual overlap among them. Preliminary analyses were once again performed in order to ensure that no violation of the assumptions of normality, linearity, and homoscedasticity were present. Subsequently, latent intercorrelations were run among the constructs. The correlations (see Table 4) confirmed that organizational commitment and job satisfaction have strong and positive relationships with work engagement. In order to ensure that these relationships were not so strong as to warrant concern over conceptual overlap, reliability corrections were performed on each correlation and these corrected correlations were compared to 1.0. The results of these calculations are presented in Table 4 . One can see that the corrected correlations that work engagement exhibited with organizational commitment and job satisfaction are less than 1.0, even after examining the top bound of the $95 \%$ confidence interval of the corrected value. The relationship between organizational commitment and job satisfaction, though not of immediate interest for this study, was also very strong and positive. However, the correlation between them was not so high as to suggest that they are identical constructs. These findings confirm that although the correlations that commitment and satisfaction have with engagement are strong and positive, these constructs are distinguishable from one another. 
Table 4.

Reliability-Corrected Correlations Work Engagement, Organizational Commitment, and Job Satisfaction

\begin{tabular}{cccc}
\hline Correlated Constructs & $r$ & $r_{c}$ & $\begin{array}{c}\text { Upper Bound } \\
95 \% \text { Confidence } \\
\text { Interval }\end{array}$ \\
\hline $\begin{array}{c}\text { Work Engagement and } \\
\text { Organizational Commitment }\end{array}$ & $.74^{* *}$ & .91 & .94 \\
$\begin{array}{c}\text { Work Engagement and Job } \\
\text { Satisfaction }\end{array}$ & $.74^{* *}$ & .78 & .82 \\
$\begin{array}{c}\text { Organizational Commitment } \\
\text { and Job Satisfaction }\end{array}$ & $.73^{* *}$ & .80 & .85 \\
\hline
\end{tabular}

Note. ${ }^{*} p<.05 .{ }^{* *} p<.01$.

Following the correlations, a CFA was performed using AMOS to test whether work engagement, organizational commitment, and job satisfaction could be empirically separated. Specifically, a uni-factor model ("general work attachment") was compared to a three-factor model that specified the three distinct constructs. The uni-factor model, pictured in Figure 3A, consisted of one latent variable ("general work attachment") with 19 indicators: mean scores of vigor, dedication, and absorption, all 8 of the organizational commitment items, and all 8 of the job satisfaction items. 
Figure 3A.

Uni-Factor Model of General Work Attachment

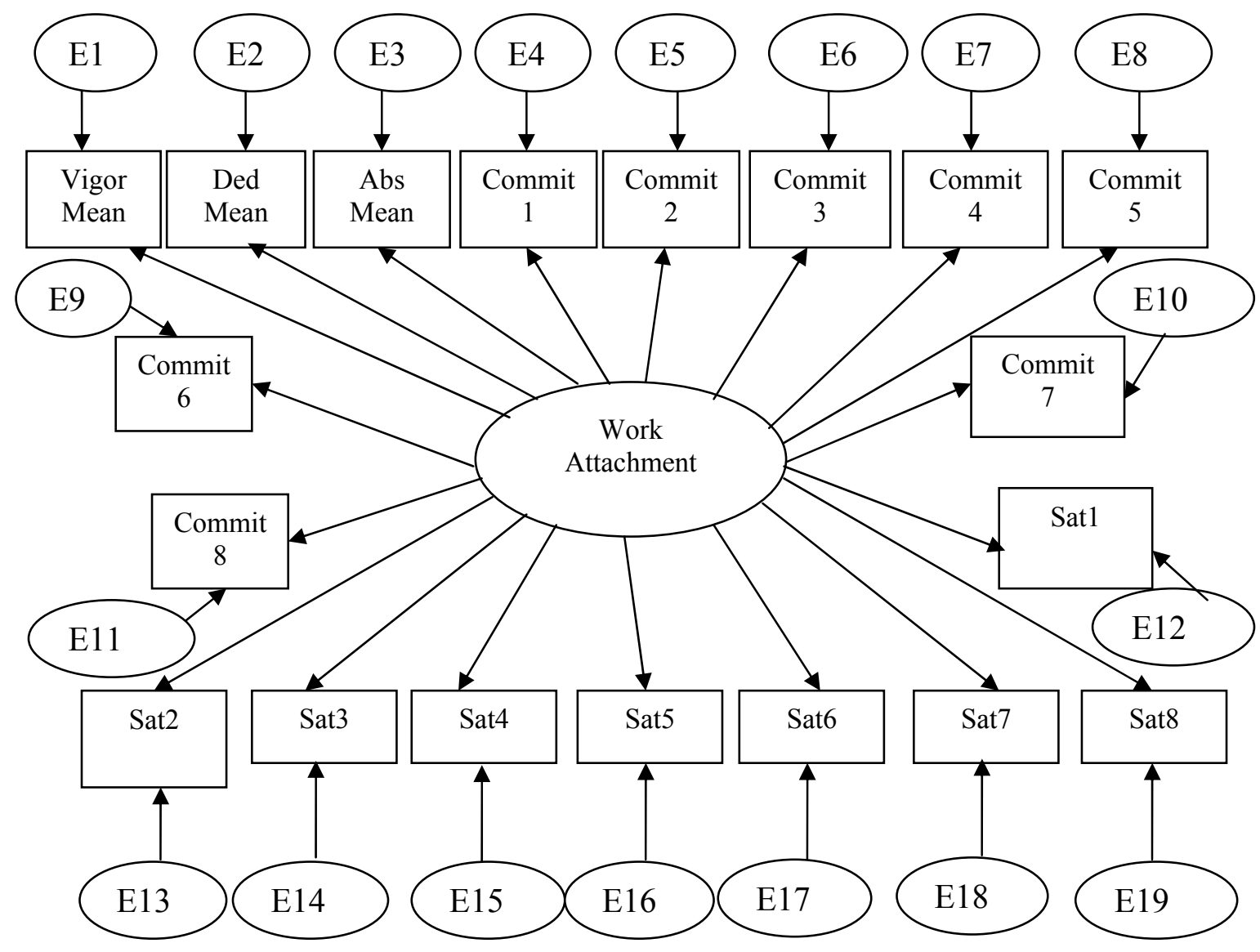

For both models, modification indices that were greater than 4.0 and suggested

paths that conceptually made sense to incorporate into the model were taken into account.

Certain errors terms of indicators were correlated, indicating that some of the covariance

in the indicators that is not explained by the latent variable is due to another exogenous

common cause (Brown, 2006). In total, thirteen covariances were incorporated into the

uni-factor model. Specifically, several error terms on the Commitment items were

correlated with one another (Commitment error terms $5 \& 6,3 \& 7,5 \& 8,6 \& 8,3 \& 6$, and $6 \& 7$ ), error terms on the Satisfaction items were correlated with each other 
(Satisfaction error terms $2 \& 4,4 \& 8,2 \& 8$, and $1 \& 8$ ), and errors on the mean scores of engagement's subscales were correlated (Error terms on vigor \& dedication, vigor \& absorption, and vigor \& absorption). This led to the achievement of a good fit to the model, with the exception that the $\mathrm{p}$-close was still significant $(\mathrm{p}<.001)$. The fit indices for this model can be found in Table 5A.

Table 5A.

Fit Indices for CFA of Engagement, Commitment, and Satisfaction

\begin{tabular}{lcccccc}
\hline Model & AIC & TLI & CFI & RMSEA & p-close & St. RMR \\
\hline Uni-Factor & 643.32 & .941 & .952 & .076 & .00 & .04 \\
3-Factor & 531.43 & .958 & .965 & .064 & .00 & .04 \\
\hline
\end{tabular}

Note. AIC =; Akaike's information criterion TLI = Tucker-Lewis index; CFI $=$ comparative fit index; RMSEA $=$ rootmean-square error of approximation; $\mathrm{p}$-close $=$ p-value for test of close fit; St. RMR = standardized root mean square residual.

Note. Good fit is indicated by a small AIC value (relative to other models); TLI closer to 1 and $\geq .9$, CFI closer to 1 and $\geq .9$, RMSEA $<.1$ (preferably $<.08$ ), p-close $>.05$, and St. RMR $<.05$.

Note. Uni-Factor Model = 'General Work Attachment' is underlying latent factor of all 3 constructs' items as indicators. 3-Factor Model $=$ Three constructs (Engagement, Commitment, Satisfaction) are three separate latent factors, with respective scale items serving as their indicators.

Note. ${ }^{*} p<.05$. ${ }^{* *} p<.01$.

The 3-factor model illustrated in Figure 3B that was tested against the uni-factor model consisted of the three latent variables of work engagement, organizational commitment, and job satisfaction, with their respective scale items or mean scores of subscales (i.e., in the case of work engagement) as indicators. Modification indices greater than 4 that made conceptual sense to incorporate into the model were taken into account, leading to the addition of seven covariances between error terms. In particular, 4 commitment error terms were correlated (Commitment error terms $5 \& 6,5 \& 8,6 \& 8$, 
and $3 \& 7$ ) and 3 satisfaction error terms were correlated with one another (Satisfaction error terms $2 \& 4,4 \& 8$, and $2 \& 8$ ). 
Figure 3B.

Three-Factor Model of Engagement, Commitment, and Satisfaction

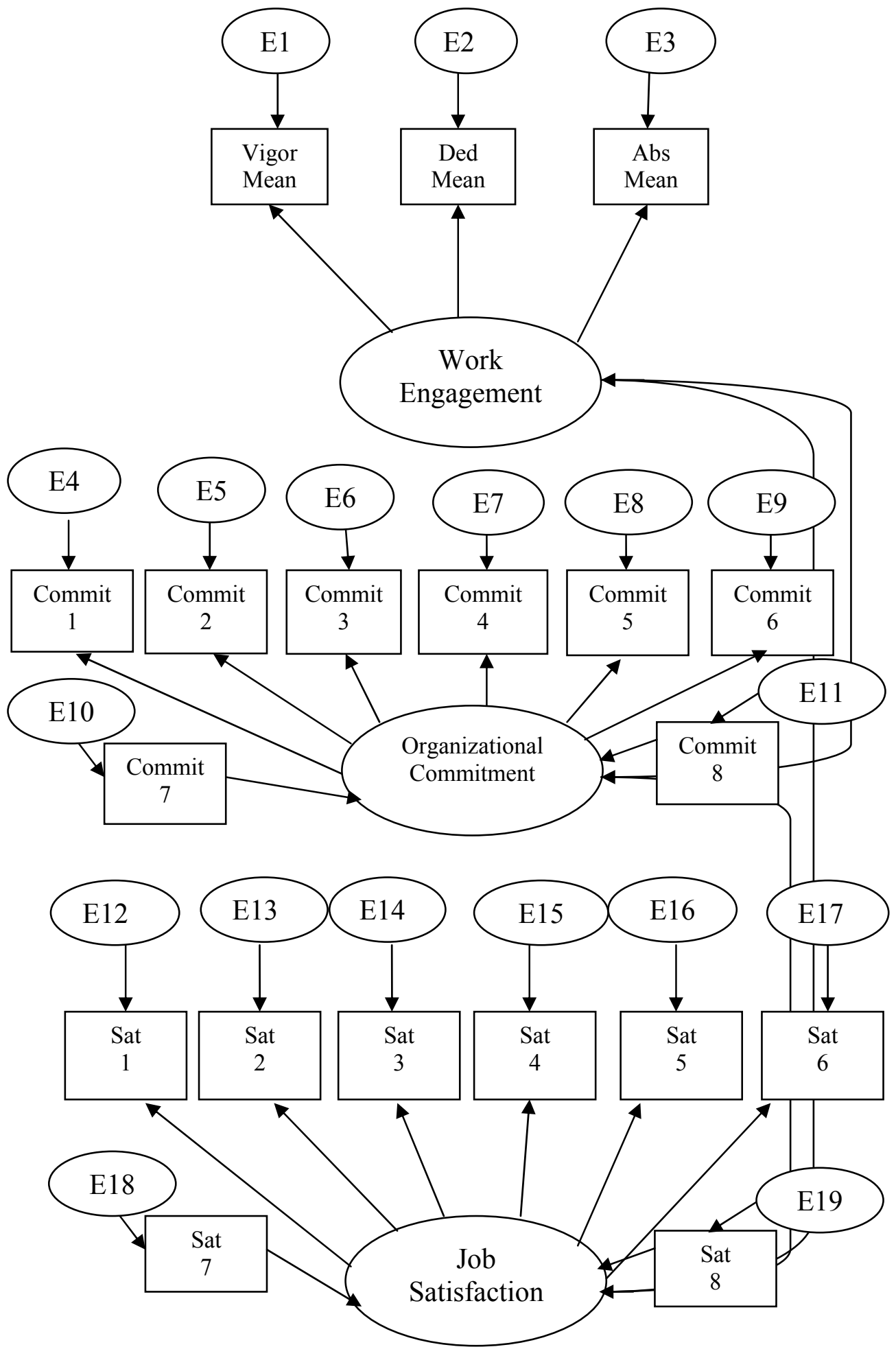


Global fit indices, presented in Table 5A, were compared between the two models in order to investigate which model was a superior fit to the data. Findings show that the three-factor model was the better fitting model between the two, despite the fact that neither model was able to achieve an adequate $\mathrm{p}$-close value. This result provides preliminary support for the argument that engagement, commitment, and satisfaction are in fact distinct from one another.

Finally, the third step in the process outlined by Hallberg and Schaufeli (2006) was to examine and compare the relationships that the three constructs have with an outcome variable, which in this study was OCB. This comparison was achieved by conducting a usefulness analysis (Darlington, 1968) to examine the unique variance that work engagement explained in OCB over and above job satisfaction and organizational commitment. In particular, two hierarchical multiple regression analyses were run in which OCB was regressed onto job satisfaction and work engagement, and then OCB was regressed onto organizational commitment and work engagement. The first analysis regressed OCB onto demographic controls, then job satisfaction, and finally work engagement. The results of this regression analysis are presented in Table 5B. 
Table 5B.

Summary of Regression Analysis to see if Engagement explains Variance in OCB over Job Satisfaction

\begin{tabular}{lccccc}
\hline \multicolumn{1}{r}{ Variable } & $\mathrm{B}$ & $\mathrm{SE} \mathrm{B}$ & $\beta$ & $\mathrm{R}^{2}$ & $\mathrm{R}^{2}$ Change \\
\hline Step 1 & & & & $.15^{* *}$ & $.01^{* *}$ \\
$\quad$ Job Satisfaction & .07 & .03 & $.14^{* *}$ & - & - \\
Step 2 & & & & $.31^{* *}$ & $.16^{* *}$ \\
$\quad$ Job Satisfaction & -.15 & .03 & $-.28^{* *}$ & - & - \\
$\quad$ Work Engagement & .36 & .03 & $.62^{* *}$ & - & - \\
\hline
\end{tabular}

Note. Dependent Variable: OCB

Note. Controls: Ethnicity, tenure, gender, work industry, weekly work hours, supervisor status, and see occupation as job or career.

Note. $\mathrm{R}^{2}$ Change in first step of each regression is the change in $\mathrm{R}^{2}$ that occurred when predictor was added to regression after the control variables were already included in the analysis.

Note. ${ }^{*} p<.05$. $* * p<.01$.

Results show that in the first step of the analysis, job satisfaction was positively related to OCB. When work engagement was added to the model, the incremental change in $R^{2}$ was significant, work engagement was positively related to OCB, and job satisfaction became negatively related to OCB. This finding demonstrates that engagement explains significant variance in OCB beyond job satisfaction (Halbesleben \& Wheeler, 2008). Furthermore, it shows that suppression effects occur when work engagement is added to the equation. These will be discussed in the next chapter of my dissertation.

In the second analysis, OCB was regressed onto demographic controls, then organizational commitment, and then work engagement. The results of this regression analysis are presented in Table 5C. 
Table 5C.

Summary of Regression Analysis to see if Engagement explains Variance in OCB over Organizational Commitment

\begin{tabular}{|c|c|c|c|c|c|}
\hline Variable & $\mathrm{B}$ & SE B & $\beta$ & $\mathrm{R}^{2}$ & $\mathrm{R}^{2}$ Change \\
\hline Step 1 & & & & $.19^{* *}$ & $.06^{* *}$ \\
\hline Organizational Commitment & .14 & .02 & $.27 * *$ & - & - \\
\hline Step 2 & & & & $.27 * *$ & $.09 * *$ \\
\hline Organizational Commitment & -.02 & .03 & -.03 & - & - \\
\hline Work Engagement & .27 & .04 & $.46^{* *}$ & - & - \\
\hline
\end{tabular}

Note. Dependent Variable: OCB

Note. Controls: Ethnicity, tenure, gender, work industry, weekly work hours, supervisor status, and see occupation as job or career.

Note. $\mathrm{R}^{2}$ Change in first step of each regression is the change in $\mathrm{R}^{2}$ that occurred when predictor was added to regression after the control variables were already included in the analysis.

Note. $* p<.05$. $* * p<.01$.

Results show that in the first step of the analysis, organizational commitment was positively related to OCB. When work engagement was added to the model, the incremental change in $R^{2}$ was significant, work engagement was positively related to OCB, and organizational commitment became non-significant. This finding demonstrates that engagement explains significant variance in OCB beyond organizational commitment. Furthermore, the fact that organizational commitment becomes non-significant when work engagement is added to the equation shows that work engagement is accounting for whatever variance organizational commitment explained in OCB.

Hypothesis 2 stated that work engagement is distinct from (a) organizational commitment and (b) job satisfaction. The results of the three-step process used to test this 
hypothesis confirm that work engagement is distinct from organizational commitment and job satisfaction. Therefore, support was found for Hypotheses $2 \mathrm{a}$ and $2 \mathrm{~b}$.

\section{Partial Model Testing}

Individual paths within the proposed research model presented in Chapter II were tested using zero-order correlations and multiple regressions. Preliminary analyses were performed prior to these analyses in order to ensure that no violations of the assumptions of normality, linearity, and/or homoscedasticity were present.

Correlations. Correlations were calculated between all variables that were hypothesized to be significantly related to one another in Chapter II (i.e., Hypotheses 316, 18-23, 25-27, and 29-32). Tables 6A, 6B, and 6C display the Pearson productmoment correlations between variables. 
Table 6A.

Correlations between Job Features, Psychological Conditions, and Work Engagement

\begin{tabular}{|c|c|c|c|c|c|c|c|c|c|c|}
\hline & $\begin{array}{l}\text { Person- } \\
\text { job fit }\end{array}$ & Autonomy & $\begin{array}{c}\text { Co- } \\
\text { worker } \\
\text { relations }\end{array}$ & $\begin{array}{l}\text { Supervisor } \\
\text { support }\end{array}$ & $\begin{array}{l}\text { Procedural } \\
\text { justice }\end{array}$ & $\begin{array}{c}\text { Interactional } \\
\text { justice }\end{array}$ & $\begin{array}{l}\text { Psych. } \\
\text { meaning. }\end{array}$ & $\begin{array}{l}\text { Psych. } \\
\text { safety }\end{array}$ & $\begin{array}{l}\text { Psych. } \\
\text { avail. }\end{array}$ & Work eng. \\
\hline \multicolumn{11}{|l|}{ Person-job fit } \\
\hline & .93 & - & - & - & - & - & - & - & - & - \\
\hline Autonomy & $57 * *$ & .84 & - & - & - & - & - & - & & \\
\hline $\begin{array}{l}\text { Co-worker } \\
\text { relations }\end{array}$ & $.41^{* *}$ & $.41^{* *}$ & .84 & - & - & - & - & - & - & - \\
\hline $\begin{array}{l}\text { Supervisor } \\
\text { support }\end{array}$ & $.49 * *$ & $.46^{* *}$ & $.74 * *$ & .91 & - & - & - & - & - & - \\
\hline $\begin{array}{l}\text { Procedural } \\
\text { justice }\end{array}$ & $.55 * *$ & $.60^{* *}$ & $.46^{* *}$ & $.55^{* *}$ & .89 & - & - & - & - & - \\
\hline $\begin{array}{l}\text { Interactional } \\
\text { justice }\end{array}$ & $.49 * *$ & $.43 * *$ & $.63^{* *}$ & $.76^{* *}$ & $.68^{* *}$ & .93 & - & - & - & - \\
\hline $\begin{array}{l}\text { Psychological } \\
\text { meaningfulness }\end{array}$ & $.83^{* *}$ & $.56^{* *}$ & $.32 * *$ & $.42^{* *}$ & $.56^{* *}$ & $.47^{* *}$ & .97 & - & - & - \\
\hline $\begin{array}{l}\text { Psychological } \\
\text { safety }\end{array}$ & $.46 * *$ & $.37^{* *}$ & $.60 * *$ & $.63 * *$ & $.39 * *$ & $.52^{* * *}$ & $.32 * *$ & .67 & - & - \\
\hline $\begin{array}{l}\text { Psychological } \\
\text { availability }\end{array}$ & $.32 * *$ & $.36 * *$ & $.47 * *$ & $.48 * *$ & $.34 * *$ & $.44^{* *}$ & $.31 * *$ & $.54 * *$ & .91 & - \\
\hline $\begin{array}{c}\begin{array}{c}\text { Work } \\
\text { engagement }\end{array}\end{array}$ & $.78^{* *}$ & $.59 * *$ & $.27 * *$ & $.37^{* *}$ & $.56^{* *}$ & $.41^{* *}$ & $.84 * *$ & $.31 * *$ & $.30^{* *}$ & .93 \\
\hline
\end{tabular}

Note. ${ }^{*} p<.05,{ }^{*} p<.01$.

Note. Numbers on the diagonal are Cronbach's alpha (reliability) coefficients of the corresponding scale. 
Table 6B.

Correlations between Personal Characteristics, Psychological Conditions, and Work Engagement

\begin{tabular}{|c|c|c|c|c|c|c|c|c|}
\hline & $\begin{array}{c}\text { Self- } \\
\text { consciousness }\end{array}$ & Self-Efficacy & Extraversion & Neuroticism & $\begin{array}{l}\text { Psychological } \\
\text { meaningfulness }\end{array}$ & $\begin{array}{l}\text { Psychological } \\
\text { safety }\end{array}$ & $\begin{array}{l}\text { Psychological } \\
\text { availability }\end{array}$ & $\begin{array}{c}\text { Work } \\
\text { engagemen }\end{array}$ \\
\hline $\begin{array}{c}\text { Self- } \\
\text { consciousness }\end{array}$ & .80 & - & - & - & - & - & - & - \\
\hline Self-efficacy & -.00 & .90 & - & - & - & - & - & - \\
\hline Extraversion & $.12 * *$ & $.27 * *$ & .92 & - & - & - & - & - \\
\hline Neuroticism & $.16^{* *}$ & $-.34^{* *}$ & $-.40^{* *}$ & .91 & - & - & - & - \\
\hline $\begin{array}{l}\text { Psychological } \\
\text { meaningfulness }\end{array}$ & .08 & $.31 * *$ & $.23 * *$ & $-.19^{* * *}$ & .97 & - & - & - \\
\hline $\begin{array}{l}\text { Psychological } \\
\text { safety }\end{array}$ & $-.23^{* *}$ & $.33^{* *}$ & .00 & $-.19^{* *}$ & $.32 * *$ & .67 & - & - \\
\hline $\begin{array}{l}\text { Psychological } \\
\text { availability }\end{array}$ & $-.09 *$ & $.56^{* *}$ & .05 & $-.18^{* *}$ & $.31 * *$ & $.54^{* *}$ & .91 & - \\
\hline $\begin{array}{c}\text { Work } \\
\text { engagement }\end{array}$ & $.11^{*}$ & $.31 * *$ & $.29^{* *}$ & $-.19 * *$ & $.84 * *$ & $.31^{* *}$ & $.30^{* *}$ & .93 \\
\hline
\end{tabular}

Note. ${ }^{*} p<.05, * * p<.01$.

Note. Numbers on the diagonal are Cronbach's alpha (reliability) coefficients of the corresponding scale. 
Table 6C.

Correlations between Job Features and Personal Characteristics

\begin{tabular}{|c|c|c|c|c|c|c|c|c|c|c|}
\hline & $\begin{array}{l}\text { Person- } \\
\text { job fit }\end{array}$ & Autonomy & $\begin{array}{c}\text { Co- } \\
\text { worker } \\
\text { relations }\end{array}$ & $\begin{array}{l}\text { Supervisor } \\
\text { support }\end{array}$ & $\begin{array}{l}\text { Procedural } \\
\text { justice }\end{array}$ & $\begin{array}{l}\text { Interactional } \\
\text { justice }\end{array}$ & Self-Consc. & $\begin{array}{l}\text { Self- } \\
\text { Eff. }\end{array}$ & Extrav. & Neurot. \\
\hline Person-job fit & & & & & & & & & & \\
\hline & .93 & - & - & - & - & - & - & - & - & - \\
\hline Autonomy & $.57^{* *}$ & .84 & - & - & - & - & - & - & - & - \\
\hline $\begin{array}{l}\text { Co-worker } \\
\text { relations }\end{array}$ & $.41^{* *}$ & $.41^{* *}$ & .84 & - & - & - & - & - & - & - \\
\hline $\begin{array}{l}\text { Supervisor } \\
\text { support }\end{array}$ & $.49 * *$ & $.46^{* *}$ & $.74 * *$ & .91 & - & - & - & - & - & - \\
\hline $\begin{array}{l}\text { Procedural } \\
\text { justice }\end{array}$ & $.55^{* *}$ & $.60^{* *}$ & $.46^{* *}$ & $.55^{* *}$ & .89 & - & - & - & - & - \\
\hline $\begin{array}{l}\text { Interactional } \\
\text { justice }\end{array}$ & $.49 * *$ & $.43 * *$ & $.63 * *$ & $.76^{* *}$ & $.68^{* *}$ & .93 & - & - & - & - \\
\hline $\begin{array}{c}\text { Self- } \\
\text { Consciousness }\end{array}$ & -.05 & .00 & $-.13^{* *}$ & $-.11^{*}$ & .04 & .02 & .80 & - & - & - \\
\hline Self-Efficacy & $.26 * *$ & .36 ** & $.36^{* *}$ & $.34 * *$ & $.39 * *$ & $.40^{* *}$ & -.00 & .90 & - & - \\
\hline Extraversion & $.20^{* *}$ & $.20^{* *}$ & .05 & .04 & $.23 * *$ & .05 & $.12^{* *}$ & $.27 * *$ & .92 & - \\
\hline Neuroticism & $-.23^{* *}$ & $-.16^{* * *}$ & $-.21 * *$ & $-.18^{* *}$ & $-.19 * *$ & $-.12^{* * *}$ & $.16^{* *}$ & $-.34 * *$ & $-.40^{* *}$ & .91 \\
\hline
\end{tabular}

Note. Self-Consc $=$ Self-Consciousness, Self-Eff. $=$ Self-Efficacy, Neurot. $=$ Neuroticism, Extrav. $=$ Extraversion.

Note. ${ }^{*} p<.05, * * p<.01$.

Note. Numbers on the diagonal are Cronbach's alpha (reliability) coefficients of the corresponding scale.

Correlations with work engagement. Hypotheses 3 through 7 predicted that all job features would be positively correlated with work engagement. According to results from correlation analyses, all of these hypotheses were supported (see Table 6A). PJ fit exemplified an exceptionally strong relationship with work engagement, providing strong support for Hypothesis 3. Autonomy and procedural justice exhibited strong relationships with work engagement, lending support for both Hypothesis 4 and Hypothesis 7a. 
Finally, co-worker relations, supervisor support, and interactional justice each demonstrated moderately strong relationships with work engagement, providing support for Hypothesis 5, Hypothesis 6, and Hypothesis 7b.

Hypotheses 8 through 10 made propositions regarding the relationships that personal characteristics would exemplify with work engagement. Correlation analyses results relevant to these hypotheses are presented in Table 6B. Hypothesis 8 and Hypothesis $10 \mathrm{~b}$ predicted that self-consciousness and neuroticism would exhibit negative relationships with work engagement. Of these two, support was only found for a negative relationship between neuroticism and engagement (Hypothesis 10b). Contrary to expectations, self-consciousness exhibited a small significant and positive relationship with engagement. Hypothesis 9 and Hypothesis 10a predicted that self-efficacy and extraversion would be positively related to work engagement. According to correlation results, these hypotheses were supported—both self-efficacy and extraversion displayed moderately strong positive relationships with work engagement.

Hypotheses 11, 18, and 29 concerned the relationships that the psychological conditions have with work engagement. Correlation results for these hypotheses can be found in Table $6 \mathrm{~A}$ or $6 \mathrm{~B}$. Hypothesis 11 proposed that meaningfulness would be positively related to engagement. Support was found for this hypothesis in that the relationship between meaningfulness and engagement was extremely strong, even as high as to warrant concern that these two constructs might be one in the same. Hypothesis 18 proposed that there would be a positive relationship between psychological safety and work engagement. This hypothesis was supported in that safety exhibited a moderately strong positive relationship with engagement. Finally, Hypothesis 29 predicted that 
psychological availability would be positively related to work engagement. Once again, support was found for this hypothesis as availability displayed a moderately strong positive relationship with engagement.

Correlations with psychological conditions. Hypotheses 12 through 16 proposed that all job features would be positively related to psychological meaningfulness. All of these hypotheses were supported and their specific correlation results can be found in Table 6A. The relationship between PJ fit and meaningfulness was exceptionally large and in the hypothesized direction. Other job features displayed moderate to large positive relationships with meaningfulness.

Hypotheses 19 through 23 predicted that all job features would be positively related to psychological safety. The correlation results relevant to these hypotheses can be found in Table 6A. All of these hypotheses were also supported, with especially strong positive correlation coefficients found between safety and the job features of coworker relations and supervisor support. Moderate to strong positive correlation coefficients were found between safety and all other job features.

Psychological safety was also predicted to be significantly related to the personal characteristics. Correlation results for these can be found in Table 6B. Hypotheses 25 and $27 \mathrm{~b}$ proposed that self-consciousness and neuroticism would be negatively related to safety. Support was found for both of these hypotheses in that both personal characteristics exemplified significant, albeit small, negative relationships with psychological safety. Hypotheses 26 and 27a predicted that the two other personal characteristics, self-efficacy and extraversion, would be positively related to safety. Out of these two, only Hypothesis 26 was supported as a moderately sized significant and 
positive correlation existed between self-efficacy and safety. Extraversion was not significantly related to safety.

Finally, the personal characteristics measured in this study were predicted to be significantly related to psychological availability. Specifically, Hypotheses 30 and $32 \mathrm{~b}$ proposed that self-consciousness and neuroticism would exemplify negative relationships with availability, while Hypotheses 31 and 32a predicted that self-efficacy and extraversion would be positively related to availability. The correlation results relevant to these hypotheses can be found in Table 6B. Similar to results for their relationships with safety, findings provide support for hypothesized relationships between availability and self-consciousness, self-efficacy, and neuroticism, but not extraversion. Selfconsciousness and neuroticism were negatively related, while self-efficacy was positively related to psychological availability.

Testing blocks of antecedents using multiple regression. Multiple regressions were then run on blocks of antecedents to see how they functioned as a group in explaining variance in the outcome variable. For example, one of the analyses regressed the outcome variable of psychological meaningfulness onto all job features in the model. Results from this analysis enabled the researcher to see how much of the variance in meaningfulness each of the individual predictors explained, taking all other variables in the analysis into consideration. In particular, five regressions of this nature were run to test meaningfulness as an outcome of job features, safety as an outcome of job features, safety as an outcome of personal characteristics, availability as an outcome of personal characteristics, and work engagement as an outcome of meaningfulness, safety, and availability. The results of these analyses will now be discussed. 
Meaningfulness as an outcome of job features. The first multiple regression tested meaningfulness onto the job features of PJ fit, autonomy, coworker relations, supervisor support, procedural justice, and interactional justice. The results for this regression are presented in Table 7A.

Table 7A.

Summary of Hierarchical Regression Analysis Testing Job Features as a Block Explaining Variance in Meaningfulness and Safety

\begin{tabular}{|c|c|c|c|c|c|}
\hline Variable & B & SE B & $\beta$ & $\mathrm{R}^{2}$ & $\begin{array}{c}\mathrm{R}^{2} \\
\text { Change } \\
\end{array}$ \\
\hline \multicolumn{6}{|c|}{ Dependent variable: Psychological Meaningfulness } \\
\hline & & & & $.71 * *$ & $.44 * *$ \\
\hline Person-Job Fit & .73 & .04 & $.70^{* *}$ & - & - \\
\hline Autonomy & .24 & .08 & $.11 * *$ & - & - \\
\hline Coworker & -.22 & .11 & $-.08^{*}$ & - & - \\
\hline Supervisor & -.08 & .10 & -.04 & - & - \\
\hline Procedural Justice & .11 & .06 & .07 & - & - \\
\hline Interactional Justice & .17 & .07 & $.10^{*}$ & - & - \\
\hline \multicolumn{6}{|c|}{ Dependent variable: Psychological Safety } \\
\hline & & & & $.48 * *$ & $.38^{* *}$ \\
\hline Person-Job Fit & .24 & .05 & $.25 * *$ & - & - \\
\hline Autonomy & .08 & .09 & .04 & - & - \\
\hline Coworker & .58 & .13 & $.23 * *$ & - & - \\
\hline Supervisor & .62 & .12 & $.32 * *$ & - & - \\
\hline Procedural Justice & -.02 & .08 & -.01 & - & - \\
\hline Interactional Justice & .00 & .09 & .00 & - & - \\
\hline
\end{tabular}

Note. Controls: Ethnicity, tenure, gender, work industry, weekly work hours, supervisor status, and see occupation as job or career.

Note. ${ }^{*} p<.05 . * * p .01$. 
Appropriate demographics (noted below the table) were controlled for so that the researcher could really hone in on the relationships that the job features had with meaningfulness. Results show that job features and demographics accounted for $71 \%$ of the variance in meaningfulness. PJ fit exhibited the strongest positive relationship with meaningfulness, while supervisor support and procedural justice were not significantly related and co-worker relations was significantly negatively related to meaningfulness. Autonomy and interactional justice displayed significant, albeit small, positive relationships with meaningfulness. Some of the unexpected results in this analysis could be due to multicollinearity issues as the job features were highly correlated with one another.

Safety as an outcome of job features. The next multiple regression that was run in this series was one that tested safety as an outcome of job features. Psychological safety was regressed onto all job features while controlling for appropriate demographics. The results of this analysis are outlined in the bottom half of Table 7A. As a group, job features and demographics explained $48 \%$ of the variance in psychological safety. Supervisor support had the strongest positive relationship with safety. PJ fit and coworker relations were also found to be positively related to safety in this analysis. However, autonomy, procedural justice, and interactional justice were not.

Safety as an outcome of personal characteristics. Psychological safety was also tested as an outcome of personal characteristics using multiple regression. The results for this analysis are presented in Table 7B. As a group, self-consciousness, self-efficacy, extraversion, neuroticism, and relevant demographics accounted for $23 \%$ of the variance in safety. As anticipated, self-consciousness and neuroticism were both found to be 
negatively related to safety, whereas self-efficacy exhibited a positive relationship with this psychological condition. No relationship was found to exist between extraversion and safety.

Table 7B.

Summary of Hierarchical Regression Analysis Testing Personal Characteristics as a Block Explaining Variance in Safety and Availability

\begin{tabular}{|c|c|c|c|c|c|}
\hline Variable & $\mathrm{B}$ & SE B & $\beta$ & $\mathrm{R}^{2}$ & $\mathrm{R}^{2}$ Change \\
\hline \multicolumn{6}{|c|}{ Dependent variable: Psychological Safety } \\
\hline & & & & $.23 * *$ & $.14^{* *}$ \\
\hline Self-Consciousness & -.28 & .07 & $\overline{-}^{-} .17^{* *}$ & - & - \\
\hline Self-Efficacy & .66 & .10 & $.30 * *$ & - & - \\
\hline Extraversion & -.09 & .07 & -.07 & - & - \\
\hline Neuroticism & -.16 & .07 & $-.11 *$ & - & - \\
\hline \multicolumn{6}{|c|}{ Dependent variable: Psychological Availability } \\
\hline & & & & $.35^{* *}$ & $.30 * *$ \\
\hline Self-Consciousness & -.04 & .04 & -.04 & & - \\
\hline Self-Efficacy & .82 & .06 & $.57 * *$ & & - \\
\hline Extraversion & -.06 & .04 & -.06 & & - \\
\hline Neuroticism & -.04 & .04 & -.04 & & - \\
\hline
\end{tabular}

Note. Controls: Ethnicity, tenure, gender, work industry, weekly work hours, supervisor status, and see occupation as job or career.

Note. ${ }^{*} p<.05$. $* * p<.01$.

Availability as an outcome of personal characteristics. Finally, personal characteristics were also tested as a block predicting psychological availability. Results are presented in the bottom half of Table 7B and show that the personal characteristics and demographics explained $35 \%$ of the variance in psychological availability. 
Unfortunately, only self-efficacy was found to have a significant and positive effect on availability. All other personal characteristics were not significantly related to this psychological condition.

Work engagement as an outcome of the psychological conditions. The final multiple regression tested the predictive value of all three psychological conditions (meaningfulness, safety, and availability) on work engagement. The results for this analysis are presented in Table 7C. According to the findings, the three psychological conditions and demographics explain $73 \%$ of the variance in work engagement. What is striking about this analysis is how large the effect size of the relationship between meaningfulness and work engagement was, $\beta=.75, p<.01$. Accordingly, meaningfulness is a very strong predictor of work engagement, even after taking other psychological conditions' effects on engagement into account. Safety had a significant and positive effect on work engagement, though it was very small. Availability was not significantly related to work engagement in this analysis. 
Table 7C.

Summary of Hierarchical Regression Analysis Testing the Psychological Conditions as a Block Explaining Variance in Work Engagement

\begin{tabular}{lccccc}
\hline Variable & $\mathrm{B}$ & $\mathrm{SE} \mathrm{B}$ & $\beta$ & $\mathrm{R}^{2}$ & $\mathrm{R}^{2}$ Change \\
\hline & & & & & \\
& & & & $.73^{* *}$ & $.48^{* *}$ \\
Meaningfulness & .62 & .02 & $.76^{* *}$ & - & - \\
Safety & .07 & .03 & $.07^{*}$ & - & - \\
Availability & .07 & .04 & .05 & - & - \\
\hline
\end{tabular}

Note. Controls: Ethnicity, tenure, gender, work industry, weekly work hours, supervisor status, and see occupation as job or career.

Note. ${ }^{*} p<.05 . * * p .01$.

Mediation analyses. Finally, the mediation hypotheses presented in Chapter II (i.e., Hypotheses 17, 24, 28, and 33) were tested using Baron and Kenny's (1986) procedure for testing mediation. This approach required that three regression analyses be run for each assessment of mediation: first, the mediator was regressed onto the independent variable; then, the dependent variable was regressed onto the independent variable; and finally, the dependent variable was regressed onto the independent variable and the mediator. Mediation was established when results showed that the mediator was significantly affected by the independent variable in the first analysis, the dependent variable was affected by the independent variable in the second analysis, and the dependent variable was affected by the mediator and independent variable in the third analysis. Furthermore, the effect of the independent variable on the dependent variable had to be less in the third analysis than in the second. According to Baron and Kenny (1986), perfect mediation is present if all of these conditions hold in the predicted 
direction and the independent variable has no effect on the dependent variable when the mediator is controlled for (i.e., included in the model). If instead the independent variable's effect on the dependent variable is merely reduced once the mediator is entered into the model (i.e., its $\mathrm{p}$-value and/or $\beta$ coefficient decreases), then partial mediation is occurring.

Psychological meaningfulness as a mediator. Hypothesis 17 predicted that psychological meaningfulness would mediate the relationship between job features and work engagement. In order to test this hypothesis, a mediation test was performed for each individual job feature, testing whether or not psychological meaningfulness was a mediator between that predictor and work engagement. The reason that this and other mediation hypotheses were tested in this particular fashion, as opposed to testing all predictors at once, is because several job features were very highly correlated with one another (see Table 6A). Regression analyses in which all job features were included as predictors of meaningfulness and work engagement resulted in multicollinearity issues, causing the results to be misleading. For example, variables that were expected to be positively related to meaningfulness and work engagement exemplified negative or null relationships with these variables when included with variables with which they were highly correlated. Therefore, individual tests of mediation for each predictor were performed instead.

The first mediation test that was performed was one in which psychological meaningfulness was tested as a mediator between PJ fit and work engagement. The results for this analysis are presented in Table 8A. 
Table 8A.

Summary of Hierarchical Regression Analysis Testing the Mediating Role of Meaningfulness between Person-Job Fit and Work Engagement

\begin{tabular}{|c|c|c|c|c|c|}
\hline Variable & $\mathrm{B}$ & SE B & $\beta$ & $\mathrm{R}^{2}$ & $\mathrm{R}^{2}$ Change \\
\hline \multicolumn{6}{|c|}{ Dependent Variable: Meaningfulness } \\
\hline & & & & $.70 * *$ & $.42 * *$ \\
\hline Person-Job Fit & .82 & .03 & $.79 * *$ & - & - \\
\hline \multicolumn{6}{|c|}{ Dependent Variable: Work Engagement } \\
\hline Step 1 & & & & $.63 * *$ & $.38 * *$ \\
\hline Person-Job Fit & .64 & .03 & $.76^{* *}$ & - & - \\
\hline Step 2 & & & & $.75 * *$ & $.11 * *$ \\
\hline Person-Job Fit & .23 & .04 & $.27 * *$ & - & - \\
\hline Psychological Meaningfulness & .50 & .03 & $.61 * *$ & - & - \\
\hline
\end{tabular}

Note. Controls: Ethnicity, tenure, gender, work industry, weekly work hours, supervisor status, and see occupation as job or career.

Note. $\mathrm{R}^{2}$ Change in first step of each regression is the change in $\mathrm{R}^{2}$ that occurred when predictor was added to regression after the control variables were already included in the analysis.

Note. ${ }^{*} p<.05 . * * p<.01$.

The top part of Table 8A presents the regression results of the first step of Baron and Kenny’s (1986) procedure for testing mediation: psychological meaningfulness was regressed onto PJ fit. This relationship was significant. Hence, the first condition for mediation according to Baron and Kenny (1986) was met. The second half of Table 8A presents the results for the second and third conditional tests of mediation. Findings support the second condition, showing that when work engagement was regressed onto PJ fit, the relationship was significant. Finally, the third condition for mediation was met, showing that when the meaningfulness was added to the regression, the relationship between PJ fit and work engagement decreased. Specifically, PJ fit's beta value decreased from .75 to .27 . Though the beta value decreased in this particular step in the 
analysis, the p-value did not. Therefore, these results provide support for the assertion that meaningfulness is a partial mediator of the relationship between PJ fit and work engagement.

All other mediation tests that were run to determine whether or not meaningfulness mediated the relationship between job features and work engagement had similar results to those found for PJ fit. Evidence of partial mediation by psychological meaningfulness between job features and work engagement was found for autonomy, coworker relations, supervisor support, procedural justice, and interactional justice. These results are presented in Tables $8 \mathrm{~B}, 8 \mathrm{C}, 8 \mathrm{D}, 8 \mathrm{E}$, and $8 \mathrm{~F}$.

\section{Table 8B.}

Summary of Hierarchical Regression Analysis Testing the Mediating Role of Meaningfulness between Autonomy and Work Engagement

\begin{tabular}{|c|c|c|c|c|c|}
\hline Variable & $\mathrm{B}$ & SE B & $\beta$ & $\mathrm{R}^{2}$ & $\mathrm{R}^{2}$ Change \\
\hline \multicolumn{6}{|c|}{ Dependent Variable: Meaningfulness } \\
\hline & & & & $.42 * *$ & $.15^{* *}$ \\
\hline Autonomy & .94 & .09 & $.43 * *$ & - & - \\
\hline \multicolumn{6}{|c|}{ Dependent Variable: Work Engagement } \\
\hline Step 1 & & & & $.44 * *$ & $.18^{* *}$ \\
\hline Autonomy & .86 & .07 & $.48 * *$ & - & - \\
\hline Step 2 & & & & $.75^{* *}$ & $.30 * *$ \\
\hline Autonomy & .30 & .05 & $.17 * *$ & - & - \\
\hline Psychological Meaningfulness & .59 & .03 & $.73 * *$ & - & - \\
\hline
\end{tabular}

Note. Controls: Ethnicity, tenure, gender, work industry, weekly work hours, supervisor status, and see occupation as job or career.

Note. $\mathrm{R}^{2}$ Change in first step of each regression is the change in $\mathrm{R}^{2}$ that occurred when predictor was added to regression after the control variables were already included in the analysis. Note. ${ }^{*} p<.05 .{ }^{*} p<.01$. 
Table 8C.

Summary of Hierarchical Regression Analysis Testing the Mediating Role of Meaningfulness between Co-Worker Relations and Work Engagement

\begin{tabular}{|c|c|c|c|c|c|}
\hline Variable & $\mathrm{B}$ & SE B & $\beta$ & $\mathrm{R}^{2}$ & $\mathrm{R}^{2}$ Change \\
\hline \multicolumn{6}{|c|}{ Dependent Variable: Meaningfulness } \\
\hline & & & & $.35^{* *}$ & $.07 * *$ \\
\hline Co-Worker Relations & .80 & .11 & $.29 * *$ & - & - \\
\hline \multicolumn{6}{|c|}{ Dependent Variable: Work Engagement } \\
\hline Step 1 & & & & $.33 * *$ & $.07 * *$ \\
\hline Co-Worker Relations & .62 & .09 & $.27 * *$ & - & - \\
\hline Step 2 & & & & $.73 * *$ & $.41 * *$ \\
\hline Co-Worker Relations & .10 & .06 & .04 & - & - \\
\hline Psychological Meaningfulness & .65 & .02 & $.79 * *$ & - & - \\
\hline
\end{tabular}

Note. Controls: Ethnicity, tenure, gender, work industry, weekly work hours, supervisor status, and see occupation as job or career.

Note. $\mathrm{R}^{2}$ Change in first step of each regression is the change in $\mathrm{R}^{2}$ that occurred when predictor was added to regression after the control variables were already included in the analysis.

Note. ${ }^{*} p<.05$. ${ }^{* *} p<.01$. 
Table 8D.

Summary of Hierarchical Regression Analysis Testing the Mediating Role of Meaningfulness between Supervisor Support and Work Engagement

\begin{tabular}{|c|c|c|c|c|c|}
\hline Variable & $\mathrm{B}$ & SE B & $\beta$ & $\mathrm{R}^{2}$ & $\mathrm{R}^{2}$ Change \\
\hline \multicolumn{6}{|c|}{ Dependent Variable: Meaningfulness } \\
\hline Supervisor Support & .78 & .08 & $.36^{* *}$ & $\begin{array}{c}40^{* *} \\
-\end{array}$ & $\begin{array}{c}.12 * * \\
-\end{array}$ \\
\hline \multicolumn{6}{|c|}{ Dependent Variable: Work Engagement } \\
\hline Step 1 & & & & $.36^{* *}$ & $.10 * *$ \\
\hline Supervisor Support & .60 & .07 & $.34 * *$ & - & - \\
\hline Step 2 & & & & $.73 * *$ & $.37 * *$ \\
\hline Supervisor Support & .10 & .05 & $.06^{*}$ & - & - \\
\hline Psychological Meaningfulness & .64 & .03 & $.78 * *$ & - & - \\
\hline
\end{tabular}

Note. Controls: Ethnicity, tenure, gender, work industry, weekly work hours, supervisor status, and see occupation as job or career.

Note. $\mathrm{R}^{2}$ Change in first step of each regression is the change in $\mathrm{R}^{2}$ that occurred when predictor was added to regression after the control variables were already included in the analysis.

Note. ${ }^{*} p<.05 .{ }^{* *} p<.01$. 


\section{Table 8E.}

Summary of Hierarchical Regression Analysis Testing the Mediating Role of Meaningfulness between Procedural Justice and Work Engagement

\begin{tabular}{|c|c|c|c|c|c|}
\hline Variable & $\mathrm{B}$ & SE B & $\beta$ & $\mathrm{R}^{2}$ & $\mathrm{R}^{2}$ Change \\
\hline \multicolumn{6}{|c|}{ Dependent Variable: Meaningfulness } \\
\hline & & & & $.44 * *$ & $.17 * *$ \\
\hline Procedural Justice & .68 & .06 & $.44 * *$ & - & - \\
\hline \multicolumn{6}{|c|}{ Dependent Variable: Work Engagement } \\
\hline Step 1 & & & & $.42 * *$ & $.17 * *$ \\
\hline Procedural Justice & .57 & .05 & $.44 * *$ & - & - \\
\hline Step 2 & & & & $.73 * *$ & $.31 * *$ \\
\hline Procedural Justice & .15 & .04 & $.12 * *$ & - & - \\
\hline Psychological Meaningfulness & .61 & .03 & $.75 * *$ & - & - \\
\hline
\end{tabular}

Note. Controls: Ethnicity, tenure, gender, work industry, weekly work hours, supervisor status, and see occupation as job or career.

Note. $\mathrm{R}^{2}$ Change in first step of each regression is the change in $\mathrm{R}^{2}$ that occurred when predictor was added to regression after the control variables were already included in the analysis. Note. ${ }^{*} p<.05 .{ }^{*} p<.01$. 
Table 8F.

Summary of Hierarchical Regression Analysis Testing the Mediating Role of Meaningfulness between Interactional Justice and Work Engagement

\begin{tabular}{|c|c|c|c|c|c|}
\hline Variable & $\mathrm{B}$ & SE B & $\beta$ & $\mathrm{R}^{2}$ & $\mathrm{R}^{2}$ Change \\
\hline \multicolumn{6}{|c|}{ Dependent Variable: Meaningfulness } \\
\hline & & & & $.42 * *$ & $.15^{* *}$ \\
\hline Interactional Justice & .66 & .06 & $.40 * *$ & - & - \\
\hline \multicolumn{6}{|c|}{ Dependent Variable: Work Engagement } \\
\hline Step 1 & & & & $.38 * *$ & $.12 * *$ \\
\hline Interactional Justice & .49 & .05 & $.37 * *$ & - & - \\
\hline Step 2 & & & & $.73 * *$ & $.35 * *$ \\
\hline Interactional Justice & .07 & .04 & $.05^{*}$ & - & - \\
\hline Psychological Meaningfulness & .64 & .03 & $.78 * *$ & - & - \\
\hline
\end{tabular}

Note. Controls: Ethnicity, tenure, gender, work industry, weekly work hours, supervisor status, and see occupation as job or career.

Note. $\mathrm{R}^{2}$ Change in first step of each regression is the change in $\mathrm{R}^{2}$ that occurred when predictor was added to regression after the control variables were already included in the analysis.

Note. ${ }^{*} p<.05 . * * p<.01$.

\section{Psychological safety as a mediator. Hypothesis 24 asserted that psychological}

safety would partially mediate the relationship between job features and work

engagement. The results for the analyses testing this hypothesis are presented in Tables

9A through 9F. 
Table 9A.

Summary of Hierarchical Regression Analysis Testing the Mediating Role of Safety between Person-Job Fit and Work Engagement

\begin{tabular}{|c|c|c|c|c|c|}
\hline Variable & B & SE B & $\beta$ & $\mathrm{R}^{2}$ & $\mathrm{R}^{2}$ Change \\
\hline \multicolumn{6}{|c|}{ Dependent Variable: Safety } \\
\hline & & & & $.30^{* *}$ & $.20^{* *}$ \\
\hline Person-Job Fit & .52 & .04 & $.55^{* *}$ & - & - \\
\hline \multicolumn{6}{|c|}{ Dependent Variable: Work Engagement } \\
\hline Step 1 & & & & $.63^{* *}$ & $.38^{* *}$ \\
\hline Person-Job Fit & .64 & .03 & $.76^{* *}$ & - & - \\
\hline Step 2 & & & & $.63^{* *}$ & .00 \\
\hline Person-Job Fit & .64 & .03 & $.75^{* *}$ & - & - \\
\hline Psychological Safety & .01 & .03 & .01 & - & - \\
\hline
\end{tabular}

Note. Controls: Ethnicity, tenure, gender, work industry, weekly work hours, supervisor status, and see occupation as job or career.

Note. $\mathrm{R}^{2}$ Change in first step of each regression is the change in $\mathrm{R}^{2}$ that occurred when predictor was added to regression after the control variables were already included in the analysis.

Note. ${ }^{*} p<.05 . * * p<.01$. 
Table 9B.

Summary of Hierarchical Regression Analysis Testing the Mediating Role of Safety between Autonomy and Work Engagement

\begin{tabular}{|c|c|c|c|c|c|}
\hline Variable & $\mathrm{B}$ & SE B & $\beta$ & $\mathrm{R}^{2}$ & $\mathrm{R}^{2}$ Change \\
\hline \multicolumn{6}{|c|}{ Dependent Variable: Safety } \\
\hline & & & & $.22 * *$ & $.12 * *$ \\
\hline Autonomy & .79 & .09 & $.39 * *$ & - & - \\
\hline \multicolumn{6}{|c|}{ Dependent Variable: Work Engagement } \\
\hline Step 1 & & & & $.44 * *$ & $.18^{* *}$ \\
\hline Autonomy & .86 & .07 & $.48^{* *}$ & - & - \\
\hline Step 2 & & & & $.46^{* *}$ & $.02 * *$ \\
\hline Autonomy & .74 & .07 & $.41 * *$ & - & - \\
\hline Psychological Safety & .15 & .03 & $.17 * *$ & - & - \\
\hline
\end{tabular}

Note. Controls: Ethnicity, tenure, gender, work industry, weekly work hours, supervisor status, and see occupation as job or career.

Note. $\mathrm{R}^{2}$ Change in first step of each regression is the change in $\mathrm{R}^{2}$ that occurred when predictor was added to regression after the control variables were already included in the analysis.

Note. ${ }^{*} p<.05 .{ }^{* *} p<.01$. 
Table 9C.

Summary of Hierarchical Regression Analysis Testing the Mediating Role of Safety between Co-Worker Relations and Work Engagement

\begin{tabular}{|c|c|c|c|c|c|}
\hline Variable & $\mathrm{B}$ & SE B & $\beta$ & $\mathrm{R}^{2}$ & $\mathrm{R}^{2}$ Change \\
\hline \multicolumn{6}{|c|}{ Dependent Variable: Safety } \\
\hline & & & & $.37 * *$ & $.28 * *$ \\
\hline Co-Worker Relations & 1.41 & .10 & $.56 * *$ & - & - \\
\hline \multicolumn{6}{|c|}{ Dependent Variable: Work Engagement } \\
\hline Step 1 & & & & $.32 * *$ & $.07 * *$ \\
\hline Co-Worker Relations & .62 & .09 & $.27 * *$ & - & - \\
\hline Step 2 & & & & $.35 * *$ & $.04 * *$ \\
\hline Co-Worker Relations & .31 & .11 & $.14 * *$ & - & - \\
\hline Psychological Safety & .21 & .04 & $.24 * *$ & - & - \\
\hline
\end{tabular}

Note. Controls: Ethnicity, tenure, gender, work industry, weekly work hours, supervisor status, and see occupation as job or career.

Note. $\mathrm{R}^{2}$ Change in first step of each regression is the change in $\mathrm{R}^{2}$ that occurred when predictor was added to regression after the control variables were already included in the analysis.

Note. ${ }^{*} p<.05 .{ }^{* *} p<.01$. 
Table 9D.

Summary of Hierarchical Regression Analysis Testing the Mediating Role of Safety between Supervisor Support and Work Engagement

\begin{tabular}{|c|c|c|c|c|c|}
\hline Variable & $\mathrm{B}$ & SE B & $\beta$ & $\mathrm{R}^{2}$ & $\mathrm{R}^{2}$ Change \\
\hline \multicolumn{6}{|c|}{ Dependent Variable: Safety } \\
\hline & & & & $.42 * *$ & $.32 * *$ \\
\hline Supervisor Support & 1.16 & .07 & $.60 * *$ & - & - \\
\hline \multicolumn{6}{|c|}{ Dependent Variable: Work Engagement } \\
\hline Step 1 & & & & $.36^{* *}$ & $.10^{* *}$ \\
\hline Supervisor Support & .60 & .07 & $.34 * *$ & - & - \\
\hline Step 2 & & & & $.37 * *$ & $.02 * *$ \\
\hline Supervisor Support & .42 & .08 & $.24 * *$ & - & - \\
\hline Psychological Safety & .15 & .04 & $.17 * *$ & - & - \\
\hline
\end{tabular}

Note. Controls: Ethnicity, tenure, gender, work industry, weekly work hours, supervisor status, and see occupation as job or career.

Note. $\mathrm{R}^{2}$ Change in first step of each regression is the change in $\mathrm{R}^{2}$ that occurred when predictor was added to regression after the control variables were already included in the analysis.

Note. ${ }^{*} p<.05$. ${ }^{* *} p<.01$. 
Table 9E.

Summary of Hierarchical Regression Analysis Testing the Mediating Role of Safety between Procedural Justice and Work Engagement

\begin{tabular}{|c|c|c|c|c|c|}
\hline Variable & B & SE B & $\beta$ & $\mathrm{R}^{2}$ & $\mathrm{R}^{2}$ Change \\
\hline \multicolumn{6}{|c|}{ Dependent Variable: Safety } \\
\hline & & & & $.24 * *$ & $.15^{* *}$ \\
\hline Procedural Justice & .58 & .06 & $.41 * *$ & - & - \\
\hline \multicolumn{6}{|c|}{ Dependent Variable: Work Engagement } \\
\hline Step 1 & & & & $.42 * *$ & $.17 * *$ \\
\hline Procedural Justice & .57 & .05 & $.44 * *$ & - & - \\
\hline Step 2 & & & & $.44 * *$ & $.02 * *$ \\
\hline Procedural Justice & .48 & .05 & $.38^{* *}$ & - & - \\
\hline Psychological Safety & .15 & .04 & $.16 * *$ & - & - \\
\hline
\end{tabular}

Note. Controls: Ethnicity, tenure, gender, work industry, weekly work hours, supervisor status, and see occupation as job or career.

Note. $\mathrm{R}^{2}$ Change in first step of each regression is the change in $\mathrm{R}^{2}$ that occurred when predictor was added to regression after the control variables were already included in the analysis.

Note. ${ }^{*} p<.05 .{ }^{*} p<.01$. 
Table 9F.

Summary of Hierarchical Regression Analysis Testing the Mediating Role of Safety between Interactional Justice and Work Engagement

\begin{tabular}{|c|c|c|c|c|c|}
\hline Variable & $\mathrm{B}$ & SE B & $\beta$ & $\mathrm{R}^{2}$ & $\mathrm{R}^{2}$ Change \\
\hline \multicolumn{6}{|c|}{ Dependent Variable: Safety } \\
\hline & & & & $.31^{* *}$ & $.21^{* *}$ \\
\hline Interactional Justice & .72 & .06 & $.48^{* *}$ & - & - \\
\hline \multicolumn{6}{|c|}{ Dependent Variable: Work Engagement } \\
\hline Step 1 & & & & $.38^{* *}$ & $.12 * *$ \\
\hline Interactional Justice & .49 & .05 & $.37 * *$ & - & - \\
\hline Step 2 & & & & $.40^{* *}$ & $.02 * *$ \\
\hline Interactional Justice & .38 & .06 & $.28^{* *}$ & - & - \\
\hline Psychological Safety & .16 & .04 & $.18^{* *}$ & - & - \\
\hline
\end{tabular}

Note. Controls: Ethnicity, tenure, gender, work industry, weekly work hours, supervisor status, and see occupation as job or career.

Note. $\mathrm{R}^{2}$ Change in first step of each regression is the change in $\mathrm{R}^{2}$ that occurred when predictor was added to regression after the control variables were already included in the analysis.

Note. ${ }^{*} p<.05 .{ }^{*} p<.01$.

Support was found for mediation of all relationships between job features and work engagement by safety, with the exception of PJ fit. More specifically, all regressions showed that the relationships between autonomy, supervisor support, procedural justice, and interactional justice with work engagement were partially mediated by psychological safety. Additionally, results show that the relationship between co-worker relations and work engagement was fully mediated by psychological safety. That said, the mediation test that assessed whether the relationship between PJ fit and work engagement was mediated by safety was not supported. The results for this analysis are presented in Table 9A and show that though the first and second condition for mediation were met, the third was not. When psychological safety was added to the 
regression equation after PJ fit, the relationship between safety and work engagement was not significant.

Hypothesis 28 proposed that psychological safety would also be a partial mediator between personal characteristics and work engagement. The results of the analyses that were run to test this hypothesis are presented in Tables 10A through 10D.

Table 10A.

Summary of Hierarchical Regression Analysis Testing the Mediating Role of Safety between Self-Consciousness and Work Engagement

\begin{tabular}{|c|c|c|c|c|c|}
\hline Variable & $\mathrm{B}$ & SE B & $\beta$ & $\mathrm{R}^{2}$ & $\mathrm{R}^{2}$ Change \\
\hline \multicolumn{6}{|c|}{ Dependent Variable: Safety } \\
\hline & & & & $.13 * *$ & $.04 * *$ \\
\hline Self-Consciousness & -.32 & .07 & $-.20 * *$ & - & - \\
\hline \multicolumn{6}{|c|}{ Dependent Variable: Work Engagement } \\
\hline Step 1 & & & & $.25 * *$ & .00 \\
\hline Self-Consciousness & .09 & .06 & .06 & - & - \\
\hline Step 2 & & & & $.35 * *$ & $.10 * *$ \\
\hline Self-Consciousness & .18 & .06 & $.13 * *$ & - & - \\
\hline Psychological Safety & .31 & .04 & $.34 * *$ & - & - \\
\hline
\end{tabular}

Note. Controls: Ethnicity, tenure, gender, work industry, weekly work hours, supervisor status, and see occupation as job or career.

Note. $\mathrm{R}^{2}$ Change in first step of each regression is the change in $\mathrm{R}^{2}$ that occurred when predictor was added to regression after the control variables were already included in the analysis. Note. $* p<.05$. $* * p<.01$. 
Table 10B.

Summary of Hierarchical Regression Analysis Testing the Mediating Role of Safety between Self-Efficacy and Work Engagement

\begin{tabular}{|c|c|c|c|c|c|}
\hline Variable & B & SE B & $\beta$ & $\mathrm{R}^{2}$ & $\mathrm{R}^{2}$ Change \\
\hline \multicolumn{6}{|c|}{ Dependent Variable: Safety } \\
\hline & & & & $.19 * *$ & $.09^{* *}$ \\
\hline Self-Efficacy & .70 & .09 & $.32 * *$ & - & - \\
\hline \multicolumn{6}{|c|}{ Dependent Variable: Work Engagement } \\
\hline Step 1 & & & & $.32 * *$ & $.07 * *$ \\
\hline Self-Efficacy & .53 & .08 & $.27 * *$ & - & - \\
\hline Step 2 & & & & $.37 * *$ & $.05 * *$ \\
\hline Self-Efficacy & .37 & .08 & $.19 * *$ & - & - \\
\hline Psychological Safety & .23 & .04 & $.25 * *$ & - & - \\
\hline
\end{tabular}

Note. Controls: Ethnicity, tenure, gender, work industry, weekly work hours, supervisor status, and see occupation as job or career.

Note. $\mathrm{R}^{2}$ Change in first step of each regression is the change in $\mathrm{R}^{2}$ that occurred when predictor was added to regression after the control variables were already included in the analysis.

Note. ${ }^{*} p<.05 .{ }^{* *} p<.01$. 
Table 10C.

Summary of Hierarchical Regression Analysis Testing the Mediating Role of Safety between Extraversion and Work Engagement

\begin{tabular}{|c|c|c|c|c|c|}
\hline Variable & B & SE B & $\beta$ & $\mathrm{R}^{2}$ & $\mathrm{R}^{2}$ Change \\
\hline \multicolumn{6}{|c|}{ Dependent Variable: Safety } \\
\hline & & & & $.09 * *$ & .00 \\
\hline Extraversion & .04 & .07 & .03 & - & - \\
\hline \multicolumn{6}{|c|}{ Dependent Variable: Work Engagement } \\
\hline Step 1 & & & & $.27 * *$ & $.02 * *$ \\
\hline Extraversion & .20 & .05 & $.16^{* *}$ & - & - \\
\hline Step 2 & & & & $.36^{* *}$ & $.09 * *$ \\
\hline Extraversion & .19 & .05 & $.15^{* *}$ & - & - \\
\hline Psychological Safety & .28 & .03 & $.31 * *$ & - & - \\
\hline
\end{tabular}

Note. Controls: Ethnicity, tenure, gender, work industry, weekly work hours, supervisor status, and see occupation as job or career.

Note. $\mathrm{R}^{2}$ Change in first step of each regression is the change in $\mathrm{R}^{2}$ that occurred when predictor was added to regression after the control variables were already included in the analysis.

Note. ${ }^{*} p<.05$. ${ }^{* *} p<.01$. 
Table 10D.

Summary of Hierarchical Regression Analysis Testing the Mediating Role of Safety between Neuroticism and Work Engagement

\begin{tabular}{|c|c|c|c|c|c|}
\hline Variable & $\mathrm{B}$ & SE B & $\beta$ & $\mathrm{R}^{2}$ & $\mathrm{R}^{2}$ Change \\
\hline \multicolumn{6}{|c|}{ Dependent Variable: Safety } \\
\hline & & & & $.14^{* *}$ & $.05 * *$ \\
\hline Neuroticism & -.32 & .06 & $-.22 * *$ & - & - \\
\hline \multicolumn{6}{|c|}{ Dependent Variable: Work Engagement } \\
\hline Step 1 & & & & $.26^{* *}$ & .01 \\
\hline Neuroticism & -.10 & .05 & -.08 & - & - \\
\hline Step 2 & & & & $.34 * *$ & $.08 * *$ \\
\hline Neuroticism & -.01 & .05 & -.01 & - & - \\
\hline Psychological Safety & .28 & .04 & $.31 * *$ & - & - \\
\hline
\end{tabular}

Note. Controls: Ethnicity, tenure, gender, work industry, weekly work hours, supervisor status, and see occupation as job or career.

Note. $\mathrm{R}^{2}$ Change in first step of each regression is the change in $\mathrm{R}^{2}$ that occurred when predictor was added to regression after the control variables were already included in the analysis.

Note. ${ }^{*} p<.05 .{ }^{* *} p<.01$.

No support was found for the hypotheses that safety mediates the relationships that self-consciousness, extraversion, or neuroticism have with work engagement. Specifically, none of these predictors (Tables 10A, 10C, and 10D) displayed significant relationships with work engagement. Table 10B displays results found when testing safety as a mediator between self-efficacy and work engagement. Findings show that safety is a partial mediator between self-efficacy and work engagement. In particular, self-efficacy exemplified a significant and positive relationship with psychological safety as well as work engagement. When psychological safety was added to the regression equation examining the relationship between self-efficacy and work engagement, the beta coefficient for self-efficacy decreased. 
Psychological availability as a mediator. The final set of mediation tests

examined Hypothesis 33's proposition that the psychological condition of availability would mediate the relationship between personal characteristics and work engagement. Similar to the results that looked at safety as a mediator between personal characteristics and work engagement, support was only found with regard to self-efficacy. Results for these analyses are presented in Tables 11A through 11D.

Table 11A.

Summary of Hierarchical Regression Analysis Testing the Mediating Role of Availability between Self-Consciousness and Work Engagement

\begin{tabular}{|c|c|c|c|c|c|}
\hline Variable & $\mathrm{B}$ & SE B & $\beta$ & $\mathrm{R}^{2}$ & $\mathrm{R}^{2}$ Change \\
\hline \multicolumn{6}{|c|}{ Dependent Variable: Availability } \\
\hline & & & & $.05 * *$ & .00 \\
\hline Self-Consciousness & -.04 & .05 & -.04 & - & - \\
\hline \multicolumn{6}{|c|}{ Dependent Variable: Work Engagement } \\
\hline Step 1 & & & & $.25 * *$ & .00 \\
\hline Self-Consciousness & .09 & .06 & .06 & - & - \\
\hline Step 2 & & & & $.35^{* *}$ & $.10^{* *}$ \\
\hline Self-Consciousness & .11 & .05 & .07 & - & - \\
\hline Psychological Availability & .44 & .05 & $.33 * *$ & - & - \\
\hline
\end{tabular}

Note. Controls: Ethnicity, tenure, gender, work industry, weekly work hours, supervisor status, and see occupation as job or career.

Note. $\mathrm{R}^{2}$ Change in first step of each regression is the change in $\mathrm{R}^{2}$ that occurred when predictor was added to regression after the control variables were already included in the analysis.

Note. ${ }^{*} p<.05 . * *<.01$. 
Table 11B.

Summary of Hierarchical Regression Analysis Testing the Mediating Role of Availability between Self-Efficacy and Work Engagement

\begin{tabular}{|c|c|c|c|c|c|}
\hline Variable & B & SE B & $\beta$ & $\mathrm{R}^{2}$ & $\mathrm{R}^{2}$ Change \\
\hline \multicolumn{6}{|c|}{ Dependent Variable: Availability } \\
\hline & & & & $.35 * *$ & $.30^{* *}$ \\
\hline Self-Efficacy & .82 & .06 & $.57 * *$ & - & - \\
\hline \multicolumn{6}{|c|}{ Dependent Variable: Work Engagement } \\
\hline Step 1 & & & & $.32 * *$ & $.07 * *$ \\
\hline Self-Efficacy & .53 & .08 & $.27^{* *}$ & - & - \\
\hline Step 2 & & & & $.36^{* *}$ & $.04 * *$ \\
\hline Self-Efficacy & .25 & .09 & $.13^{* *}$ & - & - \\
\hline Psychological Availability & .34 & .06 & $.25 * *$ & - & - \\
\hline
\end{tabular}

Note. Controls: Ethnicity, tenure, gender, work industry, weekly work hours, supervisor status, and see occupation as job or career.

Note. $\mathrm{R}^{2}$ Change in first step of each regression is the change in $\mathrm{R}^{2}$ that occurred when predictor was added to regression after the control variables were already included in the analysis.

Note. ${ }^{*} p<.05 . * * p<.01$. 
Table 11C.

Summary of Hierarchical Regression Analysis Testing the Mediating Role of Availability between Extraversion and Work Engagement

\begin{tabular}{|c|c|c|c|c|c|}
\hline Variable & B & SE B & $\beta$ & $\mathrm{R}^{2}$ & $\mathrm{R}^{2}$ Change \\
\hline \multicolumn{6}{|c|}{ Dependent Variable: Availability } \\
\hline & & & & $.06^{* *}$ & .01 \\
\hline Extraversion & .08 & .05 & .09 & - & - \\
\hline \multicolumn{6}{|c|}{ Dependent Variable: Work Engagement } \\
\hline Step 1 & & & & $.27^{* *}$ & $.02^{* *}$ \\
\hline Extraversion & .20 & .05 & $.16^{* *}$ & - & - \\
\hline Step 2 & & & & $.36^{* *}$ & $.09^{* *}$ \\
\hline Extraversion & .17 & .05 & $.13^{* *}$ & - & - \\
\hline Psychological Availability & .43 & .05 & $.31 * *$ & - & - \\
\hline
\end{tabular}

Note. Controls: Ethnicity, tenure, gender, work industry, weekly work hours, supervisor status, and see occupation as job or career.

Note. $\mathrm{R}^{2}$ Change in first step of each regression is the change in $\mathrm{R}^{2}$ that occurred when predictor was added to regression after the control variables were already included in the analysis.

Note. ${ }^{*} p<.05$. ${ }^{* *} p<.01$. 
Table 11D.

Summary of Hierarchical Regression Analysis Testing the Mediating Role of Availability between Neuroticism and Work Engagement

\begin{tabular}{|c|c|c|c|c|c|}
\hline Variable & $\mathrm{B}$ & SE B & $\beta$ & $\mathrm{R}^{2}$ & $\mathrm{R}^{2}$ Change \\
\hline \multicolumn{6}{|c|}{ Dependent Variable: Availability } \\
\hline & & & & $.09^{* *}$ & $.04 * *$ \\
\hline Neuroticism & -.20 & .04 & $-.21 * *$ & - & - \\
\hline \multicolumn{6}{|c|}{ Dependent Variable: Work Engagement } \\
\hline Step 1 & & & & $.26^{* *}$ & .01 \\
\hline Neuroticism & -.10 & .05 & -.08 & - & - \\
\hline Step 2 & & & & $.35 * *$ & $.10^{* *}$ \\
\hline Neuroticism & -.01 & .05 & -.01 & - & - \\
\hline Psychological Availability & .44 & .05 & $.32 * *$ & - & - \\
\hline
\end{tabular}

Note. Controls: Ethnicity, tenure, gender, work industry, weekly work hours, supervisor status, and see occupation as job or career.

Note. $\mathrm{R}^{2}$ Change in first step of each regression is the change in $\mathrm{R}^{2}$ that occurred when predictor was added to regression after the control variables were already included in the analysis.

Note. ${ }^{*} p<.05 . * * p<.01$.

No support was found concerning hypotheses that predicted availability would mediate the relationships between work engagement and the personal characteristics of self-consciousness, extraversion, or neuroticism (see Tables 11A, 11B, and 11C). The results of mediation test for self-efficacy was much more promising. Findings support availability as a partial mediator for its relationship with work engagement. More specifically, self-efficacy's positive relationship with work engagement is partially mediated by availability (see Table 11B.

Work engagement and OCB. The final hypothesis in this dissertation asserts that work engagement will be positively related to OCB. This relationship was tested using multiple regression to control for appropriate demographic variables while 
assessing the relationship between engagement and OCB. The results of this analysis are presented in Table 12.

Table 12.

Summary of Hierarchical Regression Analysis Testing Work Engagement as a predictor of $O C B$

\begin{tabular}{cccccc}
\hline Variable & $\mathrm{B}$ & $\mathrm{SE} \mathrm{B}$ & $\beta$ & $\mathrm{R}^{2}$ & $\mathrm{R}^{2}$ Change \\
\hline & & & & & $.28^{* *}$ \\
Work Engagement & .25 & .03 & $.44^{* *}$ & - & $.14^{* *}$ \\
\hline
\end{tabular}

Note. Controls: Ethnicity, tenure, gender, work industry, weekly work hours, supervisor status, and see occupation as job or career.

Note. ${ }^{*} p<.05$. $* * p<.01$.

Findings show that there is a moderately strong and significant relationship between work engagement and OCB even after controlling for tenure, weekly work hours, supervisor status, whether individuals see their occupation as a 'job' or a 'career', and ethnicity. The next section will discuss the results of the Structural Equation Model that was run in order to test the conceptual model outlined in Chapter II of this study.

\section{Structural Equation Modeling (SEM)}

The conceptual model presented in Chapter II (see Figure 1 and Hypotheses 3 through 33) was tested in AMOS using Structural Equation Modeling (SEM) with a path analysis technique. The fit of the model was evaluated using a maximum likelihood algorithm. Five fit indices were calculated in order to determine whether or not the hypothesized model fit the data well: AIC, TLI, CFI, RMSEA, and Standardized RMR. 
Similar to testing SEM models for hypotheses 1 and 2, the AIC was used instead of the chi-square test of model fit due to this study's large sample size.

The conceptual model tested the proposition that the job features and personal characteristics measured in this study would affect work engagement through the medium of the three psychological conditions (psychological meaningfulness, psychological safety, and psychological availability). See Figure 4 for an illustration of this structural model. The global fit indices' results for this model are listed in Table 13. 
Figure 4.

SEM Results for Conceptual Model of Job Features, Personality Characteristics, Psychological Conditions, and Work Engagement

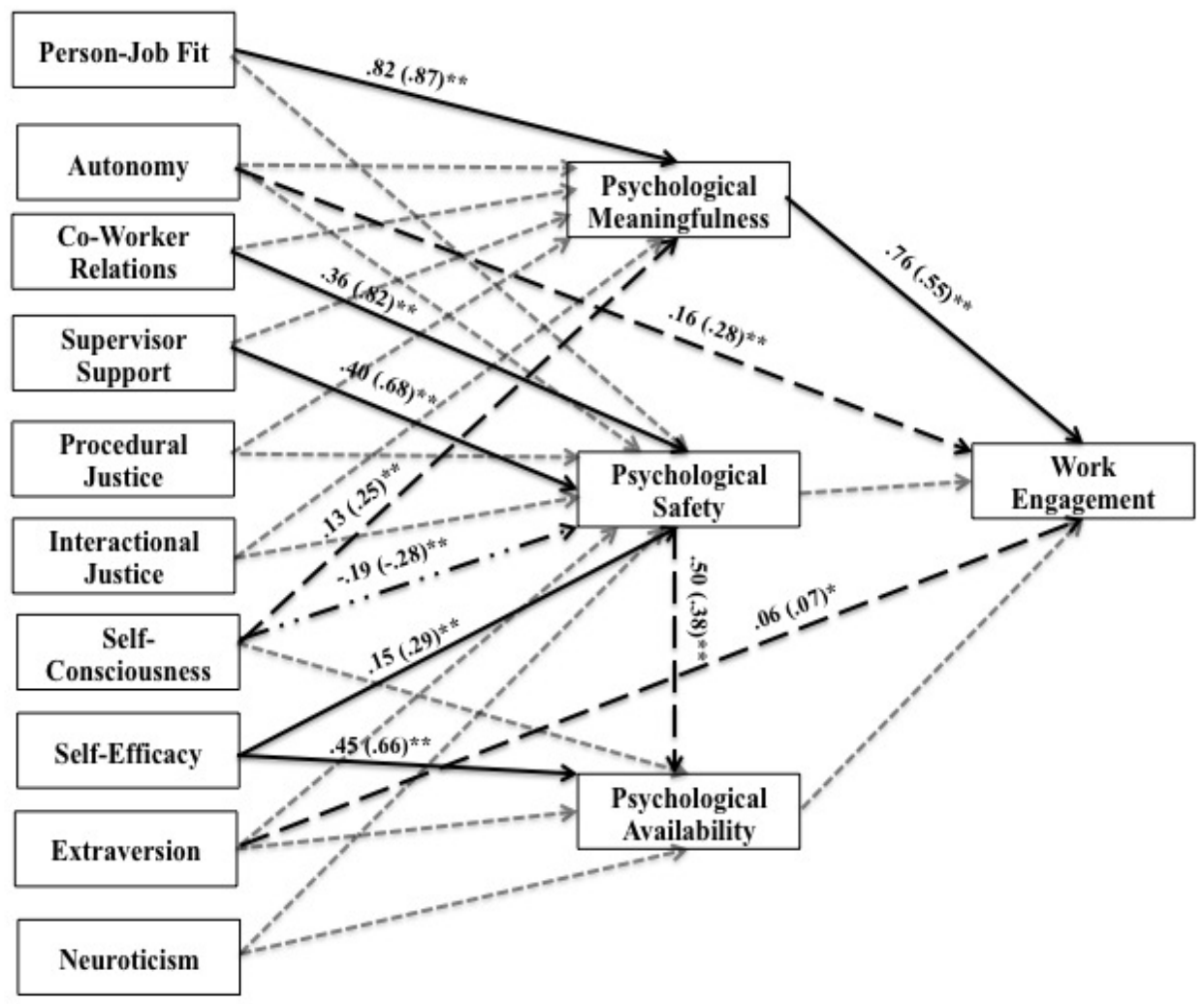

Note. Controlled for Tenure, weekly work hours, gender, see occupation as job or career, industry, ethnicity

Note. Values enclosed in parentheses represent unstandardized

Key: path coefficients.

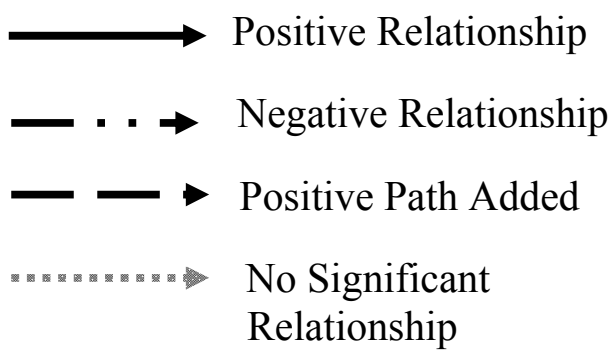


Table 13.

SEM Results for Full Model

\begin{tabular}{lcccccc}
\hline Model & AIC & TLI & CFI & RMSEA & p-close & St. RMR \\
\hline Full Model & 643.29 & .93 & .98 & .06 & .14 & .02 \\
\hline
\end{tabular}

Note. AIC = Akaike's information criterion; TLI $=$ Tucker-Lewis index $;$ CFI $=$ comparative fit index; RMSEA = rootmean-square error of approximation; $p$-close $=$ p-value for test of close fit; St. RMR = standardized root mean square residual.

Note. Good fit is indicated by a small AIC value (relative to other models); TLI closer to 1 and $\geq .9$, CFI closer to 1 and $\geq .9$, RMSEA $<.1$ (preferably $<.08$ ), p-close $>.05$, and St. RMR $<.05$.

Note. ${ }^{*} p<.05$. ${ }^{* *} p<.01$.

Modification indices greater than 4.0 were taken into consideration as they indicate that there are important associations in the data for which the estimated model neglected to account. Among these, only those paths that made conceptual sense, or had theoretical backing, were incorporated into the final model. Accordingly, four paths were added to the model: 1) a path from self-consciousness to meaningfulness, 2) a path from safety to availability, 3) a path from autonomy to work engagement, and 4) a path from extraversion to work engagement. After incorporating these additional pathways, the global fit indices for this model supported a good model fit.

The squared multiple correlations indicate the proportion of variance that is accounted for in each of the endogenous variables by those variables that precede them in the model. These results are presented in Table 14. 
Table 14.

$R^{2}=$ Variance Accounted for in Each Variable

\begin{tabular}{cccc}
\hline Meaningfulness & Safety & Availability & Engagement \\
\hline .81 & .77 & .60 & .87 \\
\hline
\end{tabular}

The variables in this model accounted for a very high amount of variance in work engagement $\left(R^{2}=.87\right)$ as well as a high amount of variance in psychological meaningfulness $\left(R^{2}=.81\right)$. Though lower, the variances accounted for in psychological safety $\left(R^{2}=.77\right)$ and availability $\left(R^{2}=.60\right)$ were still very high considering the possible number of variables that could affect these two constructs.

The standardized and unstandardized path coefficients for this model are listed in Tables 15A (Job Features, Personal Characteristics, and Psychological Conditions) and 15B (Psychological Conditions and Work Engagement). 
Table 15A.

Structural Equation Model Path Coefficients for Relationships between Job Features, Personal Characteristics, and Psychological Conditions

\begin{tabular}{lccc}
\hline \multicolumn{1}{c}{ Independent Variable } & Meaningfulness is DV & Safety is DV & Availability is DV \\
\hline Job Features & & & \\
Person-Job Fit & $.82(.87)^{* *}$ & $.21(.17)$ & - \\
Autonomy & $.06(.15)$ & $.01(.03)$ & - \\
Co-Worker Relations & $-.08(-.25)$ & $.36(.82)^{* *}$ & - \\
Supervisor Support & $-.06(-.14)$ & $.40(.68)^{* *}$ & - \\
Procedural Justice & $.09(.14)$ & $-.09(-.12)$ & - \\
Interactional Justice & $.08(.13)$ & $-.05(-.07)$ & $.05(.05)$ \\
Personal Characteristics & & & $.45(.66)^{* *}$ \\
Self-Consciousness & - & $-.19(-.28)^{* *}$ & $-.07(-.06)$ \\
Self-Efficacy & - & $.15(.29)^{* *}$ & $.06(.06)$ \\
Extraversion & - & $-.06(-07)$. & \\
Neuroticism & - & $.03(.04)$ & - \\
Additional paths & $.13(.25)^{* *}$ & - & $-50(.38)^{* *}$ \\
Self-Consciousness & - & - & \\
Safety & - & & \\
\hline
\end{tabular}

Note. $\mathrm{DV}=$ Dependent Variable.

Note. Values enclosed in parentheses represent unstandardized path coefficients.

${ }^{a}$ Paths were added according to modification indices $>4$.

Note. ${ }^{*} p<.05$. ${ }^{* *} p<.01$. 
Table 15B.

Structural Equation Model Path Coefficients for Relationships between Psychological Conditions and Work Engagement

\begin{tabular}{lc}
\multicolumn{1}{c}{ Independent Variable } & $\begin{array}{c}\text { Work Engagement } \\
\text { as DV }\end{array}$ \\
\hline Psychological Condition & $.76(.55)^{* *}$ \\
Meaningfulness & $.04(.03)$ \\
Safety & $.03(.04)$ \\
Availability & \\
Additional paths ${ }^{\mathrm{a}}$ & $.16(.28)^{* *}$ \\
Autonomy & $.06(.07)^{*}$ \\
Extraversion & \\
Total effect $\rightarrow$ Engagement & .49 \\
Person-Job Fit & .36 \\
Autonomy & -.10 \\
Co-Worker Relations & .04 \\
Supervisor Support & .04 \\
Procedural Justice & .07 \\
Interactional Justice & .07 \\
Self-Consciousness & .07 \\
Self-Efficacy & \\
Extraversion & \\
Neuroticism & .07 \\
\hline
\end{tabular}

Note. $\mathrm{DV}=$ Dependent Variable.

Note. Values enclosed in parentheses represent unstandardized path coefficients.

${ }^{a}$ Paths were added according to modification indices $>4$.

Note. ${ }^{*} p<.05 .{ }^{* *} p<.01$.

The only pathway that was found to be significant between a job feature and meaningfulness was that between PJ fit and meaningfulness. Results suggest that for every one unit increase in PJ fit, meaningfulness was predicted to increase by .87 units. 
Furthermore, for every one unit increase in meaningfulness, work engagement was predicted to increase by .55 units. These results provide strong support for the positive relationship between PJ fit and meaningfulness that was proposed in Hypothesis 12 as well as the positive relationship between meaningfulness and work engagement that was proposed in Hypothesis 11. These results also provide some support for Hypothesis 17, which proposed that psychological meaningfulness would mediate the relationship between job features and work engagement. Specifically, it supports the proposition that meaningfulness mediates the relationship between PJ fit and work engagement. Although the original model did not hypothesize that any personal characteristics would have an effect on meaningfulness, in accordance with modification indices, a pathway was added from self-consciousness to meaningfulness. This pathway was significant and suggests that for every one unit increase in self-consciousness, meaningfulness was predicted to increase by .25 units. Seeing as the pathway between meaningfulness and work engagement was significant, the combination of the significance of these two paths suggests that meaningfulness mediates the relationship between self-consciousness and work engagement.

The psychological condition of safety was hypothesized to be affected by both the job features and personal characteristics that were included in this study. Results provide support for two from each category. From job features, the pathways from co-worker relations and supervisor support to safety were significant and positive. Results of these pathways suggest that for every one unit increase in co-worker relations, safety was predicted to increase by .82 units. Furthermore, for every one unit increase in supervisor support, safety was predicted to increase by .68 units. From personal characteristics, the 
two pathways that were significant were those between self-consciousness and safety as well as self-efficacy and safety. Specifically, findings suggest that for every one unit increase in self-consciousness, safety was predicted to decrease by.28 units. Conversely, for every one unit increase in self-efficacy, safety was predicted to increase by .29 units. Seeing as the pathway leading from safety to work engagement was not significant, none of the proposed hypotheses predicting that safety would be a mediator between job features, personal characteristics, and work engagement were supported with this model. Psychological availability was hypothesized to mediate the relationship between personal characteristics and work engagement. Although no support was found for the mediation hypothesis since the pathway between availability and work engagement was not significant, results did provide support for a relationship between self-efficacy and availability. Findings suggest that for every one unit increase in self-efficacy, availability was predicted to increase by .66 units. Additionally, modification indices suggested a need for the incorporation of a pathway extending from safety to availability. This pathway was added to the model and found to be significant, its results suggesting that for every one unit increase in safety, availability was predicted to increase by .38 units.

The final two significant paths from the conceptual model are those that were added in accordance with modification indices greater than 4.0. These included a path from autonomy to work engagement and from extraversion to work engagement. The pathway coefficients suggest that for every one unit increase in autonomy, work engagement was predicted to increase by .28 units, and for every one unit increase in extraversion, work engagement was predicted to increase by .07 units. The incorporation 
of pathways directly from these two predictors to work engagement, hence bypassing the mediation pathway of any of the psychological conditions, suggest one of two things: that there are mediating variables for which this model failed to account, or that these variables simply affect engagement directly rather than through any type of psychological condition.

The final results to consider with regard to the conceptual model are those of the total effects analyses. These analyses revealed the total effects that each exogenous job feature and personal characteristics variables had on work engagement. They are presented in the second half of Table 15B. PJ fit had the greatest total effect on work engagement while autonomy had a fairly strong total effect on engagement as well. The total effects that co-worker relations and supervisor support had on work engagement were surprising in that they were in the opposite direction than anticipated. Instead of having a positive effect on work engagement, these variables had a negative effect on it. Conversely, rather than having a negative total effect on work engagement, selfconsciousness actually had a positive effect on it. 


\section{Chapter V \\ Discussion}

The present study looked further into the process that underlies work engagement. Two of the main work engagement models that have been presented and empirically tested in the literature (i.e., JD-R model and Kahn's model) were integrated in order to test a comprehensive model that assessed the effects that job and personal characteristics may have on work engagement through the psychological conditions of meaningfulness, safety, and availability. More specifically, meaningfulness and safety were tested as possible mediators between job features and engagement, while safety and availability were tested as potential mediators between personal characteristics and engagement.

\section{Factor Structure of Work Engagement}

Before the full model could be tested, analyses examined the factor structure of work engagement as well as whether or not engagement is distinct from organizational commitment and/or job satisfaction. These analyses tested whether work engagement was modeled correctly in the ultimate structural equation model and also offered some empirical results to a popular debate in work engagement research: Is work engagement really something novel to the field of I-O Psychology, or is it just another name for constructs that already exist?

The first hypothesis in my study tested the factor structure of engagement. That hypothesis stated that the three subdimensions of engagement (vigor, dedication, and absorption) would positively relate to one another and that work engagement would emerge from them as a single factor. Confirmatory factor analysis was used to test this hypothesis. When the models were first run in SEM, neither the uni-factor nor the three- 
factor model that included all work engagement items achieved good model fit, even after incorporating paths in accordance with modification indices. Since SEM follows the parsimony principle, preferring simpler models to more complex ones, models tested using SEM are more likely to achieve good model fit when there are fewer pathways and/or variables present. In response to this, the researcher consulted a study that was performed by Schaufeli et al. (2006) in order to determine how to pare each of the measures down to fewer items. Once work engagement was reduced down from 17 total items (6 VI, $5 \mathrm{DE}, 6 \mathrm{AB}$ ) to the 9 items (3 for each dimension) that were validated in this study, the models were run again with better success, leading to good fitting models from which conclusions could be drawn regarding Hypothesis 1.

The first portion of this hypothesis received support in that vigor, dedication, and absorption were found to have strong positive relationships with one another. Contrary to expectations, support was not found for the second leg of this hypothesis. When confirmatory factor analyses were run to compare a uni-factor model of engagement to a three-factor model, the better fitting model for work engagement was the three-factor model. Though this finding did not confirm the researcher's expectations, it does confirm the conceptualization of work engagement presented by Schaufeli, Salanova, Gonzalez-Roma, and Bakker (2002) that it is in fact composed of the three dimensions of vigor, dedication, and absorption. These results affected how work engagement was later depicted when testing the full structural model for the present study. Instead of portraying work engagement as one latent variable of 9 indicators ( 3 for vigor, 3 for dedication, and 3 for absorption), it was modeled as a latent variable of 3 indicators (a vigor mean score, a dedication mean score, and an absorption mean score). 


\section{Engagement's Distinction from Satisfaction and Commitment}

The second hypothesis of the present study tested one aspect of a long-standing debate since work engagement was introduced into the field of I/O Psychology: Is engagement really different from related constructs that have already been defined in this field? The hypothesis tested in this particular study investigated whether or not work engagement was distinguishable from the related constructs of organizational commitment and job satisfaction. A three-step process was implemented in order to test this hypothesis. The results of all three steps confirmed that work engagement is, in fact, distinguishable from satisfaction and commitment.

In the first step of this process, the intercorrelations between the three constructs were strong, though not so strong as to indicate that there was conceptual overlap between the three variables. In the second step, a uni-factor model was compared to a 3factor model to determine which was the better fit for the data. Final results of this step in the process revealed that the 3-factor model was a better fit for the data. These results provided further evidence that job satisfaction, organizational commitment, and work engagement are distinct constructs.

The final step in the process of testing Hypothesis 2 was to run a usefulness analysis to determine if work engagement explained variance in OCB over and above job

satisfaction and organizational commitment. Results of this analysis supported the notion that work engagement explains variance in OCB over the other two constructs. In fact, the relationship between work engagement and OCB was quite strong in each of the regressions and the changes in $R^{2}$ were significant. These results provide the final 
evidence needed to support Hypothesis 2 and conclude that the construct of work engagement is in fact distinct from job satisfaction and organizational commitment.

One detail that is interesting to note with regard to this third analysis was that when OCB was regressed onto satisfaction, the relationship between satisfaction and OCB was positive. However, when engagement was added to the regression, the beta for satisfaction became significant and negative, which is opposite from the relationship that one would expect to find between these two variables. This unexpected finding can be explained by the phenomenon of suppression that often occurs when highly correlated variables are included in the same regression analysis. Specifically, negative suppression occurred in this case because job satisfaction and work engagement were highly correlated with one another $(r=.74, p<.001)$. Maassen and Bakker (2001) explain that negative suppression happens when "Two independent variables have a positive zeroorder correlation with the dependent variable and correlate positively with each other. Although the suppressor [i.e., job satisfaction] has relevant information in common with $Y$ [i.e., $\mathrm{OCB}]$, they share fewer common elements than the common elements of irrelevant information shared by the suppressor and the other predictor [i.e., work engagement]" (Maassen \& Bakker, 2001, p.245). In other words, the amount of elements that job satisfaction and work engagement have in common that do not explain variance in $\mathrm{OCB}$, and is therefore error variance, is larger than the amount of elements that job satisfaction and OCB have in common with one another. The error variance from work engagement (in prediction of OCB) is being partialed out by job satisfaction, "purifying" work engagement and improving it as a predictor of OCB. So instead of serving to explain variance in $\mathrm{OCB}$, the primary purpose of job satisfaction in this equation is to 
suppress the error variance in work engagement. Thus, the relationship that job satisfaction displays with OCB in this regression does not accurately reflect its relationship with this dependent variable. Instead it reflects job satisfaction's relationship with OCB when work engagement is included in the regression equation.

\section{The Conceptual Model}

This study predicted that the three psychological conditions would mediate the relationships that job features and personal characteristics had with work engagement. The results from the SEM model in AMOS provided few results to support the hypotheses that were proposed for this study. In particular, support was found for meaningfulness' role as a mediator between PJ fit and work engagement, and selfconsciousness and work engagement (which was not even hypothesized). This finding may be due to the fact that in the SEM model, all variables in the model and the effects that they have on one another are taken into account. As mentioned previously, regressions that tested for mediation were performed separately for each predictor due to the high correlations that predictors had with one another. Inclusion of all predictors in the same regression model often led to misleading or null results, similar to these SEM results. In the interest of arriving at conclusions for each proposed mediated relationship, the culmination of results from SEM and regression analyses will now be discussed.

Meaningfulness as a mediator. This study expected to find that the relationships that job features have with work engagement would be mediated by the psychological condition of meaningfulness. Ample support for PJ fit's mediated relationship with engagement was found through SEM and regression analyses. According to all of these results, PJ fit exemplified the strongest relationship with meaningfulness out of all of the 
job features. Additionally, meaningfulness was the psychological condition that was most strongly related to work engagement. This study's multiple regression results provide evidence for partial mediation of the relationship between PJ fit and work engagement by meaningfulness. These results support previous findings discovered by other researchers (e.g., May et al., 2004; Oliver \& Rothmann, 2007), as well as this study's proposition that individuals that perceive a better fit between their self-concept and their work role will be more likely to experience their job as meaningful. In turn, those individuals that perceive higher meaningfulness in their job will be more likely to be engaged in their work.

According to SEM results, the remaining job features were not proven to be significant predictors of meaningfulness, initially rejecting the mediation hypotheses concerning these variables. However, regression analyses that were run on individual predictors to test for mediation told a different story. According to regression results, the relationships that engagement has with autonomy, supervisor support, procedural justice, and interactional justice are all partially mediated by meaningfulness. Furthermore, regression results also supported meaningfulness as a full mediator between co-worker relations and work engagement. Considering that the regression analyses run separately for each predictor support these conclusions, it is possible that what made these relationships null in the SEM model has nothing to do with the underlying relationships between the variables in each mediated relationship and everything to do with the predictors' relationships with one another.

The positive relationships that were found to exist between work engagement and autonomy, co-worker relations, supervisor support, procedural, and interactional justice 
fall right in line with previous research findings (Crawford et al., 2010; Halbesleben, 2010; Maslach et al., 2001; Xanthopoulou et al., 2008). However, this is the first study to provide quantitative evidence proving that meaningfulness mediates the relationships that autonomy, procedural justice, and interactional justice have with work engagement. These findings support this study's assertion that individuals that have higher autonomy in their jobs and perceive higher levels of procedural and interactional justice are more likely to see their job as meaningful and ultimately be engaged in the work that they do.

Safety as a mediator for job features. The next set of mediated relationships that were proposed in this study were those that suggested psychological safety would mediate the relationship between job features and work engagement. According to SEM results, this hypothesis was not supported as no significant relationship was found to exist between psychological safety and work engagement. However, the hierarchical regressions proved that safety was a partial mediator for the relationships between autonomy and engagement, co-worker relations and engagement, supervisor support and engagement, procedural justice and engagement, and interactional justice and engagement. Support for these mediated relationships shows that all of these predictors affect engagement, at least partially, through psychological safety. More specifically, higher levels on each of these predictors make workers feel safer to be themselves, let their guard down, as it were, in the workplace, and ultimately become engaged in their work role.

These findings confirm what research has already found with regard to co-worker relations and supervisor support (e.g., May et al., 2004; Olivier \& Rothmann, 2007). Individuals that have better co-worker relations feel accepted by their peers and perceive 
that who they are as a person and how they perform their job is acceptable to others. Therefore, they will feel safer letting their guard down. Similarly, individuals that feel supported by their supervisors, who set the boundaries on what is and is not appropriate work conduct, are more likely to feel that how they perform their job is acceptable and therefore feel safer letting their guard down in their work space.

These results provide new evidence that autonomy, procedural justice, and interactional justice affect engagement through psychological safety. When one is given higher levels of autonomy in their work, it implies that their supervisor supports them in how they perform their job. This makes them ultimately feel more safe in letting their guard down in the workplace, and leads to higher levels of engagement. With regard to findings concerning justice perceptions, by its own definition safety is associated with environments that are clear, consistent, predictable, and non-threatening (Kahn, 1990). If one perceives more procedural and interactional justice in their workplace, they perceive a work environment that embodies these qualities. Therefore, it is not very surprising that this study's findings fully support these relationships.

The only job feature for which no support was found in these tests for mediation was PJ fit. Though PJ fit exemplified a strong relationship with safety on its own, when PJ fit and safety were included in the same regression analysis examining work engagement as a dependent variable, safety's relationship with work engagement was not significant. This study hypothesized that if a good fit exists between a worker and their job, they will be more likely to feel comfortable letting their guard down and experience psychological safety in their work environment. However, seeing as meaningfulness proved to be a very strong mediator of the relationship between PJ fit and work 
engagement, these results simply show that meaningfulness is a more appropriate avenue through which PJ fit affects work engagement. Put more directly, workers that are a good fit for their job are engaged not because they feel safer in their work environment, but because their job is more meaningful to them. These findings fall in line with those achieved by Olivier and Rothmann (2007) and May et al. (2004). Though these researchers found a positive correlation between work-role fit and safety, meaningfulness was the most appropriate mediator for the relationship that this variable had with work engagement.

Safety as a mediator for personal characteristics. Psychological safety was also hypothesized to mediate the relationships between personal characteristics and work engagement. Once again, SEM results did not support any of these hypotheses since the pathway between safety and work engagement was not significant, though the pathways that self-consciousness (negative) and self-efficacy (positive) had with safety were significant. The regressions that tested the mediating role that safety played between personal characteristics and work engagement, however, gave different results. According to these analyses, safety acted as a partial mediator between self-efficacy and work engagement. More specifically, self-efficacy’s positive relationship with work engagement was partially mediated by safety. Though research has previously linked self-efficacy to work engagement (Inceoglu \& Warr, 2011; Llorens et al., 2007; Shin \& Swanger, 2009), this study is the first to demonstrate that safety mediates the relationships that this variable has with work engagement. These results provide support for the theory that individuals with high levels of self-efficacy have high confidence in their abilities and ultimately believe that how they respond to work demands is 
acceptable. They will therefore feel more comfortable taking risks and being themselves in their role, or experience higher levels of psychological safety, which will then make them more likely to become engaged in their tasks.

Safety did not prove to be a significant mediator between self-consciousness and work engagement because self-consciousness was not significantly related to work engagement in the second step of Baron and Kenny's (1986) procedure for testing for mediation. As a predictor, self-consciousness gave mixed results with regard to its relationships with other variables in the study. In the SEM model, self-consciousness was negatively related to psychological safety, yet positively related to psychological meaningfulness. Since the pathway from self-consciousness to meaningfulness, and meaningfulness to engagement, suggests that meaningfulness mediates the relationship between self-consciousness and engagement, a series of regressions tested this possibility. Regression results did not support this mediated relationship- selfconsciousness was not significantly related to meaningfulness or engagement. In the correlations, self-consciousness displayed negative relationships with safety and availability, and positive relationships with work engagement, neuroticism, and extraversion.

Self-consciousness' negative relationship to safety in the SEM model is what was originally anticipated: individuals that are so focused on and distracted by what others around them are thinking will inherently feel less safe in their work environment than those that are not so fixated on what others around them are thinking. However, its positive relationship (though small) with work engagement calls into question whether or not self-consciousness is really detrimental in the workplace. Contrary to what was 
originally proposed, perhaps higher levels of self-consciousness make one more likely to become engaged in their work because these individuals care so much about what others around them are thinking. Therefore, they may be more inclined to appear as though they are working and, as a result, become more engaged in their work because they do not want to appear as if they are not being productive.

No support was found for the theory that psychological safety is a mediator between extraversion and work engagement. The findings from the hierarchical regressions testing this relationship showed that although extraversion was significantly related to work engagement, it was not significantly related to safety. Furthermore, modification indices in the SEM model suggested that an extra pathway extending from extraversion directly to work engagement be added to the model. This pathway suggests that although extraversion is positively related to work engagement, it is not related to it through psychological safety. It also suggests that extraversion is not significantly related to perceptions of safety in the work environment. This means that those higher on extraversion are not necessarily more likely to perceive higher levels of safety than those that score lower on extraversion. A possibility of why no relationship was found here could have to do with the fact that the measure for psychological safety taps into one's perception of safety rather than how likely one is to actively open up in the work environment. Perhaps those that rate differently on extraversion have the same perception of levels of safety in the environment, but instead differ on how likely they are to actually let their guard down and open up in their workplace.

Availability as a mediator. The final group of hypotheses anticipated that psychological availability would mediate the relationship between personal 
characteristics and work engagement. SEM results for these hypotheses were similar to those for psychological safety: availability was not significantly related to work engagement, therefore, no mediation hypotheses were supported solely using the results achieved in SEM. However, the hierarchical regressions that tested the mediating hypotheses led to different conclusions. According to these results, availability acts as a partial mediator between self-efficacy and engagement. More specifically, self-efficacy's positive relationship with work engagement is partially mediated by availability. Though research has previously linked self-efficacy to work engagement (e.g., Inceoglu \& Warr, 2011; Langelaan et al., 2006; Llorens et al., 2007; Shin \& Swanger, 2009), this study is the first to prove that availability mediates the relationships that this variable has with work engagement.

Self-efficacy's relationship with availability has not been previously researched. However, Kahn suggested that "being available was partly a matter of security in abilities and status and maintaining a focus on tasks rather than anxieties" (Kahn, 1990, p.716). These findings confirm this proposition: if one has higher levels of self-efficacy, or more confidence and faith in their abilities, they will be more psychologically available to in turn become engaged in their work. With regard to extraversion, these findings provide support for the proposition that individuals who score higher on extraversion and therefore have higher energy, sociability, assertion, and gregariousness are ultimately more psychologically available than their counterparts and will, therefore, be more likely to be engaged in their job tasks.

Self-consciousness was expected to significantly affect work engagement through availability. The SEM results did not support this hypothesis (none of the pathways 
between any of the variables were significant), and neither did the hierarchical regressions that tested the mediating relationship. Though availability did prove to be significantly related to work engagement, self-consciousness did not exemplify a significant relationship with availability or work engagement. Looking at the correlation between self-consciousness and availability, one can see that these two were significantly and negatively related to one another, though that relationship was small $(r=-.09, \mathrm{p}<$ $.05)$. This finding demonstrates that though these two might be slightly related, once thrown into a regression that controls for certain demographic variables, that relationship quickly disappears. Therefore, one can conclude that though there might be a very small relationship between self-consciousness and availability, as laid forth in the first chapter of this dissertation, that relationship is not strong enough to explain variance over and above what other variables might be explaining in psychological availability. Furthermore, the relationship between self-consciousness and work engagement, according to correlations, was positive and significant $(r=.11, \mathrm{p}<.05)$. Though this was small, it once again contradicts the effect that the researcher had originally thought selfconsciousness would have on other variables in the model. Rather than having a predominantly negative effect on variables that positively influence job performance, self-consciousness seems to have sometimes positive and other times negative effects on those variables. Conclusively, self-consciousness and its effect on workplace attitudes and productivity needs to be researched further, perhaps by using all self-consciousness scales as opposed to just the one that was used for this study (Public Self-Consciousness Scale). 
One relationship that was incorporated into the SEM model remains to be discussed: the pathway from safety to availability that was incorporated into the SEM model according to modification indices. This pathway was incorporated into the model because it makes conceptual sense that one's level of psychological safety could affect how psychologically available they are. Furthermore, the correlation between these two conditions was very strong and positive. According to Kahn, psychological safety refers to feeling "able to show and employ one's self without fear of negative consequences to self-image, status, or career" (Kahn, 1990, p.708). Psychological availability is a measure of how physically, emotionally, and cognitively available one is. Kahn found that two of the factors, among others, that influenced availability were depletion of emotional energy and individual insecurity. Judging by safety's significant negative relationship with neuroticism, as seen in correlations and regressions testing for mediation, we can conclude that safety is affected by one's level of insecurity. Neuroticism also has a similar relationship with availability. Therefore, the pathway from safety to availability makes sense to incorporate as it is simply communicating that individuals that feel less safe may feel this way because they are insecure, and feeling less safe in their surroundings makes them less emotionally available to do what is required for their job. The pathway between safety and availability was moderately strong and suggests that, in addition to being independently related to work engagement, safety might also work through availability to affect engagement. To look further into this possibility, a series of regressions tested whether or not availability partially mediated the relationship that safety has with engagement. Results are presented in 
Appendix 19 and show that availability does indeed partially mediate the relationship between safety and engagement.

In the interest of examining how the psychological conditions differentially related to work engagement, the researcher studied results from the analysis in which engagement was regressed onto psychological conditions as a block. These results show that when all three conditions are included in the regression, meaningfulness and safety have a significant effect on engagement, but availability does not. To determine which psychological condition was accounting for the same variance in work engagement for which availability did, a couple more regressions were run. The psychological conditions were added one at a time in order to determine at which point availability's relationship to engagement became non-significant. In the first regression, availability was added first, then safety, and finally meaningfulness. Availability was significantly related to engagement until meaningfulness was added to the regression. In the second regression, availability was added first, then meaningfulness, and finally safety. Again, availability was significantly related to engagement until the third independent variable (in this case, safety) was added. Ultimately, this suggests that combined qualities in meaningfulness and safety account for all of the variance that availability seems to explain in work engagement. The strong correlation between safety and availability suggests that these two conditions probably explain more common variance in work engagement than one of these and meaningfulness. At this point, no final conclusions can be drawn regarding the relationship that availability has with the other psychological conditions in the context of work engagement. Future research should look further into this issue and determine 
whether it is necessary to include additional paths when using Kahn's model in order to account for the close relationship between safety and availability.

The final relationship examined in this dissertation was between work engagement and organizational citizenship behavior (OCB). The purpose of this assessment was to ensure that, after the results have given better insight into the process and predictors that lead to work engagement, work engagement itself is actually related to desirable outcomes in the workplace. Though OCB refers to behaviors that reflect going above and beyond the call of duty regarding their job description, it has been associated with such individual and organizational outcomes as performance evaluations, managers' reward allocation decisions, employee withdrawal, as well as efficiency, productivity, profitability, and costs of the organization (Allen \& Rush, 1998; Chen, 2005; Dunlop \& Lee, 2004; Ehrhart \& Naumann, 2004; Koys, 2001; MacKenzie et al., 1991; Podsakoff \& MacKenzie, 1997; Walz \& Niehoff, 2000). The results of the hierarchical regression determining the relationship between work engagement and OCB confirm previous research findings that support a strong, positive relationship between these two variables (Babcock-Roberson \& Strickland, 2010; Christian et al., 2011). Therefore, we can conclude that support was found for Kahn's (1990) assertion that engaged employees are likely to possess a broader conception of their work role, making them likely to expend effort beyond the formal boundaries of their job to benefit the organization as well as the workers within it.

Summary of conceptual model. To this day, only two studies have tested Kahn's (1990) model that assesses the psychological conditions as mediators between engagement and job/personal features. These two studies are those by May et al. (2004) 
and Olivier and Rothmann, 2007. This dissertation expanded on findings from these studies by incorporating variables into Kahn's (1990) model that have proven to be significant predictors of engagement using the JD-R model.

Previously, research had found support for meaningfulness' role as a mediator between engagement and the following predictors: job enrichment, work-role fit, and coworker relations (May et al., 2004; Olivier \& Rothman, 2007). This study confirmed some of these findings, while also arriving at new ones relevant to this relationship. Once again, meaningfulness proved to significantly mediate the relationships that PJ fit (similar to work-role fit) and co-worker relations had with work engagement. In addition, this study found that meaningfulness mediates the relationships between the following predictors and engagement: autonomy, supervisor support, procedural justice, and interactional justice.

With regard to psychological safety, May et al. (2004) and Olivier and Rothmann (2007) found that it mediates the relationship that engagement has with adherence to coworker norms and self-consciousness. This study did not find support for safety acting as a mediator between self-consciousness and engagement and did not include adherence to co-worker norms in its model. However, it did find support for other predictors whose relationships with engagement were mediated by safety. These predictors are as follows: autonomy, co-worker relations, supervisor support, procedural justice, interactional justice, self-efficacy, and neuroticism.

Finally, these two previous studies found that availability mediated the relationships of engagement with cognitive, emotional, and physical resources, as well as with outside activities. This study did not include these particular predictors in its model. 
However, it found that availability mediates the relationships of self-efficacy, extraversion, and neuroticism with work engagement.

Taking all results from this study into consideration, more support was found for the JD-R model than Kahn's model. Whereas ample support was found for the JD-R model's argument that job features are strong predictors of work engagement, mixed findings were derived regarding Kahn's proposition that the psychological conditions of meaningfulness, safety, and availability mediate the relationships between job features and work engagement. Future research should examine these psychological conditions and their relationships with engagement more closely to determine whether or not these constructs really do play a role in work engagement's nomological net.

\section{Organizational Implications}

Findings from this study support that work engagement is not only a construct unique to such related constructs as job satisfaction and organizational commitment, but it is also one that organizations should pay attention to, considering its strong, positive relationship with OCB. Employees that are highly engaged in their work are more likely to go above and beyond the roles that are expected of them and perform tasks that are helpful to co-workers and the organization at large. One of the most significant and powerful predictors of work engagement is how meaningful one's job is to them. Meaningfulness is strongly associated with the fit between self and job. Individuals whose jobs are a closer fit with their authentic selves as well as their abilities are highly likely to perceive their jobs as meaningful. In other words, if individuals feel as though their job gives them an avenue through which to express their own personal beliefs and values while also allowing them to utilize the abilities that they have, they will be more 
likely to feel as though they are doing meaningful work and, as a result, be engaged in their job.

With regard to the finding concerning PJ fit, meaningfulness, and engagement, organizations would benefit from selecting employees that demonstrate higher fit with positions for which they are hiring. Such fit could initially be observed during interviews as well as through assessments used during selection to determine applicants' knowledge, skills, abilities, and other characteristics (KSAOs). Individuals that seem to have beliefs and values in line with those of the organization as well as KSAOs that line up with the requirements of the job will be more likely to perceive it as meaningful and, in turn, be more engaged in it. Realistic job previews (RJPs) could also help the employee and company ensure that a good fit is achieved between a new hire and the position.

Results show that meaningfulness was also influenced by such variables as autonomy, co-worker relations, supervisor support, procedural justice, and interactional justice. Many of these variables are controlled and influenced by organizational factors. Therefore, organizations should do what they can to help employees experience high levels of each of these. Supervisors in the company can play a pivotal role in encouraging their employees to take control of their job responsibilities and making workers feel supported and fairly treated. Furthermore, the organization should do what is necessary to foster a culture where co-workers have the chance to get to know those working around them and connect with them outside of their work roles so that they can foster good relationships. Companies can make significant positive steps in this direction by arranging social events to take place outside of work hours, gathering employees on a monthly basis to celebrate the birthdays of each month, constructing a break/lunch room 
that is comfortable and appealing so that employees will take breaks together rather than be tempted to go out to lunch alone, etc. Finally, the procedures that are performed in the organization should be fair and have high face validity in order to help foster high procedural justice perceptions among employees.

Perceptions of psychological safety also influenced work engagement among employees. Safety was affected by autonomy, co-worker relations, supervisor support, procedural justice, interactional justice, self-efficacy, and neuroticism. The previous paragraph discussed how organizations can help to increase all of the job features that were listed as predictors of safety, so now the focus turns to how the organization can foster higher levels of self-efficacy and emotional stability among its employees. One way to do so is to select employees that score higher on these characteristics. Again, such selection can be achieved through the interview as well as other assessment tools. Organizations can also attempt to foster higher self-efficacy and at least help calm those that are more neurotic by being more supportive of them and giving positive feedback on a regular basis to the employees. They can also ensure that employees have the appropriate skills for the job that they are performing by holding training sessions regularly throughout the year. This practice will help employees feel more confident in their abilities to perform the job and will likely foster higher levels of self-efficacy and help to keep anxieties down to a minimum.

Psychological availability was influenced by self-efficacy, extraversion, and neuroticism. Individuals that were more psychologically available proved to be more engaged in their work. Therefore, it would be in the best interest of the organization to try to help employees become more psychologically available for their positions. One 
way to do this, again, would be to select employees with higher levels of self-efficacy, extraversion, and lower neuroticism. It is not possible to foster higher extraversion levels among current employees. However, organizations could try to foster higher levels of self-efficacy and emotional stability in employees by alleviating some outside stressors and responsibilities. They could, for example, provide employee wellness programs and benefits such as good healthcare packages, on-site daycare, yoga and/or gym facilities, and other perks to help employees achieve better work-life balance. If employees do not feel so inundated with life's stressors (work and non-work), they will feel and possibly be more available for their work role.

\section{Limitations}

There are a few limitations to this study that were previously mentioned but not thoroughly discussed. One of the first limitations is that the data for this study was gathered online from employees working across a range of locations, occupations, and fields. Though this variable was controlled for in most of the analyses run for this study, it would still be most beneficial to run this study in one organization and see if the results would be different. Another limitation of this study was the reliability that was achieved for the measure of psychological safety, $\alpha=.67$, which is lower than the guideline of .70 (Nunnally \& Bernstein, 1994). Though the alpha was not so low as to warrant dropping psychological safety from the model, it still brings up questions as to whether stronger relationships would have been found between safety and engagement as well as its predictors had the measure been more reliable. Previous researchers (e.g., Olivier \& Rothmann, 2007) have had problems with this measure before (they only achieved an alpha of .41), most likely due to the fact that not only does this measure have 3 items, but 
two of those items are reverse-coded. Before future research is done to test the Kahn's (1990) model further, it would be most beneficial for researchers to perform a scale development study on the measure for psychological safety so that this problem is not encountered in the future.

A final limitation to this study was that the predictors chosen to represent job features were highly correlated with one another. Because of such high correlations, the researcher encountered issues when trying to run analyses to see if the psychological conditions mediated the relationships between job features and engagement. Specifically, when testing for mediation, the job features could not be included in the same regression analysis. This limitation may be what is responsible for not finding many significant relationships between job feature predictors and meaningfulness or safety in the SEM model. When testing a similar model in the future, researchers should try to choose predictors that are not so highly correlated with one another. On a related note, future research might benefit from running a study to determine how much incremental validity this study's predictors explain in engagement over and above one another. Such a future study could help other researchers decide which predictors would be best to use in future studies that examine the nomological net of work engagement and help practitioners narrow down exactly which characteristics they need to look for and promote in the workplace to increase engagement levels.

\section{Conclusion}

This study examined the factor-structure of work engagement, its distinction from related I-O psychology constructs, its relationship with $\mathrm{OCB}$, and the underlying process and predictors that lead to work engagement. Findings support the three-factor model of 
engagement that was proposed by Schaufeli et al. (2002) as well as its distinction from the related constructs of job satisfaction and organizational commitment. Two of the most prominent models used to research engagement (the JD-R model and Kahn's model) were merged to test certain job features and personal characteristics as predictors of engagement that work through the three psychological conditions of meaningfulness, safety, and availability to affect it. The only predictor for which support was not found of its effect on engagement through these conditions was self-consciousness. Future researchers should build upon these findings in order to further assess the construct of work engagement and its underlying process. Organizations should take these results into account and not only understand that work engagement is an extremely important construct relative to job performance, but also one that can easily be fostered through employee selection, training, culture, benefits, and interpersonal relations within the workplace. 


\section{REFERENCES}

Adams, J.S. (1965). Inequity in social exchange. In L. Berkowitz (Ed.), Advances in experimental social psychology (Vol. 2, pp.267-299). New York: Academic Press.

Aktouf, O. (1992). Management and theories of organizations in the 1990s: Toward a critical radical humanism. Academy of Management Review, 17, 407-431.

Alderfer, C.P. (1972). Existence, relatedness and growth: Human needs in organizational settings. New York: The Free Press.

Alderfer, C.P. (1985). An intergroup perspective on group dynamics. In J.Lorsch (Ed.). Handbook of organizational behavior. 190-222. Englewood Cliffs, N.J.: PrenticeHall.

Allen, J., \& Mellor, D. (2002). Work context, personal control, and burnout among Nurses. Western Journal of Nursing Research, 24, 905-917.

Allen, N.J., \& Meyer, J.P. (1990). The measurement and antecedents of affective, continuance and normative commitment to the organization. Journal of Occupational Psychology, 63, 1-18.

Allen, T.D., \& Rush, M.C. (1998). The effects of organizational citizenship behavior on performance judgments: A field study and a laboratory experiment. Journal of Applied Psychology, 83, 247-260.

Amabile, T.M. (1983). The social psychology of creativity. New York: Springer.

Amabile, T.M., Conti, R., Coon, H., Lazenby, J., \& Herron, M. (1996). Assessing the Work Environment for Creativity. The Academy of Management Journal, 39, 1154-1184.

Arnold, K.A., Turner, N., Barling, J., Kelloway, E.K., \& McKee, M.C. (2007). Transformational leadership and psychological well-being: The mediating role of meaningful work. Journal of Occupational Health Psychology, 12, 193-203.

Babcock-Roberson, M.E., \& Strickland, O.J. (2010). The Relationship Between Charismatic Leadership, Work Engagement, and Organizational Citizenship Behaviors. The Journal of Psychology, 144, 313-326.

Bachrach, D.G., Bendoly, E., \& Podsakoff, P.M. (2001). Attributions of the "causes" of group performance as an alternative explanation of the relationship between organizational citizenship behavior and organizational performance. Journal of Applied Psychology, 86, 1285-1293. 
Bakker, A.B., \& Bal, P.M (2010). Weekly work engagement and performance: A study among starting teachers. Journal of Occupational and Organizational Psychology, 83, 189-206.

Bakker, A.B., \& Demerouti, E. (2007). The job demands-resources model: state of the art. Journal of Managerial Psychology, 22, 309-328.

Bakker, A.B., \& Demerouti, E. (2008). Towards a model of work engagement. Career Development International, 13, 209-223.

Bakker, A.B., Demerouti, E., \& Schaufeli, W.B. (2003). Dual processes at work in a call centre: An application of the Job Demands-Resources model. European Journal of Work and Organizational Psychology, 12, 393-417.

Bakker, A.B., Demerouti, E., \& Schaufeli, W.B. (2005). The crossover of burnout and work engagement among working couples. Human Relations, 58, 661-689.

Bakker, A.B., Demerouti, E., \& Verbeke, W. (2004). Using the Job Demands-Resources model to predict burnout and performance, Human Resource Management, 43, 83-104.

Bakker, A.B., Gierveld, J.H., \& Van Rijswijk, K. (2006). Successfactoren bij vrouwelijke schoolleiders in het primair onderwijs: Een onderzoek naar burnout, bevlogenheid en prestaties (Success factors among female school principals in primary teaching: A Study on Burnout, Work Engagement, and Performance), Right Management Consultants, Diemen.

Bakker, A.B., Hakanen, J.J., Demerouti, E., \& Xanthopoulou, D. (2007). Job resources boost work engagement, particularly when job demands are high. Journal of Educational Psychology, 99, 274-284.

Bakker, A.B., \& Leiter, M.P. (2010). A Handbook of Essential Theory and Research. New York: Psychology Press.

Bakker, A.B., Schaufeli, W.B., Leiter, M.P., \& Taris, T.W. (2008). Work engagement: An emerging concept in occupational health psychology. Work \& Stress, 22, 187 200.

Bakker, A.B., Van Emmerik, I.J., \& Euwema, M.C. (2006). Crossover of burnout and engagement in work teams. Work and Occupations, 33, 464-489.

Bakker, A.B., Van Veldhoven, M., \& Xanthopoulou, D. (2010). Beyond the DemandControl Model: Thriving on High Job Demands and Resources. Journal of Personnel Psychology, 9, 3-16. 
Bandura, A. (1977a). Social learning theory. Englewood Cliffs, NJ: Prentice-Hall.

Bandura, A. (1977b). Self-efficacy: Toward a unified theory of behavioral change. Psychological Review, 84, 191-215.

Bandura, A. (1982). Self-efficacy mechanism in human agency. American Psychologist, $37,122-147$.

Bandura, A. (1986). The social foundations of thought and action. Englewood Cliffs, NJ: Prentice-Hall.

Barrick, M.R., \& Mount, M.K. (1991). The big five personality dimensions and job performance: A meta-analysis. Personnel Psychology, 44, 1-26.

Barrick, M.R., Mount, M.K., \& Judge, T.A. (2001). Personality and Performance at the Beginning of the New Millennium: What do we know and where do we go next? Personality and Performance, 9, 9-30.

Baron, R.M, \& Kenny, D.A. (1986). The Moderator-Mediator Variable Distinction in Social Psychological Research: Conceptual, Strategic, and Statistical Considerations. Journal of Personality and Social Psychology, 51, 1173-1182.

Bennis, W., Schein, E.H., Berlew, D.E., \& Steele, F.I. (1964). Interpersonal dynamics: Essays and readings on human interaction. Homewood, Ill.: Dorsey Press.

Bies, R.J., \& Moag, J.F. (1986). Interactional justice: Communication criteria of fairness. In R.J. Lewicki, B.H. Sheppard, \& M.H.Bazerman (Eds.), Research on negotiations in organizations (Vol. 1, pp. 43-55). Greenwich, CT: JAI Press.

Bion, W.R., (1961). Experience in groups. New York: Basic Books.

Bogels, S.M., Alberts, M., \& de Jong, P.J. (1996). Self-consciousness, self-focused attention, blushing propensity and fear of blushing. Person. Individ. Diff., 21 573581.

Borman, W.C., \& Motowidlo, S.J. (1993). Expanding the criterion domain to include elements of contextual performance. In N. Schmitt, W.C. Borman, \& Associates (Eds.), Personnel selection in organizations (pp. 71-98). San Francisco JosseyBass.

Borman, W.C., \& Motowidlo, S.J. (1997). Task performance and contextual performance: The meaning for personnel selection research. Human Performance, 10, 99-109. 
Brief, A., \& Nord, W.R. (1990). Work and nonwork connections. In A. Brief \& W.R. Nord (Eds.), Meanings of occupational work (pp. 171-199). Lexington, MA: Lexington Books.

Britt, T.W., Adler, A.B., \& Bartone, P.T. (2001). Deriving benefits from stressful events: The role of engagement in meaningful work and hardiness. Journal of Occupational Health Psychology, 6, 53-63.

Brkich, M., Jeffs, D., \& Carless, S.A. (2002). A Global Self-Report Measure of PersonJob Fit. European Journal of Psychological Assessment, 18, 43-51.

Brooke, P., Russell, D., \& Price, J. (1988). Discriminant validation of measures of job satisfaction, job involvemen, and organizational commitment. Journal of Applied Psychology, 73, 139-145.

Brown, S.P., \& Leigh, T.W. (1996). A new look at psychological climate and its relationship to job involvement, effort, and performance. Journal of Applied Psychology, 81, 358-368.

Brown, T.A. (2006). Confirmatory Factor Analysis for Applied Research. New York: Guildford Press.

Buhrmester, M., Kwang, T., \& Gosling, S.D. (2011). Amazon's Mechanical Turk: A New Source of Inexpensive, Yet High-Quality, Data? Perspectives on Psychological Science, 6, 3-5.

Byrne, B.M. (2001). Structural Equation Modeling with AMOS. New Jersey: Lawrence Erlbaum Associates, Inc.

Cartwright, S., \& Holmes, N. (2006). The meaning of work: The challenge of regaining employee engagement and reducing cynicism. Human Resource Management Review, 16, 199-208.

Carver, C.S. (1974). Facilitation of physical aggression through objective self-awareness. Journal of Experimental Social Psychology, 10, 365-370.

Carver, C.S. (1975). Physical aggression as a function of objective self-awareness and attitudes toward punishment. Journal of Experimental Social Psychology, 11, 510-519.

Carver, C.S., \& Scheier, M.F. (1978). Self-Focusing Effects of Dispositional SelfConsciousness, Mirror Presence, and Audience Presence. Journal of Personality and Social Psychology, 36, 324-332.

Caplan, R.D. (1983). Person-environment fit: Past, present, and future. In Cooper CL 
(Ed.), Stress research (pp. 35-78). New York: Wiley.

Chalofsky, N., \& Krishna, V. (2009). Meaningfulness, Commitment, and Engagement: The Intersection of a Deeper Level of Intrinsic Motivation. Advances in Developing Human Resources, 11, 189-203.

Chen, X.-P. (2005). Organizational citizenship behavior: A predictor of employee voluntary turnover. In D.L. Turnipseed (Ed.), Handbook of organizational citizenship behavior (pp. 435-454). New York: Nova Science.

Chen, Z., Zhang, X., \& Vogel, D. (2011). Exploring the Underlying Processes Between Conflict and Knowledge Sharing: A Work-Engagement Perspective. Journal of Applied Social Psychology, 41, 1005-1033.

Christian, M.S., Garza, A.S., \& Slaughter, J.E. (2011). Work Engagement: A quantitative Review and Test of its Relations with Task and Contextual Performance. Personnel Psychology, 64, 89-136.

Cho, J., Laschinger, H.K.S., \& Wong, C. (2006). Workplace Empowerment, Work Engagement, and Organizational Commitment of New Graduate Nurses. Nursing Leadership, 19, 43-60.

Colquitt, J.A. (2001). On the Dimensionality of Organizational Justice: A Construct Validation of a Measure. Journal of Applied Psychology, 86, 386-400.

Colquitt, J.A., Conlon, D.E., Wesson, M.J., Porter, C.O.L.H., \& Ng, K.Y. (2001). Justice at the millennium: A meta-analytic review of 25 years of organizational justice research. Journal of Applied Psychology, 86, 386-400.

Colquitt, J.A., Noe, R.A., \& Jackson, C.L. (2002). Justice in teams: Antecedents and consequences of procedural justice climate. Personnel Psychology, 55, 83-109.

Crawford, E.R., LePine, J.A., \& Rich, B.L. (2010). Linking Job Demands and Resources to Employee Engagement and Burnout: A Theoretical Extension and MetaAnalytic Test. Journal of Applied Psychology, 95, 834-848.

Csikszntmihalyi, M. (1975). Beyond boredom and anxiety. San Francisco: Jossey-Bass.

Csikszntmihalyi, M. (1990). Flow: The psychology of optimal experience. New York: Harper.

Darling, J., \& Chalofsky, N. (2004). Spirituality in the workplace. In M. Marquardt (Ed.), Encyclopedia of life support systems (EOLSS). Oxford, UK: EOLSS.

Darlington, R.B. (1968). Multiple regression in psychological research. Psychological 
Bulletin, 79, 161-182.

Day, D.V., \& Bedeian, A.G. (1995). Personality similarity and work-related outcomes among African-American nursing personnel: A test of the supplementary model of person-environment congruence. Journal of Vocational Behavior, 46, 55-70.

Deci, E.L., \& Ryan, R.M. (1985). The General Causality Orientations Scale: SelfDetermination in Personality. Journal of Research in Personality, 19, 109-134.

Deci, E.L., \& Ryan, R.M. (1987). The support of autonomy and the control of behavior. Journal of Personality and Social Psychology, 53, 1024-1037.

Deci, E.L., Connell, J.P., \& Ryan, R.M. (1989). Self-determination in a work organization. Journal of Applied Psychology, 74, 580-590.

De Vries, J., Van Heck, G.L. (2002). Fatigue: relationships with basic personality and temperament dimensions. Personality and Individual Differences, 33, 1311-1324.

Demerouti, E., Bakker, A.B., De Jonge, J., Janssen, P.P.M., \& Schaufeli, W.B. (2001). Burnout and engagement at work as a function of demands and control. Scandinavian Journal of Work, Environment and Health, 27, 279-286.

Demerouti, E., Bakker, A.B., Nachreiner, F., \& Schaufeli, W.B. (2001). The job demands-resources model of burnout. Journal of Applied Psychology, 86, 499512.

Demerouti, E., \& Cropanzano, R. (2010). From thought to action: Employee work engagement and job performance. In A.B. Bakker \& M.P. Leiter (Eds.), Work Engagement: A Handbook of Essential Theory and Research. New York: Psychology Press.

Deutsch, M. (1975). Equity, equality, and need: What determines which value will be used as the basis of distributive justice? Journal of Social Issues, 31, 137-150.

Diener, E., \& Lucas, R.E. (1999). Personality and subjective well-being. In D. Kahneman, E. Diener, \& N. Schwarz (Eds.), Well-being: The foundations of hedonic psychology (pp. 215-229). New York: Russell Sage Foundation.

Dollard, M.F., \& Bakker, A.B. (2010). Psychosocial safety climate as a precursor to conducive work environments, psychological health problems, and employee engagement. Journal of Occupational and Organizational Psychology, 83, 579599 .

Dunlop, P.D., \& Lee, K. (2004). Workplace deviance, organizational citizenship 
behavior, and business unit performance: The bad apples do spoil the whole barrel. Journal of Organizational Behavior, 25, 67-80.

Duval, S., \& Wicklund, R.A. (1972). A theory of objective self-awareness. New York: Academic Press.

Eden, D. (2001). Vacations and other respites: Studying stress on an off the job. In C.L. Cooper, \& I.T. Robertson (Eds.), International review of industrial and organizational psychology. New York: Wiley.

Edmondson, A. (2004). Psychological Safety, Trust and Learning: A Group-level Lens. In R. Kramer, \& K. Cook (Eds.), Trust and Distrust in Organizations: Dilemmas and Approaches. New York: Russell Sage.

Edwards, J.R. (1991). Person-job fit: A conceptual integration, literature review, and methodological critique. In Cooper CLRIT (Ed.), International review of industrial and organizational psychology. Chichester, UK: Wiley.

Edwards, J.R., \& Cooper, C.L. (1990). The Person-Environment Fit Approach to Stress: Recurring Problems and Some Suggested Solutions. Journal of Organizational Behavior, 11, 293-307.

Ehrhart, M.G. (2004). Leadership and procedural justice climate as antecedents of unitlevel organizational citizenship behavior. Personnel Psychology, 57, 61-94.

Ehrhart, M.G., \& Naumann, S.E. (2004). Organizational citizenship behavior in work groups: A group norms approach. Journal of Applied Psychology, 89, 960-974.

Farh, J.L., Earley, P.C., \& Lin, S.C. (1997). Impetus for action: A cultural analysis of justice and organizational citizenship behavior in Chinese society. Administrative Science Quarterly, 42, 421-444.

Farh, J.L., Zhong, C.B., \& Organ, D.W. (2004). Organizational citizenship behavior in the People's Republic of China. Organization Science, 15, 241-253.

Fenigstein, A., Scheier, M.F., \& Buss, A.H. (1975). Public and Private SelfConsciousness: Assessment and Theory. Journal of Consulting and Clinical Psychology, 43, 522-527.

Frankl, V. (1992). Man's search for meaning: An introduction to logotherapy. Boston: Beacon.

Fredrickson, B.L. (2001). The role of positive emotions in positive psychology: The broaden-and-build theory of positive emotions. American Psychologist, 56, 218226. 
Fredrickson, B.L., \& Losada, M.F. (2005). Positive affect and the complex dynamics of human flourishing. American Psychologist, 60, 678-686.

French, J.R.P. Jr., Caplan, R.D., \& Harrison, R.V. (1982). The mechanisms of job stress and strain. London: Wiley.

French, J.R.P. Jr., Rogers, W., \& Cobb, S. (1974). Adjustment as person-environment fit. In Coelho, D.A.H.G.V., Adams, J.E. (Ed.), Coping and adaptation. New York: Basic Books.

Fried, Y.C., \& Ferris, G.R., (1987). The validity of the job characteristics model: A review and meta-analysis. Personnel Psychology, 40, 287-322.

Frone, M.R. (2003). Work-family balance. In Quick, J.C. (Ed.), Handbook of occupational health psychology. Washington, DC: American Psychological Association.

Fox, S., \& Spector, P.E. (2011). Organizational Citizenship Behavior Checklist (OCB-C). Retrieved May 16, 2012, from http://shell.cas.usf.edu/ ppspector/scales/ocbcpage.html

Fox, S., Spector, P.E., Goh, A., Bruursema, K., \& Kessler, S.R. (In press). The deviant citizen: Measuring potential positive relations between counterproductive work behavior and organizational citizenship behavior. Journal of Occupational and Organizational Psychology.

Ganster, D.C., \& Schaubroeck, J. (1991). Work stress and employee health. Journal of Management, 17, 235-271.

Goddard, R., Patton, W., \& Creed, P. (2004). The importance and place of neuroticism in predicting burnout in employment service case managers. Journal of Applied Social Psychology, 34, 282-296.

Goffman, E. (1959). The presentation of self in everyday life. New York: Doubleday Anchor.

Goffman, E. (1961). Encounters: Two studies in the sociology of interaction. Indianapolis: Bobbs-Merrill Co.

Goldberg, L. R. (1999). A broad-bandwidth, public-domain, personality inventory measuring the lower-level facets of several five-factor models. In I. Mervielde, I. Deary, F. De Fruyt, \& F. Ostendorf (Eds.), Personality Psychology in Europe. Tilburg, The Netherlands: Tilburg University Press. 
Goldberg, L.R., Johnson, J.A., Eber, H.W., Hogan, R., Ashton, M.C., Cloninger, C.R., \& Gough, H.G. (2006). The international personality item pool and the future of public-domain personality measures. Journal of Research in Personality, 40, 8496.

Graham, J.W. (1989). Organizational citizenship behavior: Construct redefinition, operationalization, and validation. Unpublished working paper, Loyola University of Chicago.

Graham, J.W. (1991). An essay on organizational citizenship behavior. Employee Responsibilities and Rights Journal, 4, 249-270.

Greco, P., Laschinger, H.K.S., \& Wong, C. (2006). Leader empowering behaviors, staff nurse empowerment and work engagement/burnout. Nursing Leadership, 19, 4156.

Greenberg, J. (1990). Employee theft as a reaction to underpayment inequity: The hidden cost of pay cuts. Journal of Applied Psychology, 75, 561-568.

Greenberg, J. (1993). The social side of fairness: Interpersonal and informational classes of organizational justice. In R. Cropanzano (Ed.), Justice in the workplace: Approaching fairness in human resource management. Hillsdale, NJ: Erlbaum.

Hackman, J.R. (1986). The psychology of self-management in organizations. In M.S. Pallak \& R.O. Perloff (Eds.), Psychology and work: Productivity, change, and employment. Washington, D.C.: American Psychological Association.

Hackman, J.R., \& Oldham, G.R. (1976). Motivation through the design of work: Test of a theory. Organizational Behavior and Human Performance, 16, 250-279.

Hackman, J.R., \& Oldham, G.R. (1980). Work redesign. Reading, MA: Addison-Wesley.

Hakanen, J.J., Bakker, A.B., \& Schaufeli, W.B. (2006). Burnout and work engagement among teachers. Journal of School Psychology, 43, 495-513.

Hakanen, J.J., \& Roodt, G. (2010). Using the job demands-resources model to predict engagement: Analysing a conceptual model. In A.B. Bakker \& M.P. Leiter (Eds.), Work Engagement: A Handbook of Essential Theory and Research. New York: Psychology Press.

Hakanen, J.J., Perhoniemi, R., \& Toppinen-Tanner, S. (2008). Positive gain spirals at work: From job resources to work engagement, personal initiative, and work-unit innovativeness. Journal of Vocational Behavior, 73, 78-91.

Hakanen, J.J., Schaufeli, W.B., \& Ahola, K. (2008). The job demands-resources model: 
A three-year cross-lagged study of burnout, depression, commitment, and work engagement. Work \& Stress: An International Journal of Work, Health \& Orgaisations, 22, 224-241.

Halbesleben, J.R.B., \& Wheeler, A.R. (2008). The relative roles of engagement and embeddedness in predicting job performance and intention to leave. Work \& Stress, 22, 242-256.

Halbesleben, J.R.B. (2010). A meta-analysis of work engagement: Relationships with burnout, demands, resources, and consequences. In A.B. Bakker \& M.P. Leiter (Eds.), Work Engagement: A Handbook of Essential Theory and Research. New York: Psychology Press.

Hallberg, U.E., Johansson, G., \& Schaufeli, W.B. (2007). Type A behavior and work situation: Associations with burnout and work engagement. Scandinavian Journal of Psychology, 48, 135-142.

Hallberg, U., \& Schaufeli, W.B. (2006). "Same same" but different? Can work engagement be discriminated from job involvement and organizational commitment? European psychologist, 11, 119-127.

Hansez, I., \& Chmiel, N. (2010). Safety behavior: Job demands, job resources, and perceived management commitment to safety. Journal of Occupational Health Psychology, 15, 267-278.

Harrison, R.V. (1978). Person-environment fit and job stress. In Cooper C.L., Payne, R. (Eds.), Stress at work. New York: Wiley.

Harter, J.K., Schmidt, F.L., \& Hayes, T.L. (2002). Business-unit level relationship between employee satisfaction, employee engagement, and business outcomes: A meta-analysis. Journal of Applied Psychology, 87, 268-279.

Herzberg, F., Mausner, B., \& Snyderman, B.B. (1959). The motivation to work. New York: Wiley.

Hobfoll, S.E. (1989). Conservation of resources: A new attempt at conceptualizing stress. American Psychologist, 44, 513-524.

Hobfoll, S.E., Johnson, R.J., Ennis, N., \& Jackson, A.P. (2003). Resources loss, resource gain, and emotional outcomes among inner city women. Journal of Personality and Social Psychology, 84, 632-643.

Hochschild, A.R. (1983). The managed heart: Commercialization of human feeling. Berkeley: University of California Press. 
Homans, G. (1961). Social behavior: Its elementary forms. London: Routledge \& Kegan Paul.

Hu, L.-T., \& Bentler, P.M. (1995). Evaluating model fit. In R.H. Hoyle (Ed.), Structural equation modeling: Concepts, issues, and applications (pp.76-99). Thousand Oaks, CA: Sage.

Inceoglu, I., \& Warr, P. (2011). Personality and Job Engagement. Journal of Personnel Psychology, 10, 177-181.

Jaccard, J., \& Wan, C.K. (1996). LISREL analyses of interaction effects in multiple regression. Newbury Park, CA: Sage.

James, J.B., McKechnie, S., \& Swanberg, J. (2011). Predicting employee engagement in an age-diverse retail workforce. Journal of Organizational Behavior, 32, 173-196.

Johnson, J.V., \& Hall, E.M. (1988). Job strain, workplace social support and cardiovascular disease: A cross-sectional study of a random sample of the Swedish working population. American Journal of Public Health, 78, 1336-1342.

Judge, T.A., Bono, J.E., Erez, A., \& Locke, E.A. (2005). Core self-evaluations and job and life satisfaction: The role of self-concordance and goal attainment. Journal of Applied Psychology, 90, 257-268.

Judge, T.A., \& Colquitt, J.A. (2004). Organizational Justice and Stress: The Mediating Role of Work-Family Conflict. Journal of Applied Psychology, 89, 395-404.

Judge, T.A., Van Vianen, A.E.M., \& De Pater, I. (2004). Emotional stability, core selfevaluations, and job outcomes: A review of the evidence and an agenda for future research. Human Performance, 17, 325-346.

Kahn, W.A. (1990). Psychological conditions of personal engagement and disengagement at work. Academy of Management Journal, 33, 692-724.

Kahn, W.A. (1992). To be fully there: Psychological presence at work. Human Relations, $45,321-349$.

Karasek, R.A. (1979). Job demands, job decision latitude, and mental strain: Implications for job redesign. Administrative Science Quarterly, 24, 285-308.

Kenny, D. A. (2012, July 5). Measuring Model Fit. Retrieved from http://davidakenny.net/cm/fit.htm

Kilic, K.C., Keles, C., \& Gelibolu, L. (2010, June 8-9). The relationship between person- 
organization congruence, person-role conflict, and job outcomes of salesperson: A study in the international medicine company in Turkey. Paper presented at the $20102^{\text {nd }}$ International Symposium on Sustainable Development.

Kim, H.J., Shin, K.H., \& Umbreit, T. (2007). Hotel job burnout: The role of personality characteristics. International Journal of Hospitality Management, 26, 421-434.

Kim, H.J., Shin, K.H., \& Swanger, N. (2009). Burnout and engagement: A comparative analysis using the Big Five personality dimensions. International Journal of Hospitality Management, 28, 96-104.

Kline, R.B. (1998). Principles and practice of structural equation modeling. New York: Guildford Press.

Kline, R.B. (2011). Principles and Practice of Structural Equation Modeling $\left(3^{\text {rd }}\right.$ ed.). New York, NY: The Guilford Press.

Koys, D.J. (2001). The effects of employee satisfaction, organizational citizenship behavior, and turnover on organizational effectiveness: A unit-level, longitudinal study. Personnel Psychology, 54, 101-114.

Kristof-Brown, A.L., Zimmerman, R.D., \& Johnson, E.C. (2005). Consequences of individuals' fit at work: A meta-analysis of person-job, person-organization, person-group, and person-supervisor fit. Personnel Psychology, 58, 281-342.

Langelaan, S., Bakker, A.B., Van Doornen, L.J.P., \& Schaufeli, W.B. (2006). Burnout and work engagement: Do individual differences make a difference? Personality and Individual Differences, 40, 521-532.

LePine, J.A., LePine, M.A., \& Jackson, C.L. (2004). Challenge and hindrance stress: Relationships with exhaustion, motivation to learn, and learning performance. Journal of Applied Psychology, 89, 883-891.

LePine, J.A., \& Van Dyne, L. (1998). Predicting voice behavior in work groups. Journal of Applied Psychology, 853-868.

Leventhal, G.S. (1976). The distribution of rewards and resources in groups and organizations. In L. Berkowitz \& W. Walster (Eds.), Advances in experimental social psychology. New York: Academic Press.

Leventhal, G.S. (1980). What should be done with equity theory? New approaches to the study of fairness in social relationships. In K. Gergen, M. Greenberg, \& R. Willis (Eds.), Social exchange: Advances in theory and research. New York: Plenum.

Leventhal, G.S., Karuza, J., \& Fry, W.R. (1980). Beyond fairness: A theory of allocation 
preferences. In G. Mikula (Ed.), Justice and social interaction. New York: Springer-Verlag.

Llorens, S., Schaufeli, W., Bakker, A., \& Salanova, M. (2007). Does a positive gain spiral of resources, efficacy beliefs, and engagement exist? Computers in Human Behavior, 23, 825-841.

Locke, E.A. (1969). What is job satisfaction? Organizational Behavior and Human Performance, 4, 309-336.

Locke, E.A., \& Taylor, M.S. (1990). Stress, coping, and the meaning of work. In A. Brief $\&$ W.R. Nord (Eds.), Meanings of occupational work. Lexington, MA: Lexington Books.

Luthans, F., \& Youssef, C.M. (2007). Emerging positive organizational behavior. Journal of Management, 33, 321-349.

Maassen, G.H., \& Bakker, A.B. (2001). Suppressor Variables in Path Models. Sociological Methods \& Research, 30, 241-270.

Macey, W.H., \& Schneider, B. (2008). The meaning of employee engagement. Industrial and Organizational Psychology, 1, 3-30.

MacKenzie, S.B., Podsakoff, P.M., \& Fetter, R. (1991). Organizational citizenship behavior and objective productivity as determinants of managerial evaluations of salesperson's performance. Organizational Behavior and Human Decision Processes, 50, 123-150.

Madlock, P.E. (2008). The link between leadership style, communicator competence, and employee satisfaction. Journal of Business Communication, 45, 61-78.

Martela, F. (2010). Meaningful work-An integrative model based on the human need for meaningfulness. Retrieved April 14, 2012 from http://www.frankmartela.fi/bibliography/Martela2010_MeaninfulWork.doc

Maslach, C., Jackson, S. E., \& Leiter, M. P. (1996). Maslach Burnout Inventory. (3rd ed.). Palo Alto, CA: Consulting Psychologists Press.

Maslach, C., \& Leiter, M. P. (1997). The truth about burnout: How organizations cause personal stress and what to do about it. San Francisco, CA: Jossey-Bass.

Maslach, C., \& Leiter, M.P. (2008). Early predictors of job burnout and engagement. Journal of Applied Psychology, 93, 498-512. 
Maslach, C., Schaufeli, W. B., \& Leiter, M. P. (2001). Job Burnout. Annual Review of Psychology, 52, 397-422.

Maslow, A.H. (1943). A theory of human motivation. Psychological Review, 50, 370396.

Maslow, A.H. (1954). Motivation and personality. New York: Harper.

Maslow, A.H. (1971). The farther reaches of human nature. New York: Penguin.

Matamala, A. C., Pace, V. L., \& Jacobs, H. (2010, April). Work engagement as a mediator between personality and citizenship behavior. Interactive poster session at the 25th Annual Conference of the Society for Industrial and Organizational Psychology, Atlanta, GA.

Mauno, S., Kinnunen, U., \& Ruokolainen, M. (2007). Job demands and resources as antecedents of work engagement: A longitudinal study. Journal of Vocational Behavior, 70, 149-171.

May, D.R. (2003). Fostering the human spirit at work: Toward an understanding of the influences on employees' experienced meaningfulness at work. Unpublished manuscript.

May, R., Angel, E., \& Ellenberger, H.F. (Eds.). Existence. New York: Touchstone.

May, D.R., Gilson, R.L., \& Harter, L.M. (2004). The psychological conditions of meaningfulness, safety, and availability and the engagement of the human spirit at work. Journal of Occupational and Organizational Psychology, 77, 11-37.

McClelland, D.C. (1965, November/December). Achievement motivation can be developed. Harvard Business Review, 43, 7-16.

McGregor, D. (1960). The human side of enterprise. New York: McGraw-Hill.

Meyer, J.P., Allen, N.J., \& Smith, C.A. (1993). Commitment to organizations and occupations: Extension and test of a three-component conceptualization. Journal of Applied Psychology, 78, 538-551.

Meyer, J.P., Irving, P.G., \& Allen, N.J. (1998). Examination of the combined effets of work values and early work experiences on organizational commitment. Journal of Organizational Behavior, 19, 29-52.

Mills, L.B., \& Huebner, E.S. (1998). A prospective study of personality characteristics, 
occupational stressors, and burnout among school psychology practitioners. Journal of School Psychology, 36, 103-120.

Montgomery, A.J., Peeters, M., Schaufeli, W.B., \& Den Ouden, M. (2003). Work-home interference among newspaper managers: Its relationship with burnout and engagement. Anxiety, Stress, and Coping, 16, 195-211.

Morgeson, F.P., \& Humphrey, S.E. (2006). The work design questionnaire (WDQ): Developing and validating a comprehensive measure for assessing job design and the nature of work. Journal of Applied Psychology, 91, 1321-1339.

Morrison, E.W., \& Phelps, C.C. (1999). Taking charge at work: Extrarole efforts to initiate workplace change. Academy of Management Journal, 42, 403-419.

Nahrgang, J.D., Morgeson, F.P., \& Hofmann, D.A. (2011). Safety at work: A metaanalytic investigation of the link between job demands, job resources, burnout, engagement, and safety outcomes. Journal of Applied Psychology, 96, 71-94.

Nembhard, I.M., \& Edmondson, A.C. (2006). Making it safe: The effects of leader inclusiveness and professional status on psychological safety and improvement efforts in health care teams. Journal of Organizational Behaviour, 27, 941-966.

Nielsen, K., Randall, R., Yarker, J., \& Brenner, S. (2008). The effects of transformational leadership on followers' perceived work characteristics and psychological wellbeing: A longitudinal study. Work \& Stress, 22, 16-32.

Norman, W.T. (1963). Toward an adequate taxonomy of personality attributes: Replicated factor structure in peer nomination personality ratings. Journal of Abnormal and Social Psychology, 66, 574-583.

Nunnally, J.C. \& Bernstein, I.H. (1994). Psychometric theory ( $3^{r d}$ ed.). New York: McGraw-Hill.

Olivier, A., \& Rothmann, S. (2007). Antecedents of work engagement in a multinational oil company. Journal of Industrial Psychology, 33, 49-56.

Organ, D.W. (1988). Organizational citizenship behavior: The good soldier syndrome. Lexington, MA: Lexington Books.

Organ, D.W. (1990). The motivational basis of organizational citizenship behavior. In B.M. Staw \& L.L. Cummings (Eds.), Research in organizational behavior. Greenwich, CT: JAI Press.

Organ, D.W. (1997). Organizational citizenship behavior: It's construct cleanup time. Human Performance, 10, 85-97. 
Paolacci, G., Chandler, J., \& Ipeirotis, P.G. (2010). Running experiments on Amazon Mechanical Turk, Judgment and Decision Making, 5, 411-419.

Parzefall, M.R., \& Hakanen, J. (2010). Psychological contract and its motivational and health-enhancing properties. Journal of Managerial Psychology, 25, 4-21.

Pearlin, L.I. (1983). Role strains and personal stress. In H.B. Kaplan (Ed.), Psychological stress: Trends in theory and research (pp.3-32). New York: Academic Press.

Piedmont, R.L. (1993). A longitudinal analysis of burnout in the health care setting: The role of personal dispositions. Journal of Personality Assessment, 61, 457-473.

Podsakoff, P.M., \& MacKenzie, S.B. (1997). Impact of organizational citizenship behavior on organizational performance: A review and suggestions for future research. Human Performance, 10, 133-151.

Podsakoff, N.P., Whiting, S.W., Podsakoff, P.M., \& Blume, B.D. (2009). Individual- and Organizational-Level Consequences of Organizational Citizenship Behaviors: A Meta-Analysis. Journal of Applied Psychology, 94, 122-141.

Porter, L.W. (1961). A study of perceived job satisfactions in bottom and middle management jobs. Journal of Applied Psychology, 45, 1-10.

Porter, L.W. (1962). Job attitudes in management: I. Perceived deficiencies in need fulfillment as a function of job level. Journal of Applied Psychology, 46, 375-384.

Renn, R.W., \& Vandenberg, R.J. (1995). The critical psychological states: An underrepresented component in job characteristics model research. Journal of Management, 21, 279-303.

Rich, B.L., LePine, J.A., \& Crawford, E.R. (2010). Job engagement: Antecedents and effects on job performance. Academy of Management Journal, 53, 617-635.

Roch, S.G., \& Shanock, L.R. (2006). Organizational justice in an exchange framework: Clarifying organizational justice distinctions. Journal of Management, 32, 299322.

Rodriguez-Munoz, A., Baillien, E., De Witte, H., Moreno-Jimenez, B., \& Pastor, J.C. (2009). Cross-lagged relationships between workplace bullying, job satisfaction and engagement: Two longitudinal studies. Work \& Stress: An International Journal of Work, Health, \& Organisations, 23, 225-243.

Rogers, C.R. (1958). The characteristics of a helping relationship. Personnel and 
Guidance Journal, 37, 6-16.

Rogers, C. (1959). A theory of therapy, personality, and interpersonal relationships as developed in the client-centered framework. In S. Koch (Ed.), Psychology: A study of science (Vol. 3, pp. 184-256). New York: McGraw-Hill.

Rogers, C. (1961). On becoming a person. Boston: Houghton Mifflin.

Rothbard, N.P. (2001). Enriching or depleting? The dynamics of engagement in work and family roles. Administrative Science Quarterly, 46, 655-684.

Rusell, S.S., Spitzmuller, C., Lin, L.F., Stanton, J.M., Smith, P.C., \& Ironson, G.H. (2004). Shorter can also be better: The Abridged Job in General scale. Educational and Psychological Measurement, 64, 878-893.

Ryan, R.M., \& Deci, E.L. (2000). Self-determination theory and the facilitation of intrinsic motivation, social development, and well-being. American Psychologist, $55,58-68$.

Ryan, R.M., \& Kuczkowski, R. (1994). The imaginary audience, self-consciousness, and public individuation in adolescence. Journal of Personality, 62, 219-238.

Saks, A.M. (2006). Antecedents and consequences of employee engagement. Journal of Managerial Psychology, 21, 600-619.

Salanova, M., Agut, S., \& Peiro, J.M. (2005). Linking organizational facilitators and work engagement to employee performance and customer loyalty: The mediation of service climate. Journal of Applied Psychology, 90, 1217-1227.

Schaufeli, W.B., \& Bakker, A.B. (2003). UWES-Utrecht Work Engagement Scale: test manual. Unpublished manuscript, Department of Psychology, Utrecht University.

Schaufeli, W.B., \& Bakker, A.B. (2004). Job demands, job resources, and their relationship with burnout and engagement: a multi-sample study. Journal of Organizational Behavior, 25, 293-315.

Schaufeli, W.B., Bakker, A.B., \& Salanova, M. (2006). The measurement of work engagement with a short questionnaire: A cross-national study. Educational and Psychological Measurement, 66, 701-716.

Schaufeli, W.B., Bakker, A.B., \& Van Rhenen, W. (2009). How changes in job demands and resources predict burnout, work engagement, and sick absenteeism. Journal of Organizational Behavior, 30, 893-917.

Schaufeli, W.B., \& Salanova, M. (2007). Efficacy or inefficacy, that's the question: 
Burnout and work engagement, and their relationships with efficacy beliefs. Anxiety, Stress, and Coping, 20, 177-196.

Schaufeli, W. B., Salanova, M., Gonzalez-Roma, V., \& Bakker, A. B. (2002). The measurement of engagement and burnout: A two sample confirmatory analytic approach. Journal of Happiness Studies, 3, 71-92.

Schaufeli, W.B., Taris, T.W., Le Blanc, P., Peeters, M., Bakker, A.B., \& De Jonge, J. (2001). Maakt arbeid gezond? Op zoek naar de bevlogen werknemer [Does work make happy? In search of the engaged worker]. De Psycholoog, 36, 422-428.

Schaufeli, W.B., Taris, T.W., \& Bakker, A.B. (2006). Dr. Jekyll and Mr. Hyde: On the differences between work engagement and workaholism. In R.J. Burke (Ed.), Research companion to working time and work addiction (pp. 193-217). Northampton: Edward Elgar.

Schaufeli, W.B., Taris, T.W., \& Van Rhenen, W. (2008). Workaholism, burnout, and work engagement: Three of a kind or three different kinds of employee wellbeing? Applied Psychology: An International Review, 57, 173-203.

Scheier, M.F., Fenigstein, A., \& Buss, A.H. (1974). Self-awareness and physical aggression. Journal of Experimental Social Psychology, 10, 264-273.

Schlenker, B.R. (1980). Impression management: The self-concept, social identity, and interpersonal relations. Monterey, CA: Brooks/Cole.

Schwarzer, R., \& Jerusalem, M. (1995). Generalized Self-Efficacy scale. In J. Weinman, S. Wright, \& M. Johnson, Measures in health psychology: A user's portfolio. Causal and control beliefs (pp. 35-37). Windsor, UK: NFER-NELSON.

Scott, K.S., Moore, K.S., \& Miceli, M.P. (1997). An exploration of the meaning and consequences of workaholism. Human Relations, 50, 287-314.

Shamir, B. (1991). Meaning, self, and motivation in organizations. Organizational Studies, 12, 405-424.

Skogstad, A., Einarsen, S., Torsheim, T., Aasland, M.S., \& Hetland, H. (2007). The destructiveness of laissez-faire leadership behavior. Journal of Occupational Health Psychology, 12, 80-92.

Smith, K.K., \& Berg, D.N. (1987). Paradoxes of group life. San Francisco: JosseyBass.

Sonnentag, S. (2003). Recovery, work engagement, and proactive behavior: A new look 
at the interface between nonwork and work. Journal of Applied Psychology, 88, 518-528.

Spreitzer, G. (1995). Psychological empowerment in the work place: Dimensions, measurement, and validation. Academy of Management Journal, 38, 1442-1465.

Taris, T.W., Schaufeli, W.B., \& Shimazu, A. (in press). Workaholism versus engagement: What's the difference? In A.B. Bakker \& M.P Leiter (Eds.), Work engagement: Recent developments in theory and research. New York: Psychology Press.

Thibaut, J., \& Walker, L. (1975). Procedural justice: A psychological analysis. Hillsdale, NJ: Erlbaum.

Toffler, B.L. (1986). Tough choices: Managers talk ethics. New York: John Wiley and Sons.

Tuckey, M.R., Bakker, A.B., \& Dollard, M.F. (2012). Empowering leaders optimize working conditions for engagement: A multilevel study. Journal of Occupational Health Psychology, 17, 15-27.

UWES*Utrecht Work Engagement Scale: test manual. Unpublished manuscript, Department of Psychology, Utrecht University.

Van den Broeck, A., De Witte, H., Lens, W., \& Vansteenkiste, M. (2008). The role of basic need satisfaction in explaining the relationships between job demands, job resources, burnout and engagement. Work \& Stress, 22, 277-294.

Van Dierendonck, D., Haynes, C., Borrill, C., \& Stride, C. (2004). Leadership behavior and subordinate well-being. Journal of Occupational Health Psychology, 9, 165175.

Van Scotter, J.R., \& Motowidlo, S.J. (1996). Interpersonal facilitation and job dedication as separate facets of contextual performance. Journal of Applied Psychology, 81, $525-531$

Van Veldhoven, M., \& Meijman, T. (1994). Questionnaire on the experience and assessment of work. Retrieved May 16, 2012 from http://www.marcvanveldhoven.com/ques.html

Vinarski-Peretz, H., \& Carmeli, A. (2011). Linking care felt to engagement in innovative behaviors in the workplace: The mediating role of psychological conditions. Psychology of Aesthetics, Creativity, and the Arts, 5, 43-53.

Walz, S.M., \& Niehoff, B.P. (2000). Organizational citizenship behaviors: Their 
relationship to organizational effectiveness. Journal of Hospitality \& Tourism Research, 24, 301-319.

Warr, P. (1999). Well-being and the workplace. In D. Kahneman, E. Diener, \& N. Schwarz (Eds.), Well-being: The foundations of hedonic psychology. New York: Russell Sage Foundation Press.

Wefald, A.J., \& Downey, R.G. (2009). Construct Dimensionality of Engagement and its Relation with Satisfaction. The Journal of Psychology, 143, 91-111.

Weisbord, M. (1987). Productive workplaces. San Francisco: Jossey-Bass.

Westman, M. (2001). Stress and strain crossover. Human Relations, 54, 557-591.

Williams, L.J., \& Anderson, S.E. (1991). Job satisfaction and organizational commitment as predictors of organizational citizenship and in-role behaviors. Journal of Management, 17, 601-617.

Xanthopoulou, D., Bakker, A.B., Demerouti, E., \& Schaufeli, W.B. (2007). The role of personal resources in the job demands-resources model. International Journal of Stress Management, 14, 121-141.

Xanthopoulou, D., Bakker, A.B., Demerouti, E., \& Schaufeli, W.B. (2009). Work engagement and financial returns: A diary study on the role of job and personal resources. Journal of Occupational and Organizational Psychology, 82, 183-200.

Xanthopoulou, D., Bakker, A.B., Heuven, E., Demerouti, E., \& Schaufeli, W.B. (2008). Working in the sky: A diary study on work engagement among flight attendants. Journal of Occupational Health Psychology, 13, 345-356.

Xanthopoulou, D., Bakker, A.B., Demerouti, E., \& Schaufeli, W.B. (2008). Work engagement: A cycle of job and personal resources. Manuscript submitted for publication.

Zellars, K.L., Perrewe, P.L., \& Hochwarter, W.A. (2000). Burnout in health care: The role of the five factors of personality. Journal of Applied Social Psychology, 30, 1570-1598.

Zhang, Y., Fang, Y., Wei, K.K., \& Chen, H. (2010). Exploring the role of psychological safety in promoting the intention to continue sharing knowledge in virtual communities. International Journal of Information Management, 30, 425-436.

Zhang, Y., Gan, Y., \& Cham, H. (2007). Perfectionism, academic burnout and engagement among Chinese college students: A structural equation modeling analysis. Personality and Individual Differences, 43, 1529-1540. 


\section{APPENDICES}

Appendix 1

\section{Utrecht Work Engagement Scale}

7-point scale: 0 'Never' to 6 'Always'

Vigor (VI)

1. When I get up in the morning, I feel like going to work.

2. At my work, I feel bursting with energy.

3. At my work I always persevere, even when things to do not go well.

4. I can continue working for very long periods at a time.

5. At my job, I am very resilient, mentally.

6. At my job I feel strong and vigorous.

Dedication (DE)

1. To me, my job is challenging.

2. My job inspires me.

3. I am enthusiastic about my job.

4. I am proud of the work that I do.

5. I find the work that I do full of meaning and purpose.

Absorption (AB)

1. When I am working, I forget everything else around me.

2. Time flies when I am working.

3. I get carried away when I am working.

4. It is difficult to detach myself from my job.

5. I am immersed in my work.

6. I feel happy when I am working intensely. 


\section{Appendix 2}

\section{Affective Commitment Scale}

7-point scale: 1 'Strongly Disagree' to 7 'Strongly Agree'

1. I would be very happy to spend the rest of my career with this organization

2. I enjoy discussing my organization with people outside it

3. I really feel as if this organization's problems are my own

4. I think that I could easily become as attached to another organization as I am to this one $(\mathrm{R})$

5. I do not feel like 'part of the family' at my organization (R)

6. I do not feel 'emotionally attached' to this organization (R)

7. This organization has a great deal of personal meaning for me

8. I do not feel a strong sense of belonging to my organization (R) 


\section{Appendix 3}

\section{Abridged Job in General (Job Satisfaction) Scale}

7-point scale: 1 'Strongly Disagree' to 7 'Strongly Agree'

Think of your job in general. All in all, what is it like most of the time?

Good

_ Undesirable (R)

Better than most

_ Disagreeable (R)

Makes me content

_Excellent

Enjoyable

— Poor (R) 
Appendix 4

Organizational Citizenship Behavior Checklist

5-point scale: 1 'Never' to 5 'Every day'

\begin{tabular}{|c|c|}
\hline $\begin{array}{l}\text { How often have you done each of the following } \\
\text { things on your present job? }\end{array}$ & 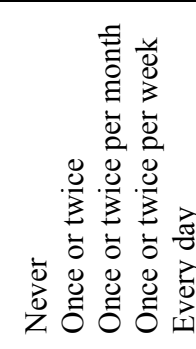 \\
\hline 1. Picked up meal for others at work & $\begin{array}{lllll}1 & 2 & 3 & 4 & 5\end{array}$ \\
\hline 2. Took time to advise, coach, or mentor a co-worker. & $\begin{array}{lllll}1 & 2 & 3 & 4 & 5\end{array}$ \\
\hline 3. Helped co-worker learn new skills or shared job knowledge. & $\begin{array}{lllll}1 & 2 & 3 & 4 & 5\end{array}$ \\
\hline 4. Helped new employees get oriented to the job. & $\begin{array}{lllll}1 & 2 & 3 & 4 & 5\end{array}$ \\
\hline 5. Lent a compassionate ear when someone had a work problem. & $\begin{array}{lllll}1 & 2 & 3 & 4 & 5\end{array}$ \\
\hline 6. Lent a compassionate ear when someone had a personal problem. & $\begin{array}{lllll}1 & 2 & 3 & 4 & 5\end{array}$ \\
\hline $\begin{array}{l}\text { 7. Changed vacation schedule, work days, or shifts to accommodate co- } \\
\text { worker's needs. }\end{array}$ & $\begin{array}{lllll}1 & 2 & 3 & 4 & 5\end{array}$ \\
\hline 8. Offered suggestions to improve how work is done. & $\begin{array}{lllll}1 & 2 & 3 & 4 & 5\end{array}$ \\
\hline 9. Offered suggestions for improving the work environment. & $\begin{array}{lllll}1 & 2 & 3 & 4 & 5\end{array}$ \\
\hline 10. Finished something for co-worker who had to leave early. & $\begin{array}{lllll}1 & 2 & 3 & 4 & 5\end{array}$ \\
\hline 11. Helped a less capable co-worker lift a heavy box or other object. & $\begin{array}{lllll}1 & 2 & 3 & 4 & 5 \\
\end{array}$ \\
\hline 12. Helped a co-worker who had too much to do. & $\begin{array}{lllll}1 & 2 & 3 & 4 & 5\end{array}$ \\
\hline 13. Volunteered for extra work assignments. & $\begin{array}{lllll}1 & 2 & 3 & 4 & 5\end{array}$ \\
\hline 14. Took phone messages for absent or busy co-worker. & $\begin{array}{lllll}1 & 2 & 3 & 4 & 5\end{array}$ \\
\hline 15. Said good things about your employer in front of others. & $\begin{array}{lllll}1 & 2 & 3 & 4 & 5 \\
\end{array}$ \\
\hline 16. Gave up meal and other breaks to complete work. & $\begin{array}{lllll}1 & 2 & 3 & 4 & 5\end{array}$ \\
\hline $\begin{array}{l}\text { 17. Volunteered to help a co-worker deal with a difficult customer, } \\
\text { vendor, or co-worker. }\end{array}$ & $\begin{array}{lllll}1 & 2 & 3 & 4 & 5\end{array}$ \\
\hline $\begin{array}{l}\text { 18. Went out of the way to give co-worker encouragement or express } \\
\text { appreciation. }\end{array}$ & $\begin{array}{lllll}1 & 2 & 3 & 4 & 5\end{array}$ \\
\hline $\begin{array}{l}\text { 19. Decorated, straightened up, or otherwise beautified common work } \\
\text { space. }\end{array}$ & $\begin{array}{lllll}1 & 2 & 3 & 4 & 5\end{array}$ \\
\hline $\begin{array}{l}\text { 20. Defended a co-worker who was being "put-down" or spoken ill of by } \\
\text { other co-workers or supervisor. }\end{array}$ & $\begin{array}{lllll}1 & 2 & 3 & 4 & 5\end{array}$ \\
\hline
\end{tabular}




\section{Appendix 5}

\section{Psychological Meaningfulness Scale}

7-point scale: 1 'Strongly Disagree' to 7 'Strongly Agree'

1. The work I do on this job is very important to me.

2. My job activities are personally meaningful to me.

3. The work I do on this job is worthwhile.

4. My job activities are significant to me.

5. The work I do on this job is meaningful to me.

6. I feel that the work I do on my job is valuable. 


\section{Appendix 6}

Psychological Safety Scale

7-point scale: 1 'Strongly Disagree’ to 7 'Strongly Agree’

1. I'm not afraid to be myself at work.

2. I am afraid to express my opinions at work. (R)

3. There is a threatening environment at work. (R) 


\section{Appendix 7}

\section{Psychological Availability Scale}

7-point scale: 1 'Strongly Disagree' to 7 'Strongly Agree’

1. I am confident in my ability to handle competing demands at work.

2. I am confident in my ability to deal with problems that come up at work.

3. I am confident in my ability to think clearly at work.

4. I am confident in my ability to display the appropriate emotions at work.

5. I am confident that I can handle the physical demands at work. 


\section{Appendix 8}

\section{Person-Job Fit Scale}

7-point scale: 1 'Strongly Disagree' to 7 'Strongly Agree'

1. My current job is not really me (R)

2. This job is not really what I would like to be doing (R)

3. All things considered, this job suits me

4. I feel like this is not the right type of work for me (R)

5. I feel that my goals and needs are met in this job

6. I find my current job motivating

7. My abilities, skills, and talents are the right type for this job

8. I'm sure there must be another job for which I am better suited (R)

9. I am able to use my talents, skills and competencies in my current job 


\section{Appendix 9}

\section{Autonomy Scale}

4-point scale: 1 'Never' to 4 'Always'

1. Do you have freedom in carrying out your work activities?

2. Do you have influence in the planning of your work activities?

3. Can you decide the order in which you carry out your work on your own?

4. Can you participate in the decision about when something must be completed?

5. Do you resolve problems arising in your work yourself? 


\section{Appendix 10}

\section{Co-Worker Relations Scale}

4-point scale: 1 'Never' to 4 'Always'

1. Can you count on your colleagues when you encounter difficulties in your work?

2. If necessary, can you ask your colleagues for help?

3. Do you get along well with your colleagues?

4. Do you have conflicts with your colleagues? (R)

5 . In your work, do you feel appreciated by your colleagues?

6. Do you experience any aggressiveness from colleagues? (R)

7. Are your colleagues friendly towards you?

8. Is there a good atmosphere between you and your colleagues?

9. Have there been any unpleasant occurrences between you and your colleagues? (R) 


\section{Appendix 11}

\section{Supervisor Support Scale}

4-point scale: 1 'Never' to 4 'Always'

1. Can you count on your superior when you come across difficulties in your work?

2. If necessary, can you ask your superior for help?

3. Do you get along well with your superior?

4. Do you have conflicts with your superior? (R)

5. In your work, do you feel appreciated by your superior?

6. Do you experience any aggressiveness from your superior? (R)

7. Is your superior friendly towards you?

8. Is there a good atmosphere between you and your superior?

9. Have there been any unpleasant occurrences between you and your superior? (R) 
Appendix 12

Procedural Justice Scale

5-point scale: 1 'To a small extent' to 5 'To a large extent'

- The following items refer to the procedures used to arrive at your (outcome). To what extent:

1. Have you been able to express your views and feelings during those procedures?

2. Have you had influence over the (outcome) arrived at by those procedures?

3. Have those procedures been free of bias?

4. Have those procedures been based on accurate information?

5. Have you been able to appeal the (outcome) arrived at by those procedures?

6. Have those procedures upheld ethical and moral standards? 
Appendix 13

Interactional Justice Scale

5-point scale: 1 'To a small extent' to 5 'To a large extent'

\section{Interpersonal justice}

The following items refer to (the authority figure who enacted the procedure). To what extent:

1. Has (he/she) treated you in a polite manner?

2. Has (he/she) treated you with dignity?

3. Has (he/she) treated you with respect?

4. Has (he/she) refrained from improper remarks or comments?

\section{Informational justice}

The following items refer to (the authority figure who enacted the procedure). To what extent:

1. Has (he/she) been candid in (his/her) communications with you?

2. Has (he/she) explained the procedures thoroughly?

3. Were (his/her) explanations regarding the procedures reasonable?

4. Has (he/she) communicated details in a timely manner?

5. Has (he/she) seemed to tailor (his/her) communications to individuals' specific needs? 


\section{Appendix 14}

\section{Public Self-Consciousness Scale}

5-point scale: 0 'Extremely Uncharacteristic' to 5 'Extremely Characteristic'

1. I'm concerned about my style of doing things.

2. I'm concerned about the way I present myself.

3. I'm self-conscious about the way I look.

4. I usually worry about making a good impression.

5. One of the last things I do before I leave my house is look in the mirror.

6. I'm concerned about what other people think of me.

7. I'm usually aware of my appearance. 


\section{Appendix 15}

\section{General Self-Efficacy Scale}

4-point scale: 1 'Not at all true' to 5 'Exactly true'

1. I can always manage to solve difficult problems if I try hard enough.

2. If someone opposes me, I can find the means and ways to get what I want.

3. It is easy for me to stick to my aims and accomplish my goals.

4. I am confident that I could deal efficiently with unexpected events.

5. Thanks to my resourcefulness, I know how to handle unforeseen situations.

6. I can solve most problems if I invest the necessary effort

7. I can remain calm when facing difficulties because I can rely on my coping abilities.

8. When I am confronted with a problem, I can usually find several solutions.

9. If I am in trouble, I can usually think of a solution.

10. I can usually handle whatever comes my way. 


\section{Appendix 16}

International Personality Item Pool (Extraversion) Scale

5-point scale: 1 'Very Inaccurate' to 5 'Very Accurate'

Describe yourself as you generally are now, not as you wish to be in the future. Describe yourself as you honestly see yourself, in relation to other people you know of the same sex as you are, and roughly your same age. So that you can describe yourself in an honest manner, your responses will be kept in absolute confidence.

1. Am the life of the party.

2. Don't talk a lot. (R)

3. Feel comfortable around people.

4. Keep in the background. (R)

5. Start conversations.

6. Have little to say. (R)

7. Talk to a lot of different people at parties.

8. Don't like to draw attention to myself. (R)

9. Don't mind being the center of attention.

10. Am quiet around strangers. (R) 


\section{Appendix 17}

International Personality Item Pool (Neuroticism) Scale

5-point scale: 1 'Very Inaccurate' to 5 'Very Accurate'

Describe yourself as you generally are now, not as you wish to be in the future. Describe yourself as you honestly see yourself, in relation to other people you know of the same sex as you are, and roughly your same age. So that you can describe yourself in an honest manner, your responses will be kept in absolute confidence.

1. Get stressed out easily. (R)

2. Am relaxed most of the time.

3. Worry about things. (R)

4. Seldom feel blue.

5. Am easily disturbed. (R)

6. Get upset easily. (R)

7. Change my mood a lot. (R)

8. Have frequent mood swings. (R)

9. Get irritated easily. (R)

10. Often feel blue. (R) 
1. What is your gender?

- Male

- Female

2. What is your ethnicity?

- White (non-Hispanic)

- Black (non-Hispanic)

- Hispanic

- Asian/Pacific Islander

- Native American/ Alaskan Native

- Middle Eastern

- Other

3. What is your age (in years)?

4. Which US state do you work in?

5. How many hours per week do you work?

- Less than 30 hours

- Between 30 and 40 hours

- 40 hours or more

- I am not employed

6. How long have you been employed at your current job (in years)?

7. What industry do you work in?

- Manufacturing

- Transportation

- Retail/Sales

- Services

- Public Administration/Government

- Health Care

- Financial/ Real Estate

- Education

- Other

8. What is your current annual income?

- $\$ 10,000$ to $\$ 14,999$

- $\$ 15,000$ to $\$ 24,999$

- $\$ 25,000$ to $\$ 34,999$ 
- $\$ 35,000$ to $\$ 49,999$

- $\$ 50,000$ to $\$ 74,999$

- $\$ 75,000$ to $\$ 99,999$

- $\$ 100,000$ to $\$ 149,999$

- $\$ 150,000$ to $\$ 199,999$

- $\$ 200,000$ or more

9. Are you a supervisor to any employee(s)?

- No

- Yes

10. Would you consider your current employment position to be just a job (i.e., something you do just to earn money) or a part of your career (i.e., your lifework)?

- Just a job

- A part of my career 
Appendix 19

Summary of Hierarchical Regression Analyses Testing the Mediating Role of Availability between Safety and Work Engagement

\begin{tabular}{|c|c|c|c|c|c|}
\hline Variable & $\mathrm{B}$ & SE B & $\beta$ & $\mathrm{R}^{2}$ & $\mathrm{R}^{2}$ Change \\
\hline \multicolumn{6}{|c|}{ Dependent Variable: Availability } \\
\hline Psychological Safety & .33 & .03 & $.51 * *$ & $.31 * *$ & $.23 * *$ \\
\hline \multicolumn{6}{|c|}{ Dependent Variable: Work Engagement } \\
\hline Step 1 & & & & $.36^{* *}$ & $.10^{* *}$ \\
\hline Psychological Safety & .30 & .04 & $.33 * *$ & - & - \\
\hline Step 2 & & & & $.39 * *$ & $.04 * *$ \\
\hline Psychological Safety & .19 & .04 & $.21 * *$ & - & - \\
\hline Psychological Availability & .32 & .06 & $.23^{* *}$ & - & - \\
\hline
\end{tabular}

Note. Controls for Availability: Ethnicity and US Region

Note. Controls for Work Engagement: Tenure, weekly work hours, gender, supervisor status, see occupation as job or career, work industry, and ethnicity

Note. $\mathrm{R}^{2}$ Change in first step of each regression is the change in $\mathrm{r}^{2}$ that occurred when predictor was added to regression after the control variables were already included in the analysis.

Note. ${ }^{*} \mathrm{p}<.05 .{ }^{* *} \mathrm{p}<.01$ 
Appendix 20

Correlations between Demographics and Study Variables

\begin{tabular}{|c|c|c|c|c|c|c|c|c|c|}
\hline & Gender & Ethnicity & Age & Income & $\begin{array}{l}\text { Work } \\
\text { Industry }\end{array}$ & Hrs Work & Tenure & Supervise & Job_Career \\
\hline Person-job fit & -.08 & -.02 & $.09^{*}$ & $.19^{* *}$ & $.13^{* *}$ & $.15^{* *}$ & $.10^{*}$ & $.14^{* *}$ & $.57^{* *}$ \\
\hline Autonomy & -.04 & -.02 & .01 & $.18^{* *}$ & .01 & $.15^{* *}$ & $.11^{*}$ & $.21 * *$ & $.41 * *$ \\
\hline $\begin{array}{l}\text { Co-worker } \\
\text { relations }\end{array}$ & $.13^{* *}$ & $.25^{* *}$ & .05 & .01 & .03 & .02 & .01 & $-.12^{*}$ & $.13^{* *}$ \\
\hline $\begin{array}{l}\text { Supervisor } \\
\text { support }\end{array}$ & .07 & $.20^{* *}$ & .04 & .03 & .06 & -.01 & .01 & $-.13 * *$ & $.18^{* *}$ \\
\hline Procedural justice & .01 & -.08 & -.03 & $.15^{* *}$ & .05 & .05 & .09 & $.21 * *$ & $.32 * *$ \\
\hline $\begin{array}{l}\text { Interactional } \\
\text { justice }\end{array}$ & .07 & $.13^{* *}$ & .02 & .05 & .00 & -.01 & .06 & -.01 & $.19 * *$ \\
\hline $\begin{array}{c}\text { Self- } \\
\text { Consciousness }\end{array}$ & -.02 & $-.21^{* *}$ & $-.19^{* *}$ & -.03 & -.05 & -.08 & $-.10^{*}$ & $.11^{*}$ & $.09 *$ \\
\hline Self-Efficacy & -.05 & .08 & -.01 & $.11^{*}$ & -.04 & $.12^{* *}$ & .04 & $.19^{* *}$ & $.10 *$ \\
\hline Extraversion & $-.13^{* *}$ & $-.14^{* *}$ & -.02 & $.14^{* *}$ & .00 & -.03 & .02 & $.35^{* *}$ & $.25^{* *}$ \\
\hline Neuroticism & $.21 * *$ & .08 & -.08 & $-.23 * *$ & -.02 & -.01 & -.08 & $-.22 * *$ & $-.19 * *$ \\
\hline $\begin{array}{l}\text { Psychological } \\
\text { Meaningfulness }\end{array}$ & -.01 & $-.10^{*}$ & .07 & $.14 * *$ & $.14 * *$ & $.10^{*}$ & $.11^{*}$ & $.16^{* *}$ & $.52 * *$ \\
\hline $\begin{array}{l}\text { Psychological } \\
\text { Safety }\end{array}$ & .08 & $.24 * *$ & .07 & -.03 & -.02 & .04 & .01 & $-.11^{*}$ & $.13^{* *}$ \\
\hline $\begin{array}{l}\text { Psychological } \\
\text { Availabiity }\end{array}$ & .05 & $.22^{* *}$ & .06 & -.02 & -.01 & .08 & .02 & -.05 & .03 \\
\hline $\begin{array}{c}\text { Work } \\
\text { Engagement }\end{array}$ & $-.12 * *$ & $-.19^{* *}$ & .04 & $.09^{*}$ & .06 & $.12 * *$ & .09 & $.21 * *$ & $.50 * *$ \\
\hline $\begin{array}{c}\text { Organizational } \\
\text { Commitment }\end{array}$ & -.02 & -.07 & .04 & $.10^{*}$ & .07 & $.10^{*}$ & $.14^{* *}$ & $.19^{* *}$ & $.47^{* *}$ \\
\hline Job Satisfaction & -.04 & $-.17^{* *}$ & .02 & $.18^{* *}$ & .08 & -.01 & .06 & $.19 * *$ & $.51 * *$ \\
\hline $\begin{array}{l}\text { Organizational } \\
\text { Citizenship } \\
\text { Behavior } \\
\end{array}$ & -.01 & $-.16^{* *}$ & -.07 & .03 & -.02 & .08 & $.13^{* *}$ & $.36^{* *}$ & $.16^{* *}$ \\
\hline
\end{tabular}

Note. ${ }^{*} p<.05,{ }^{* *} p<.01$. 
VITA

\section{HOLLY JACOBS}

May 25, 1983

2005

2010

2010-2013
Born, Memphis, Tennessee

B.A., Psychology

Boston College

Chestnut Hill, MA

M.S., Psychology

Florida International University

Miami, Florida

Ph.D., Industrial/Organizational Psychology

Florida International University

Miami, Florida

\section{PRESENTATIONS}

Jacobs, H. \& Pace, V. (2010). Can Learning Goal Orientation Decrease Student

Withdrawal? Poster session presented at the conference for the Society of Industrial and Organizational Psychology, Atlanta.

Matamala, A., Pace, V., \& Jacobs, H. (2010). Work Engagement as a Mediator between Personality and Citizenship Behavior. Poster session presented at the conference for the Societyof Industrial and Organizational Psychology, Atlanta. 